\title{
Manual Operativo CINE 2011 DIRECTRICES PARA CLASIFICAR PROGRAMAS NACIONALES DE EDUCACIÓN $Y$ CERTIFICACIONES RELACIONADAS
}





\section{MANUAL OPERATIVO CINE 2011}

\section{DIRECTRICES PARA CLASIFICAR PROGRAMAS NACIONALES DE EDUCACIÓN Y CERTIFICACIONES RELACIONADAS}

Esta traducción se publica por acuerdo con la OCDE y la Unión Europea. No es una traducción oficial de la OCDE o de la Unión Europea. La calidad de la traducción española y su coherencia con el texto original es responsabilidad del Insituto de Estadística de la UNESCO. Si se diera cualquier discrepancia entre el original y la traducción, solo se considerará válido el texto original. 
La Secretaría General de la OCDE asume la responsabilidad por la publicación de este trabajo. Las ideas y opiniones expuestas en esta obra no reflejan necesariamente la postura oficial de los países miembros de la OCDE, la Unión Europea o el Instituto de Estadística de la UNESCO.

Este documento y cualquier mapa que en él figure se presentan sin perjuicio a la condición jurídica o soberanía del territorio, al trazado de sus fronteras y límites internacionales ni al nombre de cualquier territorio, ciudad o zona.

UIS ISBN 978-92-9189-181-8

Los datos estadísticos correspondientes a Israel han sido proporcionados por las autoridades competentes de ese país bajo su entera responsabilidad. El uso de dichos datos por parte de la OCDE es sin perjuicio a la condición jurídica de los Altos del Golán, Jerusalén Oriental y los asentamientos israelíes de Cisjordania bajo los términos del derecho internacional.

Originalmente publicado por la OCDE en inglés con el título ISCED 2011 Operational Manual: Guidelines for Classifying National Education Programmes and Related Qualifications (C) OECD, European Union, UNESCO-UIS 2015

(c) UNESCO-UIS 2015 para esta edición española.

Esta publicación está disponible al público general en $h$ ttp://creativecommons.org/licenses/by-nc-nd/3.o/igo/deed.en, conforme a lo establecido en la licencia CC BY-NC-ND 3.0 IGO de Creative Commons Attribution-NonCommercial-NoDerivatives 3.0 IGO. Usted podrá copiar y redistribuir este material siempre que lo utilice sin fines comerciales y bajo los siguientes términos y condiciones:

Reconocimiento - Sírvase citar el texto como se indica a continuación: Instituto de Estadística de la UNESCO (2015), Manual Operativo CINE 2011: Directrices para clasificar programas nacionales de educación y certificaciones relacionadas, Montreal: Instituto de la Estadística de la UNESCO. http://dx.doi. org/10.15220/978-92-9189-181-8-spa. Creative Commons Attribution CC BY-NC-ND 3.0 IGO.

Contenido de Terceras Personas - el Instituto de Estadística de la UNESCO no son necesariamente propietarios de cada componente del contenido que aparece en esta publicación. Por consiguiente, el Instituto de Estadística de la UNESCO no puede garantizar que la utilización de cualquier parte o componente individual de este trabajo no infrinja los derechos de dichas terceras personas. El riesgo de demandas que puedan surgir de dichas infracciones es de su entera responsabilidad. Si usted desea reutilizar un componente de este trabajo, su deber es informarse si requiere alguna autorización y obtenerla del propietario del derecho de autor. Los componentes pueden incluir aunque no están limitados a cuadros, gráficos, o imágenes. Toda solicitud de uso comercial o consulta sobre derechos o licencias se debe hacer llegar al correo electrónico: uis.publications@unesco.org. Las solicitudes de autorización para fotocopiar porciones de este material para uso comercial se deben dirigir directamente al Centro de Derechos de Autor. 


\section{Prólogo}

La estructura de los sistemas educativos varía marcadamente entre los países. Por consiguiente, la elaboración de indicadores y estadísticas de educación internacionalmente comparables hace necesario disponer de un marco que permita acopiar y reportar datos sobre programas educativos (y sus respectivas certificaciones) con niveles similares de contenido educativo. Este es precisamente el propósito de la Clasificación Internacional Normalizada de la Educación (CINE), clasificación oficial utilizada para categorizar y reportar estadísticas de educación internacionalmente comparables.

La clasificación CINE fue inicialmente elaborada por la UNESCO a mediados de la década de los 70 y objeto de una primera revisión en 1997. Debido a los cambios que experimentaron la educación y los sistemas educativos a comienzo del siglo XXI, una segunda actualización tuvo lugar entre los años 2009 y 2011 a través de extensas consultas mundiales con países, expertos regionales y organizaciones internacionales. Esta última actualización consideró importantes cambios en la estructura de la educación superior tales como el proceso de Boloña en Europa, la expansión de los programas educativos diseñados para niños de muy corta edad y el creciente interés de la comunidad internacional por estadísticas sobre los resultados de aprendizaje (es decir, logro educativo). La versión actualizada, CINE 2011, fue aprobada por la 36ª Conferencia General de la UNESCO en noviembre de 2011.

El presente documento, Manual de Operativo CINE 2011: directrices para clasificar programas nacionales de educación y certificaciones relacionadas, es producto del esfuerzo colaborativo del Instituto de Estadística de la UNESCO (UIS), la OCDE y Eurostat, e incorpora múltiples consultas sobre la adaptación de sistemas educativos nacionales a la CINE 2011. La responsabilidad elaborar de esta publicación es compartida por Alison Kennedy del Instituto de Estadística de la UNESCO; Éric Charbonnier y Nhung Truong integrantes de la División de Innovación y Evaluación del Progreso (IMEP) del Directorio de Educación de la OCDE; y Marta Beck-Domzalska de Eurostat.

El propósito de este manual operativo es ayudar a los países a implementar la CINE 2011 y asegurar que los mapas elaborados por los sistemas nacionales de educación reflejen claramente las actualizaciones incorporadas al marco de la CINE 2011. La implementación de la CINE 2011 debería ser un proceso iterativo y reiterativo que ayude a los países y a las organizaciones internacionales a establecer consensos sobre mapas que permitan mejorar la comparabilidad al momento de reportar estadísticas de educación.

La publicación de este manual operativo constituye un importante avance en el extenso proceso consultivo diseñado para mejorar permanentemente la comparabilidad de las estadísticas internacionales de educación. 


\section{Agradecimientos}

El desarrollo de esta publicación se debe a los aportes de numerosas personas.

Nuestro especial agradecimiento a todos los países que participaron en la elaboración de sus mapas nacionales CINE sin los cuales esta publicación no habría sido posible.

La OCDE desea agradecer por sus valiosas contribuciones a todos los expertos e instituciones que colaboran en el Programa de Análisis de Indicadores de Sistemas Educativos (INES) como parte del grupo de trabajo de esta organización, a los delegados de la red INES dedicados a evaluar los resultados laborales, económicos y sociales del aprendizaje (LSO) y a los integrantes del grupo informal de trabajo sobre Educación de la Primera Infancia de la INES.

Eurostat quisiera expresar su agradecimiento a los especialistas del grupo de trabajo en Estadísticas de Educación y Capacitación (ETS) que ofrecieron comentarios sobre diversas secciones de este manual y a todos los colegas de los países que colaboraron en el análisis de los mapas CINE.

Por su parte, el Instituto de Estadística de la UNESCO (UIS), quisiera extender su agradecimiento a todos los expertos nacionales que asistieron a los talleres y presentaron mapas para su posterior revisión. Asimismo, quisiera agradecer al gobierno de Japón por el apoyo financiero entregado a la UNESCO a través del fondo fiduciario japonés para la implementación de la CINE 2011 en la región de Asia y el Pacífico, así como a la Organización de la Liga Árabe para la Educación, la Cultura y la Ciencia (ALECSO) por su generoso financiamiento de talleres regionales de capacitación en los Estados Árabes.

Vaya también nuestra gratitud a los delegados franceses por la elaboración del cuadro que resume los códigos y criterios CINE 2011 (Anexo A del manual) y a los numerosos otros colegas que hicieron sustanciales aportes u ofrecieron comentarios en apoyo a la preparación de este manual. 


\section{Tabla de contenidos}

GUÍA DEL LECTOR

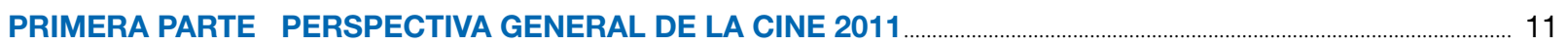

CAPÍTULO 1 PERSPECTIVA GENERAL DE LOS NIVELES CINE 2011 ......................................................................... 11

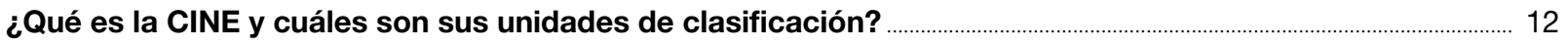

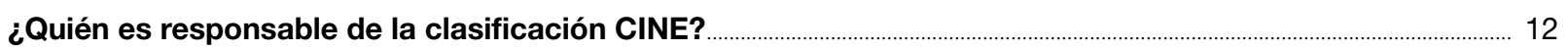

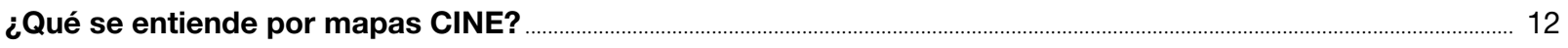

¿Qué limitaciones tiene la clasificación CINE 2011 en términos de cobertura? ........................................................... 13

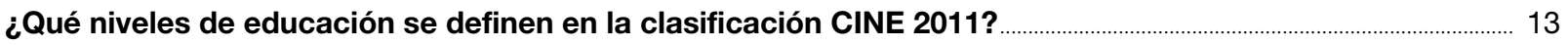

¿Cómo se asignan los programas y certificaciones relacionadas a los niveles CINE 2011? ……....................... 14

¿Los programas que abarcan más de un nivel CINE, Son secuenciales o consisten en módulos

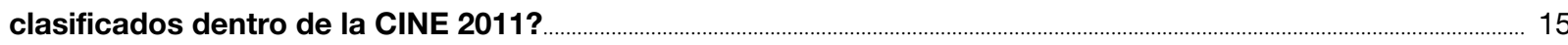

¿Qué dimensiones complementarias facilitan la clasificación de programas y certificaciones

en los niveles CINE 2011?

Campos de educación y capacitación …………………………………………………………………………………………………... 16

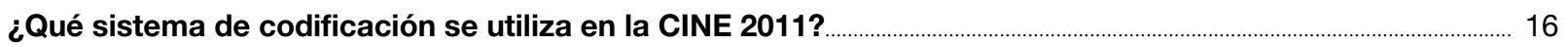

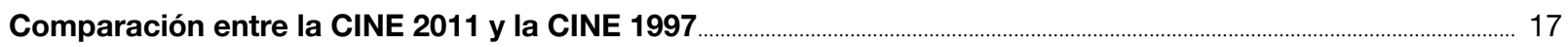

- Principales cambios entre la CINE 2011 y CINE 1997 ......................................................................................................... 17

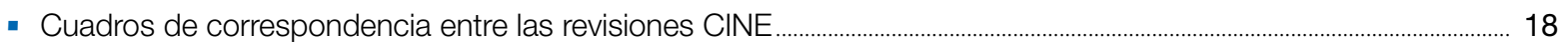

SEGUNDA PARTE NIVELES 0 A 4 - CINE 2011: DESDE EDUCACIÓN DE LA PRIMERA INFANCIA HASTA EDUCACIÓN POSTSECUNDARIA NO TERCIARIA ........................................................ 21

CAPÍTULO 2 NIVEL 0 - CINE 2011: EDUCACIÓN DE LA PRIMERA INFANCIA ....................................................... 21

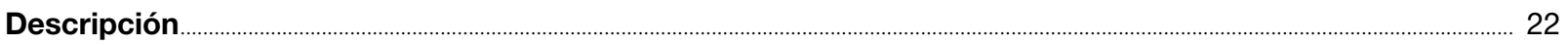

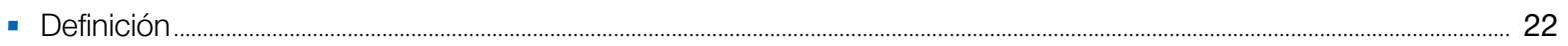

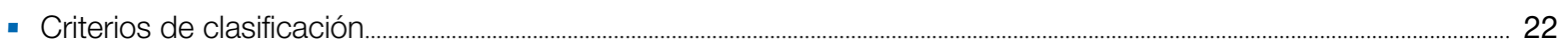

- Dimensiones complementarias ................................................................................................................................................................ 23

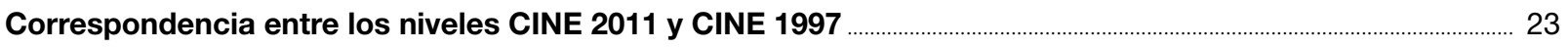

Directrices para clasificar programas de nivel CINE 0 y certificaciones reconocidas relacionadas ................. 24

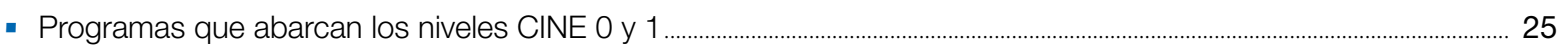

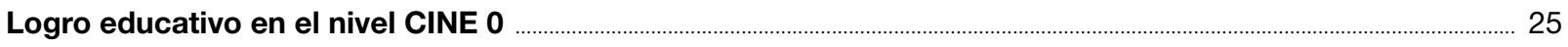

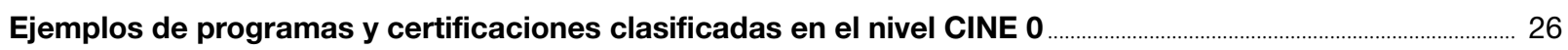

CAPÍTULO $3 \quad$ NIVEL 1 - CINE 2011: EDUCACIÓN PRIMARIA ……......................................................................... 31

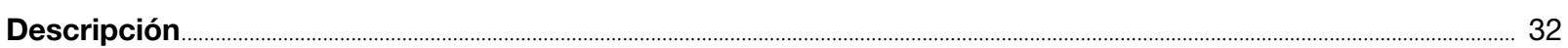

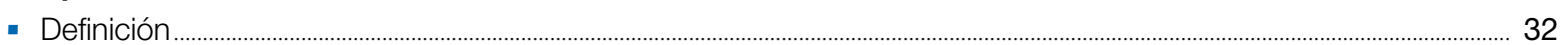

- Criterios de clasificación $(\S 124)$.............................................................................................................................................................. 32

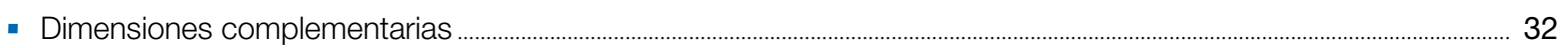




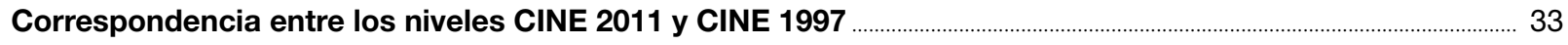

Directrices para clasificar programas de nivel CINE 1 y certificaciones reconocidas relacionadas ................ 33

- Programas que abarcan educación primaria y otro nivel CINE .............................................................................................. 34

Logro educativo en el nivel CINE 1 .

Ejemplos de programas y certificaciones clasificadas en el nivel CINE 1 ................................................................... 34

CAPÍTULO 4 NIVEL 2 - CINE 2011: EDUCACIÓN SECUNDARIA BAJA …….............................................................. 41

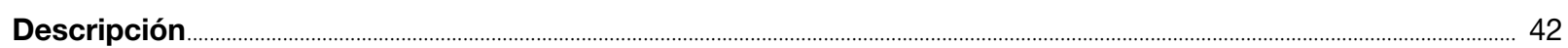

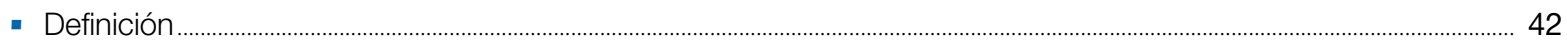

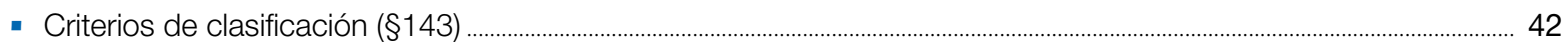

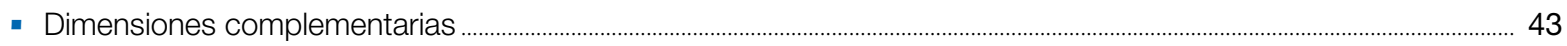

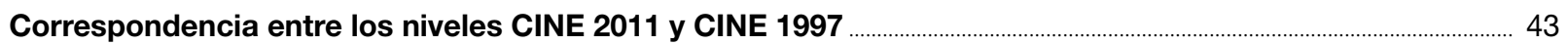

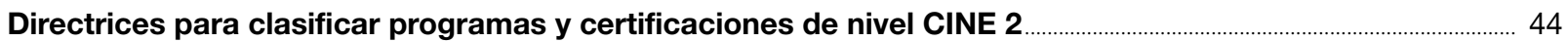

- Programas que abarcan educación secundaria baja y otro nivel CINE ................................................................................ 44

Logro educativo en el nivel CINE 2

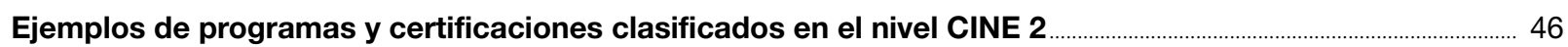

CAPÍTULO 5 NIVEL 3 - CINE 2011: EDUCACIÓN SECUNDARIA ALTA ……............................................................. 51

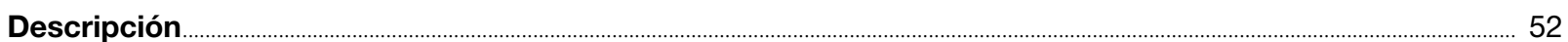

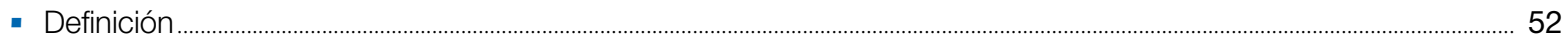

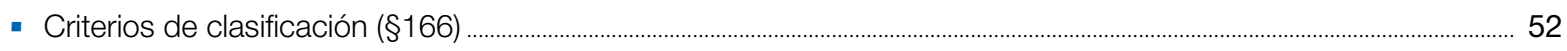

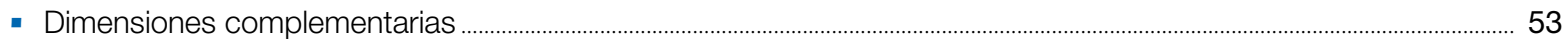

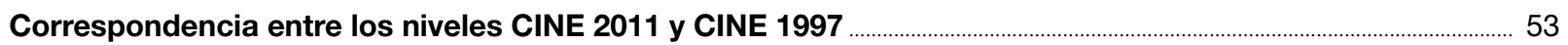

Directrices para clasificar programas y certificaciones de nivel CINE 3 ……………………………………….............. 54

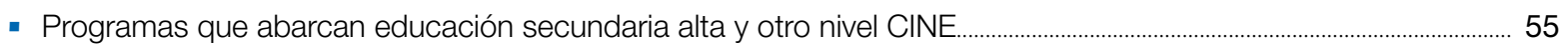

Logro educativo en el nivel CINE 3

Ejemplos de programas y certificaciones clasificadas en el nivel CINE 3

CAPÍTULO 6 NIVEL 4 - CINE 2011: EDUCACIÓN POSTSECUNDARIA NO TERCIARIA ....................................... 63

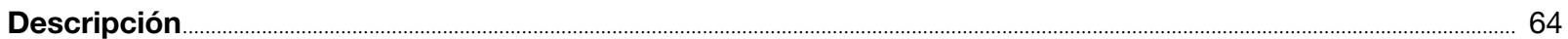

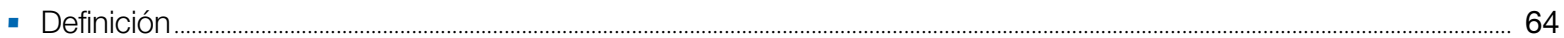

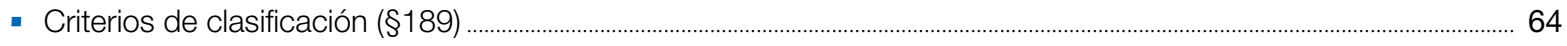

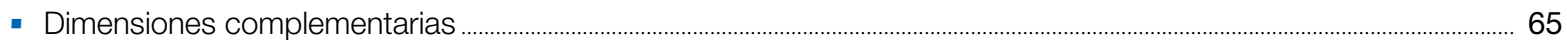

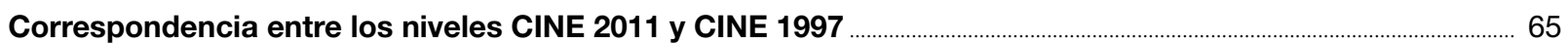

Directrices para clasificar programas y sus certificaciones relacionadas reconocidas en el nivel 4

de la CINE

- Distinción entre el nivel CINE 4 y el nivel CINE 5 ...................................................................................................................... 67

Logro educativo en el nivel CINE 4

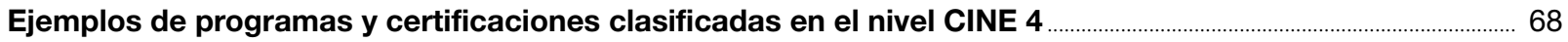

TERCERA PARTE NIVELES CINE 5 A 8: EDUCACIÓN TERCIARIA …….................................................................. 73

CAPÍTULO 7 ASPECTOS GENERALES DE LOS NIVELES CINE DE EDUCACIÓN TERCIARIA......................... 73

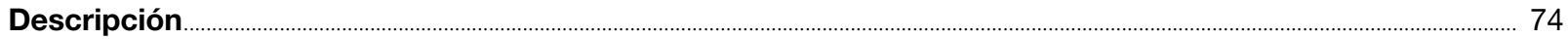

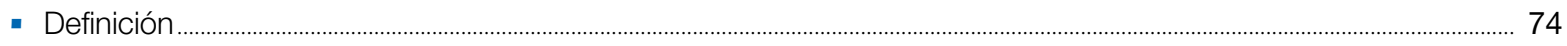

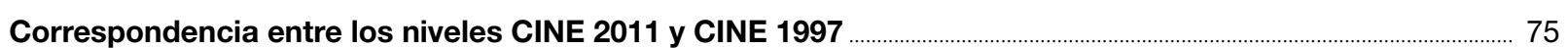


CAPÍTULO 8 NIVEL 5 - CINE 2011: EDUCACIÓN TERCIARIA DE CICLO CORTO ……......................................... 77

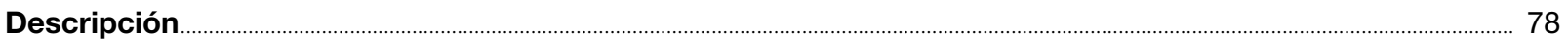

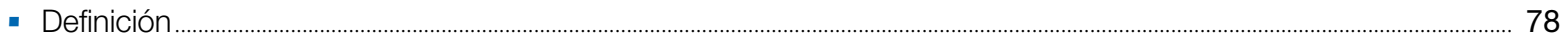

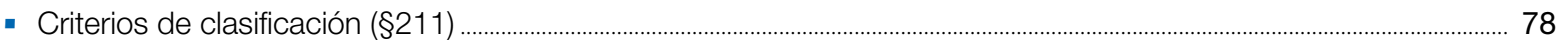

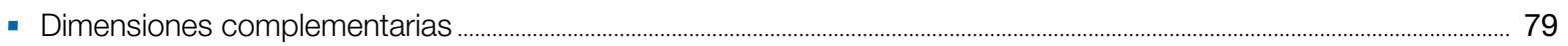

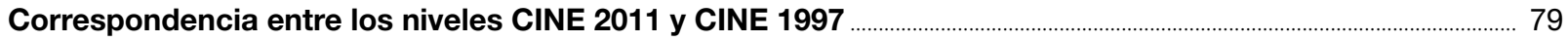

Directrices para clasificar programas de nivel CINE 5 y certificaciones reconocidas relacionadas ................ 79

Logro educativo en el nivel CINE 5

Ejemplos de programas y certificaciones clasificadas en el nivel CINE 5 ……......................................................... 80

CAPÍTULO 9 NIVEL 6 - CINE 2011: GRADO EN EDUCACIÓN TERCIARIA O NIVEL EQUIVALENTE.............. 85

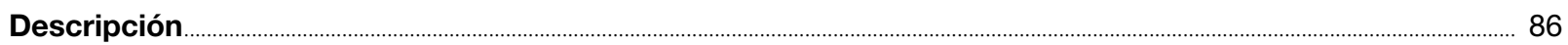

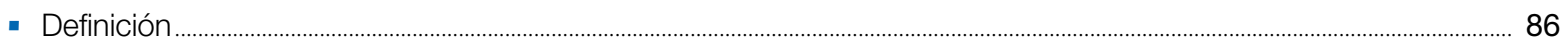

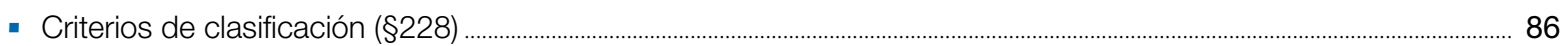

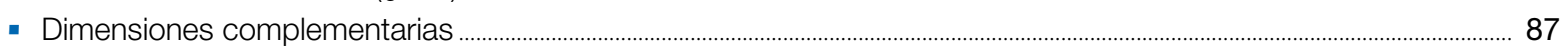

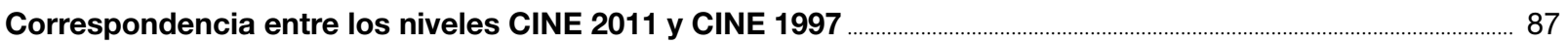

Directrices para clasificar programas de nivel CINE 6 y certificaciones reconocidas relacionadas ................ 87

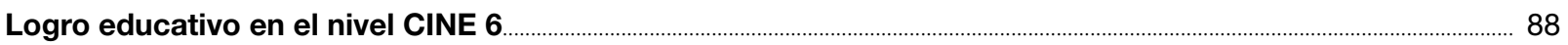

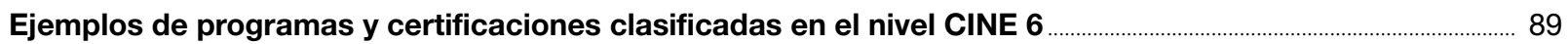

CAPÍTULO 10 NIVEL 7 - CINE 2011: NIVEL DE MAESTRÍA, ESPECIALIZACIÓN O EQUIVALENTE................... 93

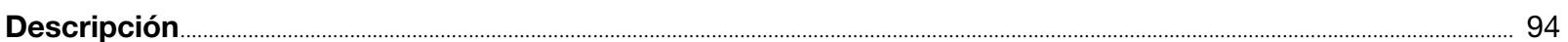

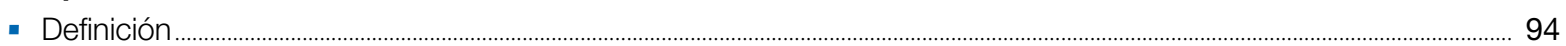

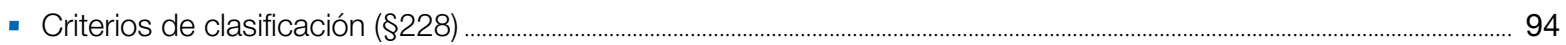

- Dimensiones complementarias ………………………………………………………………………………………………………. 95

Correspondencia entre los niveles CINE 2011 y CINE 1997 .............................................................................................. 95

Directrices para clasificar programas de nivel CINE 7 y certificaciones reconocidas relacionadas .................. 95

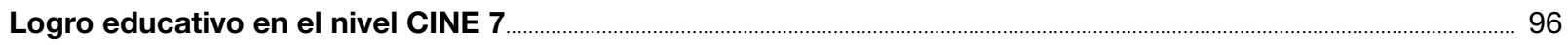

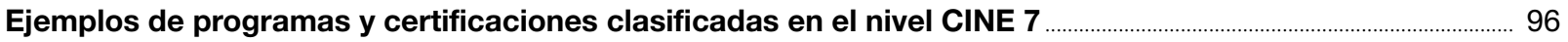

CAPÍTULO 11 NIVEL 8 - CINE 2011: NIVEL DE DOCTORADO O EQUIVALENTE .................................................. 101

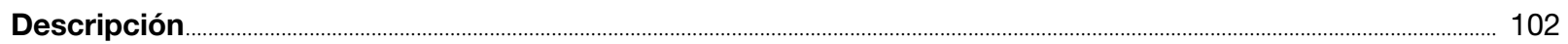

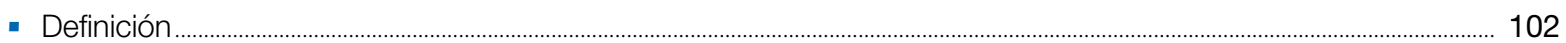

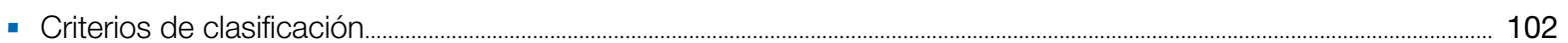

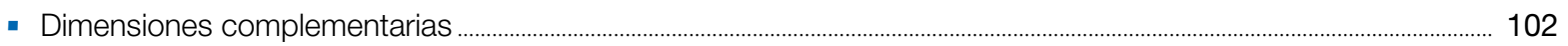

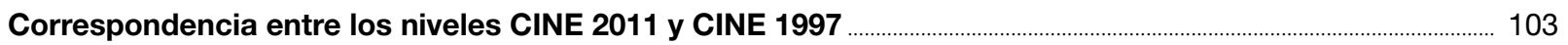

Directrices para clasificar programas de Nivel 8 y certificaciones reconocidas relacionadas .......................... 103

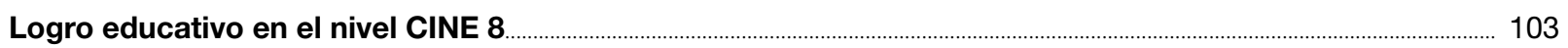

Ejemplos de programas y certificaciones clasificadas en el nivel CINE 8 ….............................................................. 104

ANEXO A CUADRO SINÓPTICO DE CÓDIGOS Y CRITERIOS CINE 2011 …………........................................... 107

ANEXO B TRAYECTORIAS EDUCATIVAS POTENCIALES EN LA CINE 2011................................................... 115

ANEXO C CUADRO DE REFERENCIA RÁPIDA DE CÓDIGOS CINE-P Y CINE-A EN LA CINE 2011 ........... 117 



\section{Guía del lector}

El propósito del Manual Operativo CINE 2011 es ayudar a los países a clasificar los programas educativos y las correspondientes certificaciones en sus mapas CINE. El manual también ayudará a los usuarios de estadísticas internacionales a determinar qué tipos de programas y certificaciones están cubiertos por los indicadores de educación. El manual proporciona directrices y notas explicativas que facilitan la interpretación de esta clasificación recientemente actualizada e incluye ejemplos de programas y certificaciones relacionadas que han sido clasificados por diversos países de acuerdo a la CINE 2011.

Todo texto citado directamente de la publicación oficial de la Clasificación Internacional Normalizada de la Educación 2011 (UNESCO-UIS, 2012), será precedido por una referencia al número del párrafo donde aparece. Por ejemplo:

(§1) La Clasificación Internacional Normalizada de la Educación (CINE) representa una clasificación de referencia que permite ordenar los programas educativos y sus respectivas certificaciones por niveles de educación y campos de estudio.

Toda referencia a un número de párrafo que aparezca al final de un texto en este manual, significa que si bien el concepto aparece en la clasificación CINE 2011, el texto de dicho párrafo no constituye una cita directa. Por ejemplo:

El desarrollo de la primera infancia está diseñado para niños entre 0 y 2 años y la educación preprimaria se orienta a niños desde los 3 años de edad hasta el inicio de la educación primaria. (§102)

La clasificación CINE 2011, que incorpora las definiciones del marco oficial, se encuentra disponible en los siguientes idiomas:

Árabe (www.uis.unesco.org/Education/Documents/isced-2011-ar.pdf)

Chino (www.uis.unesco.org/Education/Documents/isced-2011-ch.pdf)

Inglés (www.uis.unesco.org/Education/Documents/isced-2011-en.pdf)

Francés (www.uis.unesco.org/Education/Documents/isced-2011-fr.pdf)

Ruso (www.uis.unesco.org/Education/Documents/isced-2011-ru.pdf)

Español (www.uis.unesco.org/Education/Documents/isced-2011-sp.pdf)

La clasificación CINE 2011 también incluye un amplio glosario de términos relacionado con la clasificación de actividades educativas.

- Si desea consultar el glosario CINE 2011, véase el Anexo VI de la clasificación CINE 2011.

El manual operativo se ha dividido en tres partes. La primera parte describe aspectos generales de la clasificación actualizada y destaca los principales cambios que han tenido lugar entre la CINE 2011 y la CINE 1997. La segunda y tercera parte proporcionan descripciones detalladas de cada nivel CINE.

En la segunda y tercera parte, los capítulos sobre cada nivel CINE contienen descripciones de las características del nivel y directrices detalladas sobre la asignación de programas a la CINE y sus respectivas certificaciones 2011 basadas en criterios específicos. La codificación de tres dígitos utilizada en las clasificaciones paralelas de programas educativos (CINE-P) y logro educativo (CINE-A) se ilustra a través de ejemplos nacionales. Asimismo, cada capítulo incluye una relación pormenorizada de la correspondencia entre los niveles CINE 2011 y Cine 1997.

El Anexo A presenta un cuadro sinóptico de todos los códigos CINE 2011 que incluye descripciones y criterios aplicables. El Anexo B presenta un gráfico con trayectorias potenciales de educación en la CINE 2011. El Anexo C ofrece referencias cruzadas que permiten identificar en forma rápida los códigos asignados a la CINE-P y CINE-A. 



\section{PRIMERA PARTE \\ PERSPECTIVA GENERAL DE LA CINE 2011}

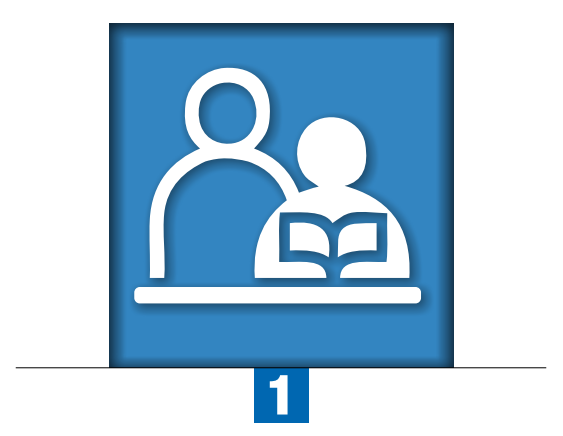

\section{Capítulo 1}

\section{Perspectiva general de los niveles CINE 2011}

La Clasificación Internacional Normalizada de la Educación (CINE) representa una clasificación de referencia que permite ordenar los programas educativos y sus respectivas certificaciones por niveles de educación y campos de estudio. Las definiciones y conceptos básicos de la CINE se han formulado de modo que sean universalmente válidos y aplicables al espectro total de sistemas educativos. La CINE 2011 representa una segunda e importante revisión de esta clasificación (originalmente elaborada en la década de los 70 y revisada por primera vez en 1997). Fue adoptada por la Conferencia General de la UNESCO en noviembre de 2011.

La CINE 2011 incorpora una actualización de los niveles CINE 1997 de los programas educativos (CINE-P) y agrega una clasificación relacionada de niveles de logro educativo (CINE-A) basada en certificaciones reconocidas. En comparación con la CINE 1997, que incluía solo siete niveles de educación, la CINE 2011 actualmente cuenta con nueve niveles. 


\section{¿QUÉ ES LA CINE Y CUÁLES SON SUS UNIDADES DE CLASIFICACIÓN?}

$(\S 1)^{1}$ La Clasificación Internacional Normalizada de la Educación (CINE) representa una clasificación de referencia que permite ordenar los programas educativos y sus respectivas certificaciones por niveles de educación y campos de estudio.

(§2) En consecuencia, las definiciones y conceptos básicos de la CINE se han formulado de modo que sean universalmente válidos y aplicables al espectro total de sistemas educativos.

La CINE 2011 representa la segunda revisión de esta clasificación (elaborada originalmente en la década de los 70 y objeto de una primera revisión en 1997). La CINE 2011 fue adoptada en la Conferencia General de la UNESCO en noviembre de 2011.

- Para mayor información general sobre la CINE, véase la Sección 1 de la Clasificación CINE 2011.

(§10) Las unidades básicas de clasificación de la CINE son el programa educativo nacional (y subnacional) y las certificaciones relacionadas reconocidas.

(§11) En términos de la CINE, un programa educativo se define como el conjunto o secuencia coherente de actividades educativas diseñadas y organizadas para lograr un objetivo predeterminado de aprendizaje o para llevar a cabo un conjunto especifico de tareas educativas a lo largo de un periodo sostenido de tiempo.

(§20) En el contexto de la CINE, el término "certificación" representa una confirmación oficial de la conclusión de un programa educativo o de una etapa de este.

- Para mayor información sobre las unidades de clasificación de la CINE, véase la Sección 2 de la Clasificación CINE 2011.

\section{¿QUIÉN ES RESPONSABLE DE LA CLASIFICACIÓN CINE?}

(§91) El Instituto de Estadística de la UNESCO (UIS) es el custodio de la CINE y es, de esta manera, responsable del desarrollo, mantenimiento, actualización y revisión de esta clasificación de referencia.

(§96) El Instituto proyecta trabajar en estrecha colaboración con los países y sus socios en materia de acopio de estadísticas de educación (incluyendo Eurostat y la OCDE) con objeto de asegurar la consistencia de los mapas con los estándares de la CINE y la actualización de estos cuando sea necesario.

- Para mayor información sobre administración de la CINE, véase la Sección 8 de la Clasificación CINE 2011.

\section{¿QUÉ SE ENTIENDE POR MAPAS CINE?}

(§8) Los "mapas CINE" representan una herramienta esencial que permite organizar la información relativa a los sistemas nacionales de educación, a los programas que los integran y a las certificaciones otorgadas por estos últimos a fin de garantizar la comparabilidad de las estadísticas asociadas con los distintos niveles de la CINE y su posterior interpretación a nivel internacional.

(§22) Dentro del esquema de la CINE, primero se clasifican los programas educativos y en un segundo término las certificaciones. Los mapas CINE representan herramientas que muestran los vínculos entre programas educativos y sus respectivas certificaciones.

Los mapas nacionales CINE permiten que las comparaciones internacionales sean más transparentes y fáciles de entender para los usuarios. Por esta razón, la información contextual presentada en los mapas es esencial. 
Dicha información incluye, entre otras, los nombres de los programas nacionales, la edad de ingreso y duración teórica de los programas, los requisitos mínimos de ingreso, y las certificaciones otorgadas tras la exitosa conclusión de un programa. Esta información se presenta junto a las dimensiones pertinentes de la CINE, tales como el nivel CINE, la orientación del programa, la conclusión y el acceso a subcategorías y, en el caso de los niveles CINE 6 (Grado en educación terciaria) y 7 (Nivel de maestría, especialización o equivalente) la posición en la estructura nacional de títulos y certificaciones.

Luego, es posible utilizar la clasificación de programas nacionales en niveles CINE y las dimensiones complementarias, para determinar el código de tres dígitos de un programa CINE-P y el código de tres dígitos CINE-A que corresponde a la certificación recibida tras la exitosa conclusión del programa.

Los mapas CINE también pueden incluir notas que describen en mayor detalle las características de los programas nacionales.

\section{¿QUÉ LIMITACIONES TIENE LA CLASIFICACIÓN CINE 2011 EN TÉRMINOS DE COBERTURA?}

(§35) La CINE 2011 cubre los programas educativos formales y no formales disponibles a una persona en cualquiera etapa de su vida. Las certificaciones reconocidas por las autoridades nacionales competentes se utilizan para medir el logro educativo independientemente de cómo se hayan obtenido, es decir, a través de la conclusión de un programa educativo formal o no formal o de una actividad de aprendizaje informal. La CINE no cubre programas de aprendizaje informal, imprevisto o aleatorio ni certificaciones no reconocidas.

(§42) Para propósitos estadísticos, la CINE 2011 establece una clara distinción entre la educación formal y no formal. En la actualidad, las actividades de recopilación de datos internacionales en materia de educación (elaboración de mapas, censos y encuestas) se centran principalmente en la educación formal.

La CINE no suele incluir información sobre programas de educación no formal en iniciativas internacionales de recopilación de datos. No obstante, para propósitos de logro educativo, normalmente se consideran las certificaciones reconocidas de programas educativos no formales siempre que sean equivalentes a las certificaciones otorgadas por la educación formal.

- Para mayor información sobre el alcance de la CINE, véase la Sección 4 de la Clasificación CINE 2011.

- Para mayor información y pormenores sobre temas relacionados con la educación no formal, véase la Sección 4 y el Anexo V de la Clasificación CINE 2011.

\section{¿QUÉ NIVELES DE EDUCACIÓN SE DEFINEN EN LA CLASIFICACIÓN CINE 2011?}

(§45) Las principales variables de clasificación cruzada de la CINE son los niveles y campos de educación.

Este manual operativo se refiere especialmente a la clasificación de programas y certificaciones relacionadas con los niveles CINE 2011.

La CINE 2011 cuenta con nueve niveles de educación que van del nivel 0 al nivel 8:

- CINE 0: educación de la primera infancia

- CINE 1: educación primaria

- CINE 2: educación secundaria baja

- CINE 3: educación secundaria alta

- CINE 4: educación postsecundaria no terciaria

- CINE 5: educación terciaria de ciclo corto

- CINE 6: grado en educación terciaria o nivel equivalente

- CINE 7: nivel de maestría, especialización o equivalente

- CINE 8: nivel de doctorado o equivalente 
(§47) La CINE está asociada con el grado de complejidad y especialización del contenido de un programa, que puede ir desde básico hasta avanzado.

(§48) Cuanto más avanzado sea el programa, más elevado será el nivel de educación.

- Para mayor información sobre los niveles CINE, véanse las Secciones 5 y 9 de la Clasificación CINE 2011.

\section{¿CÓMO SE ASIGNAN LOS PROGRAMAS Y CERTIFICACIONES RELACIONADAS A LOS NIVELES CINE 2011?}

(§50) La clasificación de los programas por nivel se debe basar en el contenido educativo. Debido a la falta de mediciones directas que permitan clasificar el contenido educativo, la CINE ha incorporado criterios de aproximación que facilitan la asignación de un programa educativo determinado al nivel apropiado de educación.

(§51) Dichos criterios de aproximación constan de criterios principales y subsidiarios.

Por ejemplo, los criterios de aproximación que permiten asignar un programa educativo al nivel apropiado de educación son la duración y duración acumulada de dichos programas dentro y entre los niveles CINE. La CINE 2011 proporciona directrices sobre duración y rangos de duración acumulada como criterios para clasificar programas educativos por nivel. Los Cuadros 1.1 y 1.2 presentan un resumen de estos criterios.

- Cuadro 1.1 -

\section{Duración por nivel CINE}

\section{\begin{tabular}{l|ll} 
Nivel CINE & Duración típica [duración más común]
\end{tabular}}

$0 \quad$ No se han establecido criterios de duración. Sin embargo, solo se deben incluir en este nivel programas que se impartan en períodos de actividades educativas equivalentes a 2 horas diarias y 100 días al año como mínimo.

\begin{tabular}{ll}
\hline 1 & 4 a 7 años [más común: 6 años] \\
\hline 2 & 2 a 5 años [más común: 3 años] \\
\hline 3 & 2 a 5 años [más común: 3 años] \\
\hline 4 & 6 meses a 2 o 3 años \\
\hline 5 & 2 a 3 años \\
\hline 6 & $\begin{array}{l}\text { 3 a } 4 \text { años a partir del nivel CINE 3; o } \\
1 \text { a } 2 \text { años a partir de otro programa del nivel CINE 6 }\end{array}$ \\
\hline 7 & $\begin{array}{l}1 \text { a } 4 \text { años a partir del nivel CINE 6; o } \\
5 \text { a } 7 \text { años a partir del nivel } 3\end{array}$ \\
\hline 8 & Tres años como mínimo \\
\hline
\end{tabular}

- Cuadro 1.2 .

Duración acumulada típica en educación primaria y secundaria

\begin{tabular}{l|l}
\hline Nivel CINE & Rango [duración acumulada más común] \\
\hline 1 & 4 a 7 años [más común: 6 años] \\
\hline $1+2$ & 8 a 11 años [más común: 9 años] \\
\hline $1+2+3$ & 11 a 13 años [más común: 12 años] \\
\hline
\end{tabular}

Otros criterios de aproximación característicos de la CINE 2011 son los requisitos para ingresar a un programa, los tipos de certificación docente, la organización de la instrucción y el diseño del programa (por ej., preparar a candidatos para su ingreso al mercado laboral u otros programas educativos). 
Al momento de clasificar un programa educativo por niveles CINE, el contexto institucional nunca deberá utilizarse como criterio principal. El criterio primario es la complejidad y especialización del contenido educativo y cómo este contenido se ve reflejado en los criterios de aproximación (§52).

- Para mayor información sobre los criterios de duración y duración acumulada de la CINE, véase la Sección 5 y el Cuadro 21 de la Clasificación CINE 2011.

(§49) La clasificación de programas educativos en niveles de progresión permite recoger la variedad de opciones disponibles en los sistemas educativos. La mayoría de estos ofrecen diferentes trayectorias potenciales entre los niveles $0 / 1$ y 8.

- Las trayectorias educativas potenciales por categorías CINE 2011, se muestran en el Gráfico 2 del Anexo I de la Clasificación CINE 2011 y en el Anexo B de este manual operativo.

\section{¿LOS PROGRAMAS QUE ABARCAN MÁS DE UN NIVEL CINE, SON SECUENCIALES O CONSISTEN EN MÓDULOS CLASIFICADOS DENTRO DE LA CINE 2011?}

(§26) Al momento de clasificar los programas nacionales de educación por niveles CINE, es posible que los puntos de transición entre estos programas y los puntos de ingreso al mercado laboral no siempre coincidan con los puntos de transición entre los niveles CINE. Se pueden identificar tres casos: i) programas que abarcan dos o más niveles CINE; ii) dos o más programas secuenciales que sumados constituyen un nivel CINE, y iii) programas impartidos bajo la modalidad de módulos o cursos sin una secuencia claramente definida.

En el caso de programas que abarcan dos o más niveles CINE, los años, grados o etapas, que cumplan con los criterios definidos para cada nivel CINE deben ser asignados a los diferentes niveles según corresponda. Los puntos de transición de cada programa pueden ayudar a identificar las líneas divisorias entre los niveles CINE.

Durante la elaboración de informes, dos o más programas secuenciales de un mismo nivel CINE requieren una consideración especial. Por ejemplo, si bien la matrícula debe considerar todos los programas de ese nivel, los datos sobre ingresos de estudiantes deben registrar solo a las personas que ingresan al primer programa del nivel. Adicionalmente, los datos sobre graduados deben incluir solamente a los participantes que han finalizado el último programa de la secuencia del nivel (excepto si también se busca recopilar datos sobre personas que han concluido con éxito programas que conducen a la conclusión parcial del nivel) (§32).

Asimismo, los programas consistentes en módulos deben ser rigurosamente evaluados para asegurar que cumplan con todos los criterios definidos en la CINE 2011 para programas educativos, y tratados con igual rigurosidad al momento de elaborar informes.

- Para mayor información sobre programas que abarcan más de un nivel CINE, programas secuenciales y modulares, véase la Sección 3 de la Clasificación CINE 2011.

\section{¿QUÉ DIMENSIONES COMPLEMENTARIAS FACILITAN LA CLASIFICACIÓN DE PROGRAMAS Y CERTIFICACIONES EN LOS NIVELES CINE 2011?}

En cada nivel de la CINE, los programas y certificaciones se subdividen por dimensiones complementarias.

Estas incluyen:

- la orientación de los programas;

- la conclusión del nivel CINE;

- el acceso a un nivel CINE más avanzado; y

- la posición en la estructura nacional de títulos y certificaciones. 
Para los niveles CINE 2 a 5, existen dos posibles orientaciones de programas: general y vocacional. La CINE 2011 también permite utilizar las categorías de orientación académica y vocacional en el nivel terciario (5 a 8). Sin embargo, ante la falta de definiciones consensuadas sobre estas categorías de orientación, en estadísticas internacionales es recomendable utilizar la categoría "no especificada" para los niveles CINE 6 a 8.

La CINE 2011 introduce una nueva dimensión complementaria: conclusión de nivel CINE y acceso a un nivel más avanzado de educación. En total, se incorporan cuatro posibles subcategorías de programas (aunque no todas aplican a todos los niveles):

- Nivel inconcluso (por consiguiente, sin acceso directo a un nivel más avanzado - en el caso del nivel CINE 3 a los niveles CINE 5, 6 o 7);

- Conclusión parcial del nivel; sin acceso directo a un nivel CINE más avanzado;

- Conclusión del nivel; sin acceso directo a un nivel CINE más avanzado;

- Conclusión del nivel; con acceso directo a un nivel CINE más avanzado (en el caso del nivel CINE 3 corresponde a programas de primer título de educación terciaria de nivel CINE 5, 6 o 7).

Los programas de nivel CINE 6 y 7 también pueden clasificarse en base a su posición en la estructura nacional de títulos y certificaciones. (Para mayor información sobre estas subcategorías consulte los capítulos pertinentes).

Cabe desatacar que no todas las dimensiones complementarias son aplicables a todos los niveles. Asimismo, el nivel CINE 0 se ha subdividido de acuerdo al tipo de programa (desarrollo educacional de la primera infancia) y al grupo etario objetivo (educación preprimaria).

- Para mayor información sobre dimensiones complementarias de la CINE, véase la Sección 5 de la Clasificación CINE 2011.

\section{CAMPOS DE EDUCACIÓN Y CAPACITACIÓN}

En el contexto de la CINE, los programas y certificaciones relacionadas se pueden clasificar por campos de educación y capacitación y por niveles. La revisión CINE 2011 se centró en los niveles CINE y en las dimensiones complementarias asociadas con estos niveles.

Tras la adopción de la CINE 2011, los campos de educación de la CINE fueron sometidos a un análisis y consultas globales en forma individual. Los campos de la CINE fueron actualizados y adoptados en la $37^{a}$ Conferencia General de la UNESCO celebrada en noviembre de 2013 bajo la designación Clasificación de Campos de Educación y Capacitación CINE 2013 (CINE-F).

La Clasificación de Campos de Educación y Capacitación CINE 2013 (UNESCO-UIS, 2014) se encuentra disponible en los siguientes idiomas:

Árabe (www.uis.unesco.org/Education/Documents/isced-fields-of-education-training-2013AR.pdf)

Chino (www.uis.unesco.org/Education/Documents/isced-fields-of-education-training-2013CH.pdf)

Inglés (www.uis.unesco.org/Education/Documents/isced-fields-of-education-training-2013.pdf)

Francés (www.uis.unesco.org/Education/Documents/isced-fields-of-education-training-2013FR.pdf)

Ruso (www.uis.unesco.org/Education/Documents/isced-fields-of-education-training-2013RU.pdf)

Español (www.uis.unesco.org/Education/Documents/isced-fields-of-education-training-2013ES.pdf)

\section{¿QUÉ SISTEMA DE CODIFICACIÓN SE UTILIZA EN LA CINE 2011?}

(§89) La clasificación de programas educativos propuesta en la CINE utiliza dos sistemas paralelos de codificación, uno para programas (Programas-CINE o CINE-P) y otro para logro educativo (Logro-CINE o CINE-A). Se ha adoptado un sistema de codificación de tres dígitos para clasificar tanto los programas como el logro educativo. 
Cabe destacar que, si bien suele haber correspondencia entre los códigos CINE-P y los códigos CINE-A asociados con la exitosa conclusión de los programas, estos últimos no siempre pueden ser derivados automáticamente de los códigos CINE-P. Por ejemplo, ciertos programas educativos pueden conducir a más de una certificación cada una de las cuales puede, a su vez, ubicarse en distintos niveles de logro educativo. El programa puede ser clasificado en la CINE-P de acuerdo a la categoría de conclusión y acceso más avanzada a la que conduzca, pero cada certificación se clasificará en la CINE-A de acuerdo al nivel real de logro académico asociado con ella.

Los códigos que finalizan en "1" en la CINE-P (programas considerados insuficientes para conclusión del nivel) no existen en la CINE-A dado que el logro educativo derivado de dichos programas se codifica en un nivel CINE inferior al del programa de estudio.

- Para mayor información sobre códigos de la CINE 2011, véanse los Cuadros 1 a 3 y los Anexos II y III en la Clasificación CINE 2011.

\section{COMPARACIÓN ENTRE LA CINE 2011 Y LA CINE 1997}

\section{Principales cambios entre la CINE 2011 y CINE 1997}

En la CINE 2011 se actualizan los niveles de programas educativos (CINE-P) presentados originalmente en la CINE 1997 y se introduce una nueva clasificación de niveles de logro educativo (CINE-A) basada en certificaciones reconocidas.

La CINE 2011 incorpora definiciones más precisas sobre educación formal y no formal y actividades y programas educativos. Esta versión también incluye un glosario ampliado para facilitar la comprensión de términos específicos relacionados con la CINE.

En comparación con la CINE 1997, que incluía solo siete niveles de educación, actualmente la CINE 2011 cuenta con nueve niveles de educación. La educación terciaria ha sido reestructurada en respuesta a cambios en la educación superior, tales como la estructura de Boloña, y actualmente comprende cuatro niveles de educación en lugar de dos, como era el caso en la CINE 1997. Los programas previamente clasificados en el nivel CINE 5 de la versión 1997, en la versión 2011 son asignados a los niveles CINE 5, 6 o 7. Asimismo, el nivel CINE 0 ha sido ampliado para incluir una nueva categoría que ahora cubre programas de desarrollo educacional de la primera infancia orientados a niños menores de tres años. Dentro de la CINE, cada nivel de educación ha sido definido con mayor claridad, hecho que puede promover algunos cambios en la clasificación de programas que anteriormente se situaban en la línea divisoria de dos niveles CINE (por ejemplo, entre los niveles CINE 3 y 4).

La CINE 2011 incluye dos clasificaciones paralelas, CINE-P y CINE-A, cada una representada por códigos de tres dígitos que si bien son similares operan como sistemas independientes.

Las dimensiones complementarias también han sido objeto de actualización. Actualmente, solo se cuenta con dos categorías de orientación: general y vocacional. Los programas anteriormente clasificados como pretécnicos (CINE 1997) no otorgan certificaciones pertinentes al mercado laboral y en la actualidad se clasifican esencialmente bajo la denominación "educación general" (\$278). La CINE 2011 ha propuesto códigos para las orientaciones "académica" y "profesional" en educación terciaria. Sin embargo, considerando que aún no se llega a un acuerdo internacional sobre la definición de estas orientaciones también se dispone del código "orientación no especificada" para utilizar en los niveles 6 a 8 de la CINE 2011.

En la CINE 1997 se distinguen dos categorías de acceso a niveles CINE más avanzados, según el tipo de educación subsecuente, en tanto que en la CINE 2011 se identifica solo un grupo de programas que dan acceso a niveles más avanzados. La subcategoría CINE 2011 "conclusión de nivel sin acceso a niveles CINE más avanzados" corresponde a la combinación de las categorías A y B de la CINE 1997. La CINE 2011 sub-clasifica los programas que no dan acceso a estudios más avanzados en las siguientes subcategorías: "nivel inconcluso", "conclusión parcial de nivel" y "conclusión de nivel". Estas tres subcategorías en la CINE 2011 corresponden a la categoría de destino "C" de la CINE 1997 (§278).

Asimismo, aunque en la CINE 1997 ya se había hecho mención de la categoría "posición en la estructura nacional de títulos y certificaciones" respecto de programas de educación terciaria, hasta la CINE 2011 no se habían asignado códigos específicos a los niveles 6 y 7 (primer título del grado en educación terciaria o nivel equivalente, o primer título del grado en educación terciaria o nivel de maestría/especialización o equivalente, respectivamente). 


\section{Cuadros de correspondencia entre las revisiones CINE}

El Cuadro 1.3 muestra la correspondencia (concordancia) entre los niveles CINE 2011 y CINE 1997.

\section{- Cuadro 1.3}

\section{Comparación entre niveles de educación CINE 2011 y CINE 1997}

\begin{tabular}{|c|c|c|c|}
\hline \multicolumn{2}{|c|}{ CINE 2011} & \multicolumn{2}{|c|}{ CINE 1997} \\
\hline 01 & Desarrollo de la primera infancia & & - \\
\hline 02 & Educación preprimaria & 0 & Educación preprimaria \\
\hline 1 & Educación primaria & 1 & Educación primaria o primer ciclo de educación básica \\
\hline 2 & Educación secundaria baja & 2 & $\begin{array}{l}\text { Primer ciclo de educación secundaria o segundo } \\
\text { ciclo de educación básica }\end{array}$ \\
\hline 3 & Educación secundaria alta & 3 & Segundo ciclo de educación secundaria \\
\hline 4 & Educación postsecundaria no terciaria & 4 & Educación postsecundaria no terciaria \\
\hline 5 & Educación terciaria de ciclo corto & \multirow[t]{3}{*}{5} & \multirow{3}{*}{$\begin{array}{l}\text { Primer ciclo de educación terciaria (no conduce } \\
\text { directamente a una certificación de investigación } \\
\text { avanzada) }(5 A, 5 B)\end{array}$} \\
\hline 6 & Grado en educación terciaria o nivel equivalente & & \\
\hline 7 & Nivel de maestría, especialización o equivalente & & \\
\hline 8 & Nivel de doctorado o equivalente & 6 & $\begin{array}{l}\text { Segundo ciclo de educación terciaria (conduce a una } \\
\text { certificación de investigación avanzada) }\end{array}$ \\
\hline
\end{tabular}

El Cuadro 1.4 muestra la correspondencia entre las dimensiones complementarias de los niveles CINE 2011 y CINE 1997.

- Cuadro 1.4 .

Comparación de dimensiones complementarias entre los niveles CINE 2011 y CINE 1997

\begin{tabular}{|c|c|c|c|c|c|}
\hline \multicolumn{3}{|c|}{ CINE 2011} & \multicolumn{3}{|c|}{ CINE 1997} \\
\hline \multicolumn{2}{|c|}{$\begin{array}{l}\text { Orientación } \\
\text { (código de segundo dígito) }\end{array}$} & \multirow{4}{*}{$\begin{array}{l}\text { Niveles } \\
\text { aplicados } \\
2 \text { a } 5\end{array}$} & \multicolumn{2}{|c|}{ Orientación } & $\begin{array}{l}\text { Niveles } \\
\text { aplicados }\end{array}$ \\
\hline \multirow[t]{2}{*}{4} & \multirow[t]{2}{*}{ Educación general } & & G & Educación general & \multirow[t]{3}{*}{2 to 4} \\
\hline & & & $P$ & Educación pre-técnica & \\
\hline 5 & Educación vocacional & & V & Educación vocacional o técnica & \\
\hline 4 & Educación académica* & 5 a 8 & & - & \\
\hline 5 & Educación vocacional* & 5 a 8 & & - & \\
\hline 6 & Orientación no especificada * & 6 a 8 & & - & \\
\hline \multicolumn{2}{|c|}{$\begin{array}{l}\text { Conclusión y acceso } \\
\text { (código CINE-P de tercer dígito) }\end{array}$} & $\begin{array}{l}\text { Niveles } \\
\text { aplicados }\end{array}$ & \multicolumn{2}{|c|}{ Destino } & $\begin{array}{l}\text { Niveles } \\
\text { aplicados }\end{array}$ \\
\hline \multirow[t]{5}{*}{4} & \multirow[t]{5}{*}{$\begin{array}{l}\text { Suficiente para la conclusión del nivel } \\
\text { con acceso directo a un nivel CINE más } \\
\text { avanzado }\end{array}$} & \multirow[t]{5}{*}{2 a 8} & \multirow[t]{2}{*}{ A } & $\begin{array}{l}\text { Programas que conducen a programas } \\
\text { del tipo "A" de un nivel CINE más } \\
\text { avanzado (en trayectoria directa a un } \\
\text { doctorado) }\end{array}$ & 2 a 4 \\
\hline & & & & $\begin{array}{l}\text { Programas teóricos del primer nivel de } \\
\text { educación terciaria }\end{array}$ & 5 \\
\hline & & & \multirow[t]{3}{*}{$\mathrm{B}$} & $\begin{array}{l}\text { Programas que conducen a programas } \\
\text { del tipo "B" de un nivel CINE más } \\
\text { avanzado (en trayectoria directa al } \\
\text { mercado laboral) }\end{array}$ & $2,3,\left(4^{\star \star}\right)$ \\
\hline & & & & $\begin{array}{l}\text { Programas que conducen al mercado } \\
\text { laboral }\end{array}$ & $4^{\star \star}$ \\
\hline & & & & $\begin{array}{l}\text { Programas impartidos en el primer nivel } \\
\text { de educación terciaria de naturaleza } \\
\text { práctica y orientados a ocupaciones } \\
\text { específicas }\end{array}$ & 5 \\
\hline
\end{tabular}


- Cuadro 1.4 (continuado) "

Comparación de dimensiones complementarias entre los niveles CINE 2011 y CINE 1997

\begin{tabular}{|c|c|c|c|c|c|}
\hline \multicolumn{3}{|c|}{ CINE 2011} & \multicolumn{3}{|c|}{ CINE 1997} \\
\hline \multicolumn{2}{|c|}{$\begin{array}{l}\text { Conclusión y acceso } \\
\text { (código CINE-P de tercer dígito) }\end{array}$} & \multirow{2}{*}{$\begin{array}{l}\text { Niveles } \\
\text { aplicados } \\
2 \text { a } 4\end{array}$} & \multicolumn{2}{|c|}{ Destino } & $\begin{array}{l}\text { Niveles } \\
\text { aplicados }\end{array}$ \\
\hline 3 & $\begin{array}{l}\text { Suficiente para conclusión del nivel sin } \\
\text { acceso directo a un nivel CINE más } \\
\text { avanzado }\end{array}$ & & \multirow[t]{3}{*}{ C } & \multirow[t]{3}{*}{$\begin{array}{l}\text { Programas que conducen al mercado } \\
\text { laboral sin acceso directo a un nivel } \\
\text { CINE más avanzado }\end{array}$} & \multirow[t]{3}{*}{$2,3,\left(4^{\star \star}\right)$} \\
\hline 2 & $\begin{array}{l}\text { Conclusión parcial del nivel sin acceso } \\
\text { directo a un nivel CINE más avanzado }\end{array}$ & 2,3 & & & \\
\hline 1 & $\begin{array}{l}\text { Insuficiente para conclusión del nivel } \\
\text { sin acceso directo a un nivel CINE más } \\
\text { avanzado }\end{array}$ & 2 a 8 & & & \\
\hline \multicolumn{2}{|c|}{$\begin{array}{l}\text { Posición en la estructura nacional de títulos } \\
\text { y certificaciones (código CINE-P de tercer } \\
\text { dígito) }\end{array}$} & $\begin{array}{l}\text { Niveles } \\
\text { aplicados }\end{array}$ & & & \\
\hline 5 & Primer título & 6 & - & - & - \\
\hline 6 & Primer título largo & 6,7 & - & - & - \\
\hline 7 & $\begin{array}{l}\text { Segundo o siguiente título tras la } \\
\text { conclusión de un programa del grado } \\
\text { en educación terciaria o equivalente }\end{array}$ & 6,7 & - & - & - \\
\hline 8 & $\begin{array}{l}\text { Segundo o siguiente título tras la } \\
\text { conclusión de un programa de nivel de } \\
\text { maestría, especialización o equivalente }\end{array}$ & 7 & - & - & - \\
\hline
\end{tabular}

* Ante la falta de definiciones internacionalmente consensuadas sobre orientaciones académicas y profesionales en educación terciaria, en la versión 2011 de la CINE se utilizará "general" o "vocacional" en los niveles 2 a 5 y se reservará "orientación no especificada" para los niveles 6 a 8.

** En la versión 1997 se agregó el destino "C" al nivel CINE 4 de los países UOE (iniciativa de recolección de datos liderada por UNESCO-OECD-Eurostat). En esta versión, solo los destinos A y B aplicaban al nivel CINE 4 de los demás países.

- Para mayor detalle sobre la correspondencia entre los niveles CINE 2011 y Cine 1997, véase la Sección 10 y los cuadros 19, 20 y 21 de la Clasificación CINE 2011.

\section{Note}

1. Los números de los párrafos refieren al documento de clasificación CINE 2011. Para mayor detalle, sírvase consultar la Guía del Lector. 



\section{SEGUNDA PARTE \\ NIVELES 0 A 4 - CINE 2011: \\ DESDE EDUCACIÓN DE LA PRIMERA INFANCIA \\ HASTA EDUCACIÓN POSTSECUNDARIA NO TERCIARIA}

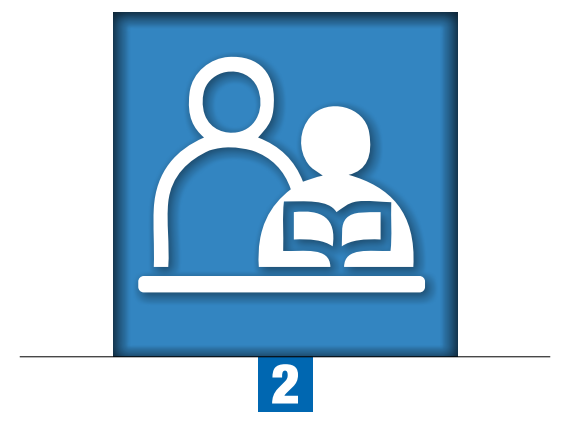

Capítulo 2

Nivel 0 - CINE 2011:

Educación de la primera infancia

El nivel CINE 0 solo incluye programas de la primera infancia que incorporan un componente educativo intencionado. Los programas del nivel CINE 0 están dirigidos a niños menores que la edad oficial de ingreso a la educación primaria (nivel CINE 1). Estos programas están orientados a desarrollar las destrezas académicas, físicas y socio-afectivas que permitirán al niño participar activamente en la vida social e ingresar a la educación primaria.

Los programas clasificados en el nivel CINE 0 pueden recibir distintas denominaciones, por ejemplo: educación y desarrollo de la primera infancia, kindergarten, jardines infantiles, educación preprimaria, preescolar o inicial. Respecto de programas llamados crèche o guarderías, es importante asegurar que estos cumplan los criterios de clasificación establecidos en la CINE 0, especificados a continuación. Para propósitos de comparación a nivel internacional, se usa el término "educación de la primera infancia" para denominar al nivel CINE 0. 


\section{DESCRIPCIÓN}

\section{Definición}

$(\$ 100)^{1}$ Los programas de nivel CINE 0, o educación de la primera infancia, se caracterizan por privilegiar un enfoque holístico orientado a dar apoyo temprano al desarrollo cognitivo, físico, social y emocional del niño y familiarizar a los niños de corta edad con la instrucción organizada fuera del entorno familiar. El nivel CINE 0 solo incluye programas de la primera infancia que incorporan un componente educativo intencionado.

(§101) En este nivel, los programas no se caracterizan por ser altamente estructurados, estando más bien diseñados para proporcionar un conjunto de actividades educativas organizadas con algún propósito dentro de un entorno seguro. A través de ellas y bajo la supervisión de un integrante del personal docente, el niño aprende en interacción con otros niños, realizando habitualmente actividades lúdicas y de naturaleza creativa.

(§102) Los programas del nivel CINE 0 están dirigidos a niños menores que la edad oficial de ingreso al nivel CINE 1. En este nivel, existen dos categorías de programas: desarrollo educacional de la primera infancia y educación preprimaria. En la primera categoría, el contenido está destinado a niños de entre 0 y 2 años, en tanto que en la segunda se orienta a niños desde los tres años de edad hasta el inicio de la educación primaria.

\section{Criterios de clasificación}

\section{Criterios principales}

a. Propiedades educativas del programa

(§105) Las propiedades educativas del desarrollo educacional de la primera infancia (CINE-P 010) comprenden un entorno de aprendizaje que es visualmente estimulante y verbalmente variado. Estos programas además promueven la autoexpresión con énfasis en la adquisición de lenguaje y su uso para lograr una comunicación significativa. Los niños tienen la oportunidad de participar en actividades lúdicas que les permiten desarrollar sus destrezas motoras y de coordinación a través de la interacción con el personal docente y bajo su supervisión.

(§106) Las propiedades educativas de la educación preprimaria (CINE-P 020) comprenden la interacción con pares y educadores, a través de la cual los niños aprenden a mejorar la utilización del lenguaje y sus habilidades sociales y comienzan a desarrollar sus destrezas de lógica y raciocinio y a articular sus procesos de reflexión. En este nivel se les expone por primera vez a conceptos alfabéticos y matemáticos. Asimismo, se promueve la exploración del mundo que los rodea y del entorno inmediato. Las actividades diseñadas para mejorar la motricidad gruesa (ejercicios, juegos, etc.) y otras actividades lúdicas supervisadas se pueden utilizar como oportunidades para promover el desarrollo de la interacción social, destrezas, autonomía y preparación para la escuela.

\section{b. Contexto institucional}

(§107) Los programas del nivel CINE 0 suelen ser impartidos en instituciones educativas o entornos institucionalizados (escuelas, centros comunitarios, hogares) preparados para acoger grupos de niños. Se excluyen de este nivel iniciativas estrictamente familiares que si bien pueden ser intencionadas no tienen la estructura de un "programa", es decir, actividades de educación informal del niño a cargo de padres, otros parientes o amigos no son consideradas en la CINE 0.

\section{c. Grupo de edad objetivo típica de niños beneficiarios de estos programas}

(§108) Dentro del nivel CINE 0, los programas de desarrollo educacional de la primera infancia están orientados a niños entre las edades de 0 a 2 años, en tanto que los programas de educación preprimaria se orientan a niños de entre los 3 años hasta la edad de ingreso al nivel CINE 1. La edad máxima de ingreso a educación preprimaria dependerá en cada caso de la edad teórica de ingreso al nivel CINE 1, es decir, a la educación primaria. 
d. Intensidad y duración del programa

(\$110) Con el objeto de mejorar la comparabilidad internacional, la CINE recomienda la siguiente intensidad y duración mínima: los programas deberán impartirse en periodos de actividades educativas equivalentes a 2 horas diarias y 100 días al año. Solo los programas que cumplan estos criterios podrán ser clasificados en la CINE.

\section{Criterios subsidiarios}

a. Certificaciones pedagógicas del personal docente

(\$111) Cuando corresponda, el requisito de certificaciones pedagógicas del personal docente en los países donde exista tal requisito puede ser un buen criterio de aproximación para clasificar un programa educativo. De hecho, este criterio se puede aplicar con el fin de distinguir entre la educación de la primera infancia y la guardería o atención infantil para la cual no existen exigencias de personal con formación pedagógica.

\section{b. Existencia de un marco regulatorio}

((§112) Cuando corresponda, la existencia de un marco referencial o regulatorio elaborado o reconocido por la autoridad nacional competente (por ejemplo, el Ministerio de Educación u otro ministerio o entidad equivalente) podría constituir un buen criterio de aproximación para clasificar un programa educativo. Dicho marco debería incluir directrices, estándares o instrucciones que detallen las oportunidades de aprendizaje disponibles a los niños de corta edad.

\section{c. Típicamente no forma parte de la educación obligatoria}

((§113) En los sistemas educativos que han adoptado la educación obligatoria, los programas educativos no obligatorios diseñados para comenzar antes del inicio de la educación obligatoria y que cumplen los criterios anteriormente reseñados se clasifican en el nivel CINE 0. Asimismo, en ciertos países la primera etapa o ciclo de educación obligatoria puede clasificarse en el nivel CINE 0 si cumple los criterios de este nivel. Debido a esto, el inicio de la educación obligatoria no es criterio suficiente para distinguir entre los programas de nivel CINE 0 y CINE 1, a pesar de que este podría ser el caso en algunos sistemas educativos.

\section{Dimensiones complementarias}

(§116) Existe una dimensión que establece la distinción entre los programas educativos de nivel CINE 0:

- Grupo de edad objetivo

El desarrollo educacional de la primera infancia, está orientado a niños entre las edades de 0 y 2 años en tanto que la educación preprimaria se imparte a niños desde los 3 años de edad hasta el inicio de la educación primaria (\$102).

\section{CORRESPONDENCIA ENTRE LOS NIVELES CINE 2011 Y CINE 1997}

(§275) En la CINE 2011, el nivel 0 cubre la educación de la primera infancia para todos los grupos de edad, incluso los niños de muy corta edad. Según el nivel de complejidad de su contenido educativo, los programas se clasifican en dos categorías: desarrollo educacional de la primera infancia (código 010) y educación preprimaria (código 020). Los programas de desarrollo educacional de la primera infancia (código 010) están destinados a niños menores de tres años. Esta clasificación ha sido incorporada por primera vez en la CINE 2011 y no está considerada en la CINE 1997. La educación preprimaria (código 020) corresponde exactamente al nivel 0 de la CINE 1997. 


\section{DIRECTRICES PARA CLASIFICAR PROGRAMAS DE NIVEL CINE 0 Y CERTIFICACIONES RECONOCIDAS RELACIONADAS}

El nivel CINE 0 solo incluye programas de la primera infancia que incorporan un componente educativo intencionado. Los programas del nivel CINE 0 están orientados a niños menores que la edad oficial de ingreso al nivel CINE 1. Generalmente, el propósito de estos programas es desarrollar habilidades cognitivas, físicas y socio-afectivas que permitirán al niño participar activamente en la vida social y escolar. $(\$ 100,102)$

Con frecuencia, el factor que establece la diferencia entre los programas ofrecidos al nivel CINE 0 es la edad del alumno. Existen dos categorías: CINE 010, desarrollo educacional de la primera infancia, y CINE 020, educación preprimaria. La categoría CINE 010 incorpora un componente educativo intencionado orientado a niños de corta edad (entre 0 y 2 años)

(Ejemplos nacionales - Grupo 1), mientras que la categoría 020 privilegia a niños entre los 3 años hasta la edad de ingreso a la educación primaria (CINE 1). (§108) (Ejemplos nacionales - Grupo 2).

Algunos programas de nivel CINE 0 abarcan las dos categorías de este nivel (es decir, cubren programas educativos para niños entre las edades de 0 años y la edad de ingreso al nivel CINE 1). Estos programas integrados de educación de la primera infancia requieren especial atención al momento de su clasificación. Los programas divididos en años, etapas o ciclos se deberán sub-dividir en estas dos categorías sobre la base de las propiedades educativas del programa (véanse los criterios principales). En el caso de programas sin subdivisiones, la clasificación en una de las dos categorías debe basarse en la edad de los participantes (\$109). Para propósitos de reporte de datos, la información de niños menores de 3 años que participan en dichos programas integrados debe ser reportada bajo la CINE 010 y en el caso de niños de 3 años o más bajo la CINE 020. (Ejemplos nacionales - Grupo 3).

Al momento de clasificar los programas que tienen lugar en el hogar se debe ser especialmente riguroso. En los Ejemplos nacionales - Grupo 4 y Ejemplos nacionales - Grupo 5, se presentan algunos programas de desarrollo de la primera infancia realizados en el entorno familiar que deben ser clasificados en el nivel CINE 0 y otros a los cuales esta clasificación no les corresponde.

En forma similar, los programas que solo proporcionan cuidado del niño (es decir, supervisión, nutrición y salud) no están cubiertos en el nivel CINE 0 . En países donde existen programas educativos y no educativos y es posible matricularse en cada uno en forma independiente, solo los primeros deben clasificarse en el nivel CINE 0. Sin embargo, es importante destacar que es aceptable clasificar en el nivel CINE 0 los programas de primera infancia que incluyen tanto componentes educacionales como de cuidado infantil, si la porción no educacional es mayor que la porción educacional, siempre y cuando esta última cumpla los criterios descritos anteriormente, incluyendo los criterios de intensidad y duración mínima.

Además del enfoque educacional y de desarrollo infantil intencionado, un factor clave en la definición de los programas de nivel CINE 0 es la intensidad y duración sostenida de las actividades educativas programadas. Estas son precisamente las características que marcan la diferencia entre el nivel CINE 0 y otros programas de la primera infancia, como son el cuidado esporádico, temporal o fuera del horario normal de las personas, proporcionado a los niños bajo circunstancias especiales. Se espera que los niños matriculados en un programa de nivel CINE 0 se beneficien de una experiencia de aprendizaje caracterizada por la sistematicidad y duración de actividades educativas intencionadas. Cuando los demás criterios principales (y subsidiarios de ser el caso) se cumplen, el componente educacional intencionado del programa debe tener una intensidad equivalente a 2 horas diarias como mínimo y una duración no menor a 100 días al año para ser clasificado en el nivel CINE 0. Obsérvese que estos representan valores mínimos de intensidad y duración, siendo perfectamente factible que tanto el componente educacional intencionado del programa como el programa mismo, superen estos valores.

Es importante establecer una distinción entre la intensidad y/o duración del componente educacional intencionado de los programas de nivel CINE 0, la intensidad y/o duración de la asistencia que se espera de los niños matriculados y las horas de atención de las instituciones que imparten los programas, ya que estas características no son necesariamente iguales.

Si el programa cumple los criterios principales definidos para el nivel CINE 0 y se espera que los niños matriculados en el programa participen en actividades educacionales intencionadas por el mínimo de intensidad y/o duración especificada, la totalidad del programa podría ser clasificada como programa educativo según la CINE 2011. Esto incluye casos de programas que incorporan actividades adicionales que no son estrictamente educativas, siempre y cuando el programa cumpla con la intensidad y/o duración mínima establecida para actividades educacionales intencionadas.

Si no se dispone de información precisa sobre la intensidad y duración del componente educativo intencionado del programa, no se deberán utilizar las horas de atención de la institución o las horas dedicadas a impartir el 
programa como criterio de aproximación para determinar la inclusión del programa en el nivel CINE 0. En este caso es recomendable utilizar una estimación de la intensidad y/o duración típica de las propiedades educativas intencionadas del programa.

Si la asistencia que se espera de los niños matriculados es inferior al valor mínimo de intensidad y duración establecido, independientemente de las horas o días que el programa esté disponible o la intensidad y/o duración de la provisión de contenido educacional intencionado, el programa debe ser excluido del nivel CINE 0. (Ejemplos nacionales Grupo 5).

Entre los ejemplos típicos de programas que deben ser excluidos del nivel CINE 0 debido a que la asistencia esperada de los niños matriculados no cumple los criterios de intensidad y duración mínima, se pueden mencionar los siguientes:

- programas con asistencia voluntaria que no aseguran que todos los niños se beneficiarán en la misma medida y en forma sostenida de un aprendizaje estructurado;

- programas de corta duración, como los realizados durante la época de vacaciones, iniciativas de cuidado de niños que pueden tener un componente educacional pero no garantizan un período sostenido de instrucción o aprendizaje; y

- programas que si bien incluyen un componente educacional intencionado no exigen un nivel mínimo de asistencia, tales como los programas que dejan a los padres en libertad de elegir para sus hijos una intensidad y duración de asistencia inferior a los criterios de intensidad y duración mínimas establecidas para en nivel CINE 0.

El comienzo de la educación obligatoria no constituye criterio suficiente para hacer una distinción entre programas de nivel CINE 0 y CINE 1, a pesar que este puede ser el criterio aplicado en algunos sistemas de educación.

El nivel CINE 0 también incluye programas para niños con necesidades especiales de educación conforme a los criterios ya reseñados para este nivel, independientemente de la edad (\$117). La instrucción organizada para niños con necesidades especiales debe incluirse en este nivel si los participantes tiene una edad similar a otros alumnos matriculados en programas educativos de desarrollo de la primera infancia o en educación primaria, o si el contenido de instrucción es de un nivel marcadamente inferior que el de los primeros años de educación primaria (incluso si los alumnos no tiene la edad típica del nivel CINE 0). Esto podría incluir la educación impartida en hospitales o en escuelas o centros de capacitación especiales.

\section{Programas que abarcan los niveles CINE 0 y 1}

Los programas educativos que abarcan los niveles CINE 0 y 1 requieren especial atención al momento de su clasificación. En los sistemas educativos donde parte de la educación de la primera infancia está incluida en el programa nacional de educación primaria, solo los grados, etapas o ciclos que corresponden a los criterios de los niveles respectivos (CINE 0 o 1) deben ser atribuidos a esos niveles. (\$114)

Si la aplicación de criterios de clasificación no proporcionara una clara línea divisoria entre los niveles CINE 0 y 1 , se recomienda lo siguiente: $(\$ 115)$

i) en el caso de programas organizados en etapas que abarcan los niveles CINE 0 y 1 , se debe utilizar el final de la etapa más cercana a los 6 años de edad como punto de transición entre estos niveles; y

ii) respecto de programas no organizados en etapas que abarcan los niveles CINE 0 y 1 , los grados que imparten educación a niños menores de 6 años se deben clasificar en el nivel CINE 0 y todos los demás en el nivel CINE 1.

\section{LOGRO EDUCATIVO EN EL NIVEL CINE 0}

(§119) En términos de clasificar el logro educativo, se reserva el nivel 0 (menos que primaria) para las personas que:

- nunca han cursado un programa educativo (CINE-A 010);

- cursaron parte de la educación de la primera infancia (CINE-A 020); o

- cursaron parte de la educación primaria pero no han concluido exitosamente el nivel CINE 1 (habiendo o no cursado el nivel CINE 0) (CINE-A 030).

El código CINE-A "020" incluye a niños que han cursado un programa de desarrollo de la primera infancia o de educación preprimaria, o ambos. 


\section{EJEMPLOS DE PROGRAMAS Y CERTIFICACIONES CLASIFICADAS EN EL NIVEL CINE 0}

(§103) Los programas clasificados en el nivel CINE 0 pueden recibir distintas denominaciones, por ejemplo: educación y desarrollo de la primera infancia, kindergarten, jardines infantiles, educación preprimaria, preescolar o inicial. Respecto de programas llamados crèche o guarderías, es importante asegurar que estos cumplan los criterios de clasificación establecidos en la CINE 0 especificados a continuación. Para propósitos de comparación a nivel internacional, se usa el término "educación de la primera infancia" para denominar al nivel CINE 0.

\section{Ejemplos nacionales - Grupo 1: \\ Programas de desarrollo educacional de la primera infancia [CINE-P: 010]}

Bahrein - (Jardines infantiles). Este programa de educación de la primera infancia está destinado a niños menores de 3 años. Supervisado por el Ministerio de Desarrollo Social, se considera parte del sistema nacional de educación preprimaria. El componente educativo del programa está orientado a desarrollar tanto las destrezas de los niños como sus habilidades de comunicación y a contribuir a su crecimiento emocional en armonía con las necesidades de cada edad. Una vez cumplidos los 3 años, los niños pueden ingresar al programa de kindergarten de 3 años de duración (CINE 020) supervisado por el Ministerio de Educación. (CINE-P: 010)

Brasil - Educação Infantil - crèche (Jardines infantiles/guarderías). La Educação Infantil es el nivel de educación impartido en los jardines infantiles (crèche) a niños de 0 a 3 años de edad, y representa la primera parte de la educación de la primera infancia (siendo la segunda parte la educación preprimaria destinada a niños entre 4 a 5 años). En conformidad con la Ley Nacional de Educación №. 9394/1996 (el principal instrumento legal que norma la educación en Brasil), la educación de la primera infancia es la primera etapa de educación básica y tiene como propósito el desarrollo físico, sicológico, intelectual y social del niño complementado el rol de la familia y la comunidad. En los jardines infantiles la enseñanza está a cargo de profesores certificados y se rige por el currículo formal. Las evaluaciones consisten en monitorear y registrar el desarrollo del niño sin imponer la obligación de dar acceso a un programa de educación más avanzado. (CINE-P: 010)

Ghana - Early Childhood Development. Este programa está destinado a niños entre las edades de 6 meses y 3 años. Está supervisado por el Departamento de Bienestar Social y su provisión es responsabilidad de instituciones privadas. Una vez cumplidos los 3 años, los niños pueden ingresar a un programa de kindergarten de 2 años de duración, supervisado por el Ministerio de Educación. (CINE-P: 010)

Grecia - Vrefonipiakos stathmos (Kindergarten/Educación de la primera infancia). Estos programas de educación de la primera infancia están organizados por instituciones municipales o privadas que atienden a niños desde las edades de 0 a 2 años. Los niños pueden participar en el programa por 1, 2 o 3 años. El Vrefonipiakos stathmos cumple los criterios de educación establecidos en la CINE 2011 para su clasificación como programas de desarrollo educacional de la primera infancia. (CINE-P: 010).

\section{Ejemplos nacionales - Grupo 2: Educación preprimaria [CINE-P: 020]}

Islas Cook - Early Childhood Education. La educación preprimaria está destinada a niños entre las edades de 3 y 5 años. Se imparte en Centros de Educación de la Primera Infancia que normalmente se encuentran anexados a escuelas primarias. (CINE-P: 020)

Grecia - Nipiagogio (Educación preprimaria). La Nipiagogio está auspiciada por el Ministerio de Educación. Forma parte de la educación formal y está orientada a familiarizar a los niños con el proceso educacional y prepararlos para la escuela primaria (Dimotiko Scholeio, CINE 1). No incluye un componente no educativo. Desde el 2007, la asistencia a la Nipiagogio ha sido obligatoria para niños de 5 años de edad. Los niños de 4 años también pueden asistir a Nipiagogios públicos, según la disponibilidad de cupos. (CINE-P: 020)

Jordania - (Kindergarten). Este programa de educación preescolar se imparte a niños a partir de los 3 años y 8 meses de edad. El programa, que se extiende hasta el inicio de la educación primaria (a la edad de 6 años) y no forma parte del sistema obligatorio de educación. (CINE-P: 020) 
Malí - Éducation préscolaire (Educación preescolar). Este es un programa de educación preescolar de cuatro años de duración que se imparte a niños a partir de los 3 años de edad. El propósito de este programa no obligatorio es preparar al niño para la educación primaria que comienza a la edad de 7 años. (CINE-P: 020)

Eslovaquia ${ }^{2}$ - Materská škola (Kindergarten). Habitualmente, el kindergarten atiende a niños entre las edades de 3 a 6 años. En forma excepcional, es posible aceptar a niños de 2 años de edad si las condiciones son favorables (esencialmente, si la institución cuenta con capacidad). Los programas de kindergarten apoyan el desarrollo de la personalidad, habilidades y destrezas en el área social, intelectual, física, moral y estética, y prepara al niño para ingresar a la Základná škola - 1. stupeň (escuela básica - $1^{\text {ra }}$ etapa, CINE 1). Asimismo, preparan para la vida en sociedad sobre la base de las personalidades individuales del niño. (CINE-P: 020)

Turquía - Ana Okullari (Kindergarten). La educación de niños de 3 a 5 años de edad es responsabilidad del kindergarten. Las instituciones de educación preprimaria se pueden establecer como kindergarten privados o pueden consistir en clases parvularias impartidas dentro de otras instituciones de educación. La ley que rige a las Instituciones de Educación Preprimaria establece que el propósito de la educación preprimaria es asegurar el desarrollo físico, mental, y emocional del niño y la adquisición de buenos hábitos y comportamientos; la preparación para educación primaria; la provisión de un entorno común para la crianza de niños en desventaja por sus antecedentes; y el correcto y adecuado uso del idioma turco. Estos programas cumplen todos los criterios definidos para la educación preprimaria según se establece en la CINE 2011. (CINE-P: 020)

Portugal - Jardins de infância (Kindergarten). La educación impartida en kindergarten está destinada a niños entre 3 y 5 años de edad, y se encuentra bajo la jurisdicción del Ministerio de Ciencias y Educación y/o el Ministerio de Solidaridad y Seguridad Social. El propósito de esta educación es estimular el desarrollo cognitivo del niño en un entorno seguro, identificar necesidades especiales de educación, e incentivar la participación de las familias en el proceso educativo. No obstante, la educación impartida en el nivel kindergarten también persigue el objetivo de preparar a los niños para ingresar a la educación primaria y promover la educación para la ciudadanía en pro del pluralismo, estimular la curiosidad intelectual y la habilidad del niño para expresarse y comunicarse con el mundo. Los componentes educativos representan 25 horas semanales y cada aula está a cargo de un profesor certificado, contándose también con un auxiliar docente por cada dos aulas. (CINE-P: 020)

Polonia - Wychowanie przedszkolne (Educación preescolar). El tiempo mínimo de aprendizaje establecido para clases típicas de educación preescolar es de 5 horas diarias y representa el tiempo asignado a implementar el programa educativo (currículo básico) proporcionado por este tipo de institución. La Wychowanie przedszkolne está destinada a niños desde la edad de 3 años hasta el comienzo de la educación primaria obligatoria. Este programa cumple con la definición y los criterios de clasificación de educación preprimaria establecidos en la CINE 2011. El propósito de la educación preescolar es satisfacer las necesidades de educación y desarrollo del niño y está típicamente orientada a los niños de 3 años de edad. El personal docente responsable ha recibido una apropiada formación en pedagogía. (CINE-P: 020)

\section{Ejemplos nacionales - Grupo 3: Programas integrados [CINE-P: 010, 020]}

Alemania - Kindergarten, Kindertagesstätte (Kindergarten). La educación de la primera infancia incorpora a todas las instituciones operadas por servicios públicos o privados de bienestar de niños y jóvenes responsables de atender a los niños hasta el inicio de su vida escolar. Además de instituciones dedicadas exclusivamente a niños menores de 3 años y otras que atienden a niños entre los 3 y 6 años de edad, existen instituciones que integran varias edades (desde 0 a 6 años). El currículo de la primera infancia del Länder contempla una serie de metas y experiencias de aprendizaje que se imparten en forma continua hasta los 6 años de edad. En la CINE 2011, los programas que se imparten en instituciones multi-etarias se asignan a las categorías CINE-P 010 y 020 en base a la edad de los niños matriculados. (CINE-P: 010 y 020)

Eslovenia - Pedšolska vzgoja (Educación preescolar). Eslovenia cuenta con un sistema integrado que incluye el aprendizaje temprano y cuidado de niños entre 1 y 6 años de edad. El sistema unitario de provisión para todos los niños opera bajo la responsabilidad del Ministerio de Educación, Ciencia, Cultura y Deportes. La educación preescolar agrupa a niños de 1 a 3 años de edad (1.starostno obdobje, primer tramo etario) (CINE-P 010), y de 3 a 6 años de edad (2.starostno obdobje, segundo tramo etario) (CINE-P 020). Ambos programas cumplen los criterios que permiten clasificarlos en el nivel CINE 0. La enseñanza es impartida por docentes certificados y se rige por el currículo formal. El 
componente educativo representa más de 2 horas diarias, en tanto que el año escolar contempla más de 100 días de actividades educativas: el $97 \%$ de los niños asisten a kindergarten a tiempo completo (todo el día) y un $3 \%$ a tiempo parcial (medio día). (Pedšolska vzgoja: CINE-P: 010 y 020)

Los países nórdicos cuentan con programas multi-etarios de la primera infancia. En la CINE 2011, estos programas se asignan a las categorías CINE-P 010 y 020 de acuerdo a la edad del niño.

Dinamarca - Aldersintegrerede institutioner (Centro multi-etario). Aldersintegrerede institutioner es uno de los entornos ofrecido por el programa Dagtilbud (Guarderías), destinado a niños desde el momento de nacer hasta la edad en que deben ingresar a la educación primaria obligatoria (folkeskole, nivel CINE 1). Este programa cumple con todos los criterios de clasificación de educación de la primera infancia establecidos en la CINE 2011. Dentro de la CINE 2011, el programa multi-etario Aldersintegrerede institutioner se ha dividido artificialmente en las categorías de desarrollo educacional de la primera infancia (CINE-P 010) para niños de 0 a 2 años y educación preprimaria (CINE-P 020) para niños de 3 a 5 años. (CINE-P: 010 y 020)

Finlandia - Päiväkoti (Kindergarten) El programa Päiväkoti está destinado a niños entre los 0 y 5 años de edad. El siguiente programa ofrecido en kindergarten y escuelas polivalentes se denomina 6-v. lasten esiopetus (educación preprimaria para niños de 6 años de edad), tiene una duración de 1 año y su propósito es preparar a los niños para la Peruskoulu (escuela polivalente, nivel CINE 1). Si bien todos los niños tienen derecho a cursar este año de educación preprimaria (6-v. lasten esiopetus), la educación no es obligatoria hasta el comienzo de la escuela polivalente. En la CINE 2011, el programa multi-etario päiväkoti se ha dividido artificialmente en dos categorías, una para niños de 0 a 2 años y otra para niños de 3 a 5 años. La categoría 0-2-v. lapset päiväkodeissa (kindergarten para niños entre 0 y 2 años) recibe la clasificación de desarrollo educacional de la primera infancia (CINE-P 010). Las categorías 3-5-v. lapset päiväkodeissa (kindergarten para niños entre 3 y 5 años) y 6-v. lasten esiopetus (preprimaria para niños de 6 años) representan, en conjunto, los años de educación preprimaria de Finlandia. Ambos programas están clasificados como CINE-P 020. (CINE-P: 010 y 020).

Islandia - Leikskóli (Escuelas de educación preprimaria) El programa Leikskóli está destinado a niños entre los 0 y 5 años de edad. Lo sigue la educación primaria (Grunnskóli l, primer ciclo de educación obligatoria) orientada a niños de 6 años y más. En la CINE 2011, el programa multi-etario Leikskóli se ha dividido artificialmente en Leikskóli I (para niños entre 0 y 2 años) y Leikskóli II (para niños entre 3 y 5 años). El programa Leikskóli I se clasifica como desarrollo educacional de la primera infancia (CINE-P 010) y Leikskóli Il como educación preprimaria (CINE-P 020). (CINE-P: 010 y 020)

Noruega - Barnehage, 0-5 åringer (Kindergarten, edades 0 a 5) Barnehage (kindergarten) es un programa destinado a niños de entre 0 y 5 años. No tiene carácter obligatorio y la edad habitual de inicio es de 1 año. La certificación exigida a los docentes es el Bachelorgrad (Grado en educación terciaria, nivel CINE 6) y el programa se rige por el currículo nacional obligatorio. Tras la conclusión de Barnehage, los niños dan inicio a la educación primaria (Barnetrinnet, nivel CINE 1) de carácter obligatorio. En la CINE 2011, el programa multi-etario Barnehage se ha dividido artificialmente en Barnehage 1 (niños de 0 a 2 años de edad) y Barnehage 2 (niños de 3 a 5 años de edad). Barnehage 1 se clasifica como desarrollo educacional de la primera infancia (CINE-P 010) y Barnehage 2 como educación preprimaria (CINE-P 020). (CINE-P: 010 y 020)

Suecia - Förskola (preescolar) El programa Förskola está destinado a niños hasta la edad de 5 años. Este programa educativo también contiene un componente de cuidado infantil. El programa que sigue al Förskola, se denomina Förskoleklass (clase preescolar), es voluntario, tiene 1 año de duración y está destinado a niños de 6 años de edad. Se imparte en un entorno similar al de una escuela y tras su conclusión los alumnos ingresan a la Grundskolan (educación obligatoria, nivel CINE 1) a partir de los 7 años. En la CINE 2011, el programa multi-etario Förskola se ha dividido artificialmente en Förskola för barn under 3 år (para niños menores de 3 años) y Förskola för barn 3 år eller äldre (para niños de 3 a 5 años). El programa Förskola för barn under 3 år se clasifica como desarrollo educacional de la primera infancia (CINE-P 020). Förskola för barn 3 år eller äldre (CINE-P 020) y Förskoleklass (CINE-P: 020) representan, en conjunto, los años de educación preprimaria de Suecia. (CINE-P: 010 y 020)

Ejemplos nacionales - Grupo 4: Programas impartidos en el hogar que deben ser incluidos en la CINE-2011 [CINE -P: 010, 020]

Dinamarca - Kommunal dagpleje (Cuidado infantil a cargo de la autoridad local). Con acuerdo a la ley que regula las instalaciones de cuidado infantil (Dagtilbudsloven), a partir de las 26 semanas de edad, todo niño debe tener la misma 
oportunidad de asistir a un centro de cuidado infantil (Dagtilbud). Por lo tanto, el consejo municipal local se ve obligado a garantizar el número de cupos necesarios para atender a la población infantil de la municipalidad, compromiso conocido como "disponibilidad garantizada de guarderías infantiles" (Pasningsgaranti). El hecho que el cuidado infantil esté a cargo de la autoridad local (Kommunal dagpleje) permite a los cuidadores de niños realizar esta labor en hogares privados. La autoridad local asigna a los niños a cuidadores individuales que deben utilizar el mismo currículo y quedan sujetos a las mismas obligaciones respecto del contenido educativo, que los centros de cuidado infantil operados por dicha autoridad (Kommunale daginstitutioner). Un cuidador puede tener bajo su responsabilidad hasta cinco niños. Si dos o más personas se asocian para prestar servicios de cuidado infantil, la autoridad local autorizará un máximo de diez niños. Los programas de cuidado infantil elaborados por la autoridad local cumplen los criterios principales que establece la CINE 2011 para clasificar en el nivel CINE 0: propiedades educativas, contexto institucional, grupos de edad objetivo, e intensidad y duración. Para propósitos de reporte de datos, la información sobre niños menores de 3 años se reporta como CINE-P 010; la información sobre niños entre los 3 años y la edad de ingreso al nivel CINE 1 se reporta como CINE-P 020. (CINE-P: 010 y 020)

Alemania - Kindertagespflege (Servicios de cuidado infantil). En el caso de niños menores de 3 años, la ley considera que el cuidado infantil, tanto en entornos institucionales como en el hogar, son opciones equivalentes ya que ambas se caracterizan por tener un contenido educacional explícito. Por lo tanto, la asistencia a guarderías se debe reportar como CINE-P: 010. La prestación de servicios de cuidado infantil a niños entre los 3 años y la edad de ingreso a la educación obligatoria es extremadamente inusual y prácticamente siempre se utiliza con el fin de complementar el cuidado institucional. Por consiguiente, para propósitos de reporte, en la CINE-P: 020 el cuidado infantil es casi inexistente (Cuidado infantil para niños menores de 3 años: CINE-P 010)

\section{Ejemplos nacionales - Grupo 5: \\ Programas impartidos en el hogar que deben ser excluidos del nivel 0 de la CINE 2011 [No clasificados]}

Ejemplo general: Este podría ser el caso de un ciudadano privado quien por voluntad propia decide proveer oportunidades de educación a niños de corta edad a través de programas que cumplen marginalmente los criterios de niveles CINE respecto de intencionalidad de la instrucción, intensidad y/o duración del programa y certificaciones de los docentes. Sin embargo, estos no son programas institucionalizados, ni regulados por las autoridades competentes.

Dinamarca - Private Pasningsordninger (Cuidado infantil privado). Los proveedores privados de cuidado infantil también están autorizados para operar guarderías para niños a partir de las 26 semanas de edad a través de un contrato operativo pactado con la autoridad local. La autoridad local no refiere niños a dichos proveedores privados. Pese a que la autoridad local paga al proveedor de estos servicios una suma acordada por cada niño y asume la responsabilidad de supervisar el sistema, no existen obligaciones asociadas con el currículo o contenido educativo. Dado que el contenido educativo de este tipo de programas no es significativo, un servicio de este tipo no sería clasificado en el nivel CINE 0.

\section{Notas}

1. Los números de los párrafos refieren al documento de clasificación CINE 2011. Para mayores detalles, sírvase consultar la Guía del Lector.

2. El Instituto de Estadística de la UNESCO (UIS) y la Unión Europea (UE) utilizan "Eslovaquia" como el nombre oficial de la "República Eslovaca". 



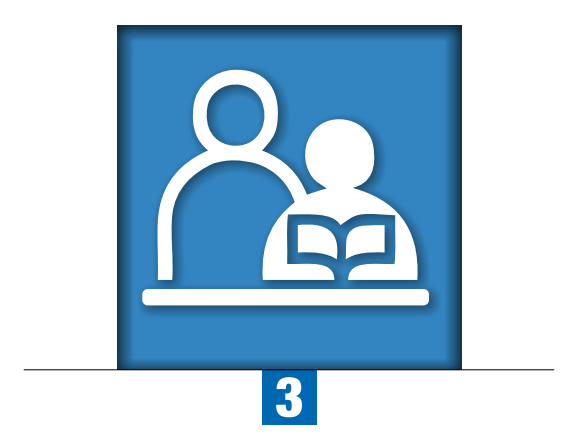

Capítulo 3

\section{Nivel 1 - CINE 2011:}

\section{Educación primaria}

La educación primaria suele iniciarse a la edad de 5, 6 o 7 años y tiene una duración típica de seis años. Los programas del nivel CINE 1 están principalmente destinados a proporcionar a los alumnos la destreza básica en lectura, escritura y matemáticas y sentar una sólida base para el aprendizaje de otras asignaturas tales como historia, geografía, ciencias naturales, ciencias sociales, música y arte. El inicio de las actividades de lectura no constituye criterio suficiente para clasificar un programa educativo en el nivel CINE 1.

Los programas clasificados en el nivel CINE 1 pueden recibir distintas denominaciones, por ejemplo: educación primaria, educación elemental o educación básica (etapa 1 o grados inferiores, si el sistema educativo cuenta con un programa que abarca los niveles CINE 1 y 2). Para propósitos de comparación a nivel internacional, se usa el término "educación primaria" para denominar al nivel CINE 1. 


\section{DESCRIPCIÓN}

\section{Definición}

$(\S 120)^{1}$ Los programas del nivel CINE 1, o educación primaria, están destinados principalmente a proporcionar a los estudiantes la destreza básica en lectura, escritura y matemáticas (es decir, alfabetismo y utilización de números - numeracy) y sentar una sólida base para el aprendizaje y la comprensión de las áreas esenciales del conocimiento y el desarrollo personal y social como preparación a la educación secundaria baja. Estos programas centran el aprendizaje a un nivel de complejidad básico con muy poca o ninguna especialización.

(§121) En el nivel CINE 1 (especialmente en los primeros años), las actividades educativas suelen estar organizadas por unidades, proyectos o amplias áreas de aprendizaje, donde se aplica usualmente un enfoque integrado de instrucción en lugar de asignaturas específicas.

\section{Criterios de clasificación (\$124)}

\section{Criterios principales}

a. Instrucción sistemática en conocimientos, destrezas y competencias básicas

(§125) La línea divisoria entre los niveles CINE 0 y 1 coincide con el punto de transición del sistema educativo donde empieza la instrucción en lectura, escritura y matemáticas en forma sistemática.

b. Duración y edad típica de ingreso

(§122) Usualmente, en este nivel el único requisito de ingreso es la edad. En general, la edad habitual o legal de ingreso no es inferior a los 5 años de edad ni superior a los 7 años de edad. Este nivel suele tener una duración de seis años, aunque esta puede fluctuar entre cuatro y siete años. La edad de salida de la educación primaria está situada típicamente en el rango de 10 a 12 años.

c. Instrucción usualmente impartida por un docente principal por clase

(§126) Habitualmente, un profesor principal es responsable de un grupo de niños y facilita el proceso de aprendizaje. Sin embargo, una clase puede tener más de un profesor, particularmente en el caso de las asignaturas más especializadas. Generalmente, en este nivel se encuentran docentes con una formación que les permite dar orientación pedagógica en asignaturas básicas.

\section{Criterios subsidiarios}

a. Forma parte de la educación obligatoria

(\$127) A menudo, el inicio de la educación primaria coincide con el inicio de la educación obligatoria, excepto en sistemas educativos donde parte o la totalidad de la educación preprimaria es actualmente obligatoria. Por lo tanto, en los países donde la educación obligatoria es materia de legislación, esta comienza en el nivel CINE 1 o antes.

\section{Dimensiones complementarias}

(§131) Ninguna.

A la totalidad de los programas de nivel CINE 1 se les asigna el código CINE-P 100. No hay categorías o subcategorías que requieran ser diferenciadas mediante el uso de un segundo dígito. (§135) 


\title{
CORRESPONDENCIA ENTRE LOS NIVELES CINE 2011 Y CINE 1997
}

\author{
(§276) En la CINE 2011, el nivel 1 (educación primaria) corresponde al nivel 1 de la CINE 1997.
}

\section{DIRECTRICES PARA CLASIFICAR PROGRAMAS DE NIVEL CINE 1 Y CERTIFICACIONES RECONOCIDAS RELACIONADAS}

La educación primaria suele iniciarse a la edad de 5, 6 o 7 años y tiene una duración típica de seis años. Los programas del nivel CINE 1 están principalmente destinados a proporcionar a los alumnos destreza básica en lectura, escritura y matemáticas y sentar una sólida base para el aprendizaje de otras asignaturas tales como historia, geografía, ciencias naturales, ciencias sociales, música y arte. El inicio de las actividades de lectura no constituye criterio suficiente para clasificar un programa educativo en el nivel CINE 1. Habitualmente, en este nivel un profesor principal es responsable de la clase, a pesar que una clase puede tener más de un profesor, particularmente en el caso de las asignaturas más especializadas. Los docentes de educación primaria suelen recibir formación que les permite dar orientación pedagógica en una variedad de asignaturas. Para una descripción de programas típicos de educación primaria, véase Ejemplos nacionales - Grupo 1.

Normalmente, la edad es el único requisito de ingreso al nivel CINE 1. En general, los programas educativos de este nivel no requieren educación formal previa, aunque la asistencia a la educación preprimaria se ha convertido en algo cada vez más común. Con frecuencia, la edad de inicio de la educación primaria coincide con la edad de inicio de la educación obligatoria, en algunos países la educación obligatoria comienza al nivel de preprimaria.

Aunque la duración típica de la educación primaria es de seis años, en los diversos países esta puede fluctuar entre cuatro y siete años. De hecho, la duración de la educación primaria también presenta variaciones dentro de un país, particularmente en los países federales donde los sistemas de educación suelen tener carácter regional y por consiguiente tienden a ser más descentralizados (véase Ejemplos nacionales - Grupo 2).

El nivel CINE 1 incluye programas para personas con necesidades especiales (discapacidades, dificultades o desventajas) siempre que el contenido de la instrucción sea similar al de otros programas del nivel CINE 1 (enseñanza básica en lectura, escritura y matemáticas impartida en forma sistemática), incluso si los alumnos no tienen la edad típica para cursar el nivel CINE 1 (§132) (véase Ejemplos nacionales - Grupo 3).

Algunos sistemas educativos pueden incluir programas de segunda oportunidad o de reintegración en este nivel. Normalmente, estos programas están destinados a personas que:

i) abandonaron la escuela antes de finalizar la educación primaria (estos programas facilitan el reingreso al sistema educativo con el fin de completar este nivel); o

ii) finalizaron la educación primaria pero han optado por cursar un programa educativo o desempeñar un oficio para el cual no se encuentran lo suficientemente preparados. Los participantes suelen ser mayores que en el grupo de edad objetivo del nivel CINE 1 (aunque no necesariamente adultos). (§133)

Adicionalmente, se incluyen en este nivel programas de alfabetización impartidos en escuelas o fuera del sistema educativo, que tienen un contenido similar en complejidad al de programas clasificados en educación primaria pero no requieren educación formal previa. Estos programas de alfabetización, que pueden ser formales o no formales, están destinados a adultos y adolescentes que han superado la edad de ingreso a la escuela (\$134). En Ejemplos nacionales - Grupo 4 se muestran algunos programas destinados a adolescentes o adultos con edades atípicas para cursar educación primaria.

Otro criterio de aproximación que puede facilitar la clasificación en el nivel CINE 1 es el punto de ingreso a la institución o programa primario designado por la autoridad nacional competente. Sin embargo, en países donde la educación primaria comienza a una edad temprana (4 o 41/2 años), los niños matriculados en estos programas deben clasificarse en el nivel CINE 1 solo si la duración del día escolar, las certificaciones del personal docente, y el nivel de contenido del programa son similares a los grados cursados por niños de 6 años de edad. De lo contrario, cualquiera de los grados anteriores que correspondan más cercanamente al nivel CINE 0, debe clasificarse como educación preprimaria en lugar de educación primaria. 
Pese a que el inicio de la educación obligatoria se considera un criterio subsidiario relativo a la línea divisoria entre los niveles CINE 0 y 1 , en países donde para algunos niños la edad de asistencia obligatoria (o al menos la edad en la cual prácticamente todos los alumnos comienzan su educación) es posterior al comienzo de estudios sistemáticos de las asignaturas anteriormente reseñadas, se puede utilizar el primer año de asistencia obligatoria para determinar la línea divisoria entre los niveles Cine 0 y 1 . Este último criterio podría ser útil cuando el comienzo del nivel CINE 1 refleja el punto que marca el inicio de estudios sistemáticos para todos los alumnos, no solo para unos pocos.

\section{Programas que abarcan educación primaria y otro nivel CINE}

Programas muy largos (de ocho o más años de duración) que abarcan la educación primaria y el nivel anterior o siguiente, requieren especial atención. En estos casos, solo se deben atribuir a estos niveles los grados, etapas o ciclos que correspondan, es decir, CINE 0, 1 o 2. (\$128)

Para casos donde la aplicación de criterios de clasificación no logre definir una clara línea divisoria entre los niveles CINE 0 y 1, consulte las instrucciones incluidas en el capítulo "Nivel CINE 0" del manual operativo.

En la mayoría de los países, el nivel CINE 1 corresponderá a la designación de educación primaria establecida por el país. En países donde la "educación básica" cubre la totalidad del periodo de educación obligatoria (por ej., donde la educación secundaria baja y alta se suceden sin interrupción) y posiblemente parte de la educación de la primera infancia, solo los grados que cumplen los criterios para el nivel CINE 1 se debe clasificar como educación primaria.

Si la utilización de criterios de clasificación no proporcionara una clara línea divisoria entre los niveles CINE 1 y 2, se recomienda lo siguiente: $(\$ 130)$

i) en el caso de programas organizados en etapas que abarcan los niveles CINE 1 y 2, se debe utilizar el final de la etapa más cercana a los seis años de escolarización a partir del inicio del nivel CINE 1 como punto de transición entre estos niveles CINE; y

ii) respecto de programas no organizados en etapas que abarcan los niveles CINE 1 y 2, solo los primeros 6 años se deben clasificar en el nivel CINE 1 y todos los demás en el nivel CINE 2.

Para programas que abarcan los niveles CINE 1 y 2, véanse Ejemplos nacionales - Grupo 5.

\section{LOGRO EDUCATIVO EN EL NIVEL CINE 1}

Al momento de codificar el logro educativo, se debe dar especial consideración a la clasificación de personas que, a pesar de haber asistido a clases, no lograron finalizar la educación primaria (§136). A estas personas se les debe asignar el código CINE-A 030 "Conclusión parcial de educación primaria (sin conclusión de nivel)" (Ejemplos nacionales Grupo 6).

A los alumnos que hayan concluido exitosamente el nivel CINE 1 se les debe asignar el código CINE-A 100.

En términos de logro educativo, las certificaciones otorgadas por programas del nivel CINE 2 consideradas insuficientes para la conclusión, o conclusión parcial, de este nivel (es decir CINE-P 241 o 251), se clasifican en el nivel CINE 1 (CINE-A 100). Estos programas tienen una duración típica inferior a dos años en el nivel CINE 2 o una duración acumulada inferior a ocho años a contar desde el inicio del nivel CINE 1 (§137).

\section{EJEMPLOS DE PROGRAMAS Y CERTIFICACIONES CLASIFICADAS EN EL NIVEL CINE 1}

(§123) Los programas clasificados en el nivel CINE 1 pueden recibir distintas denominaciones, por ejemplo: educación primaria, educación elemental o educación básica (etapa 1 o grados inferiores, si el sistema educativo cuenta con un programa que abarca los niveles CINE 1 y 2). Para propósitos de comparación a nivel internacional, se usa el término "educación primaria" para denominar al nivel CINE 1. 
Ejemplos nacionales - Grupo 1:

Programas educativos típicos de la educación primaria [CINE-P: 100; CINE-A: 100]

Austria - Volksschule, 1-4 schulstufe (escuela primaria, $1^{\mathrm{er}}$ a $4^{\text {to }}$ Grados). La educación primaria es obligatoria para todos los niños a partir de la edad de 6 años, tiene una duración de cuatro años y se imparte en escuelas primarias (Volksschule). Normalmente, la educación primaria se divide en dos niveles: los primeros dos años (nivel I) y los años 3 y 4 (nivel II). Tras la conclusión del Cuarto Grado, los alumnos reciben un certificado. La educación primaria sienta las bases que permiten asegurar una exitosa experiencia de aprendizaje en educación secundaria. Privilegiando los antecedentes personales de cada niño, el objetivo de la educación primaria es: crear y fortalecer las habilidades sociales, mejorar las competencias lingüísticas, desarrollar y transmitir conocimientos, destrezas, ideas y actitudes básicas que conduzcan a la adquisición de tres destrezas esenciales; la lectura, la escritura y la aritmética. (CINE-P/CINE-A: 100)

Bélgica (Comunidad flamenca) - Gewoon lager onderwijs (educación primaria convencional). La educación primaria convencional está destinada a niños entre las edades de 6 y 12 años y generalmente comprende seis años de estudios acumulados (si bien puede variar entre cuatro y ocho años). El aprendizaje sistemático de lectura, escritura y aritmética comienza el primer año. Cada grupo de alumnos tiene su propio profesor de aula que enseña la mayoría ( o en ocasiones todas) las asignaturas. En el caso de asignaturas como religión, música y educación física es habitual que se asignen profesores especializados. La educación primaria convencional se inicia en septiembre del año en que el niño cumple 6 años. En el caso de un niño que avance en forma normal, el comienzo de la educación obligatoria coincide con el comienzo de la educación primaria. Tras la conclusión exitosa de educación primaria, los alumnos reciben un certificado que acredita la adquisición de este nivel. (CINE-P/CINE-A: 100)

Francia - Enseignement primaire (Educación primaria). La educación primaria en este país tiene una duración de cinco años y es obligatoria desde la edad de 6 años. El programa comienza con un ciclo de aprendizaje básico que incluye: un año de clases preparatorias (cours préparatoire - CP) y el primer año de clases elementales (cours élémentaire - CE1). Los tres últimos años de educación primaria incluyen un segundo año de clases elementales (CE2) y dos años de clases de nivel intermedio (cours moyen - CM1 y CM2). Al final de cada ciclo se administra una evaluación nacional para medir el nivel de aprendizaje de los alumnos. Sin embargo, al final de la educación primaria no se otorgan certificados. Tras la exitosa conclusión de educación primaria los alumnos avanzan a educación secundaria. (CINE-P/CINE-A: 100)

Grecia-Dimotiko Scholeio (Escuelas elementales). La educación primaria es obligatoria y tiene una duración de seis años (Primer a Sexto Grado) a contar de los 6 años de edad. Su propósito es ayudar a los alumnos a fortalecer estrategias que permitan asimilar conocimientos; desarrollar la salud física y mental y cultivar destrezas motoras; aprender los conceptos más básicos y gradualmente adquirir la habilidad de derivar conceptos abstractos a partir de datos concretos; adquirir competencias en expresión escrita y oral; familiarizarse con valores éticos, religiosos, nacionales y humanistas; y cultivar aptitudes artísticas. Tras la conclusión de Sexto Grado, los alumnos reciben un certificado de educación primaria (Titulos spoudon) que les otorga acceso a educación secundaria baja (gymnasium). (CINE-P/CINE-A: 100)

India - Primary education. En India coexisten diversos sistemas educativos. La duración del tipo más común de educación primaria en los estados y territorios que el país tiene es de cinco años (Clases I a IV) y comienza a la edad de 5 años. Este programa obligatorio y gratuito conduce a un certificado de educación primaria que da acceso a la educación secundaria baja (CINE-P/CINE-A: 100)

Italia - Scuola primaria (Escuela primaria). La educación primaria representa los primeros cinco años del primer ciclo de educación. Para niños entre los 6 y 10 años de edad, la asistencia es obligatoria. La educación primaria está compuesta por tres ciclos: un primer año (Primer Grado), que hace posible una fácil transición desde la educación preprimaria (scuola dell'infanzia), seguido de dos ciclos de dos años de duración cada uno (Segundo y Tercer Grado y Cuarto y Quinto Grado). Al finalizar la educación primaria cada alumno recibe una documento de evaluación personal que autoriza su paso al próximo nivel, educación secundaria baja (scuola secondaria di primo grado), y un certificado de las competencias adquiridas en educación primaria (Certificati e/o Attestati). (CINE-P/CINE-A: 100)

Japón - Shogakko (Escuela básica). La educación básica es la primera etapa de la escolarización obligatoria. Todos los niños asisten a la escuela básica durante seis años a partir de la edad de 6. Las metas de la educación básica incluyen: entender y utilizar el japonés y las matemáticas; desarrollar una comprensión básica de las habilidades requeridas para la vida diaria; observar la naturaleza desde una perspectiva científica; y valorar la historia, el arte y la música. Tras la exitosa conclusión de la escuela básica, los alumnos avanzan hacia la educación secundaria baja (Chugakko). (CINE-P/ CINE-A: 100) 
Corea ${ }^{2}$ - Chodeung-hakgyo (Escuela elemental). Las escuelas elementales son las encargadas de impartir educación primaria para niños entre 6 y 11 años (Primer a Sexto Grado). El objetivo general de la educación elemental es cultivar ciudadanos coreanos saludables, autosuficientes, creativos y éticos. Esto incluye el desarrollo de la habilidad para expresar sentimientos e ideas, resolver problemas, valorar la cultura y la diversidad y la adquisición de competencias esenciales para la vida. Tras la exitosa conclusión de la escuela elemental, los alumnos reciben un certificado (Joleopjang), y pueden avanzar al nivel secundario (Jung-hakgyo) (CINE 2). (CINE-P/CINE-A: 100)

Líbano - (Educación primaria). La educación primaria cubre los dos primeros ciclos de educación básica obligatoria y tiene una duración total de nueve años. Cada uno de estos ciclos se compone de tres grados. Normalmente, el programa de educación primaria se orienta a niños qua ya han cumplido los seis años de edad y deben aprender competencias básicas en lectura y aritmética. A este nivel, también se incorpora un idioma (inglés o francés). Tras la conclusión exitosa del nivel, los alumnos pueden avanzar al tercer ciclo de educación básica (educación secundaria baja). (CINE-P/CINE-A:100)

Islas Salomón - Standard Education. A los 6 años de edad los niños dan inicio a su Educación Estándar que se prolonga por seis años (Estándar 1 a Estándar 6). Al finalizar Estándar 6, los alumnos rinden un examen formal que da término a la educación primaria en forma oficial. El currículo incluye lectura, escritura, aritmética, estudios comunitarios, ciencias, agricultura, arte, música educación física y educación Cristiana. (CINE-P/CINE-A: 100)

Ucrania - (Educación primaria). Programa educativo obligatorio de cuatro años de duración destinado a niños a partir de los 6 años de edad. Se imparte en escuelas básicas donde cada grupo de alumnos tiene su propio profesor responsable de enseñar la mayoría de las asignaturas. Para ciertas asignaturas como música y educación física es posible asignar un profesor especializado. Tras la conclusión exitosa del programa, los alumnos reciben un certificado de educación primaria. (CINE-P/CINE-A: 100)

\section{Ejemplos nacionales - Grupo 2: \\ Países que presentan variación en la extensión de los programas nacionales de educación primaria [CINE-P: 100; CINE-A: 100]}

Canadá y Estados Unidos - Elementary/primary schools. La educación primaria y secundaria forman un continuo, donde la duración de la educación básica o primaria está determinada principalmente por las características de las instituciones responsables, que pueden ser distintas según la provincia/estado o zona geográfica (es posible encontrar desde tres hasta ocho grados). En estos países, el continuo primario-secundario se divide al final del Sexto Grado, hecho que permite reportar cada uno de los grados que componen el nivel CINE 1 y facilitar la comparabilidad internacional. Este método de reportar programas también asegura que, dentro del contexto nacional, a cada nivel se le asignarán programas comparables ya que en las diversas provincias o estados el nivel del contenido de un grado determinado es generalmente bastante similar. (CINE-P/CINE-A: 100)

Alemania - Primarbereich (Educación primaria). La educación primaria es el primer tramo de la educación obligatoria y en la mayoría del país cubre desde Primer al Cuarto Grado, o en el caso de Berlín y Brandemburgo, desde el Primer al Sexto Grado. Todos los niños entre las edades de 6 y 10 años (entre 6 y 12 años en Berlín y Brandemburgo) asisten a la escuela primaria (Grundschulen) como parte de la educación obligatoria. La función principal de la escuela primaria es facilitar la transición de los alumnos desde las modalidades lúdicas de aprendizaje características de la educación preescolar hacia modalidades más sistemáticas de aprendizaje, sentar las bases del conocimiento para el próximo nivel (Sekundarbereich l: educación secundaria baja) e iniciar el aprendizaje a lo largo de la vida. Las lecciones impartidas en la escuela primaria se centran en lectura, escritura, aritmética, ciencias e idiomas extranjeros. La enseñanza se transmite a través de lecciones sobre materias específicas así como a través de clases que cubren distintas disciplinas. Se utiliza el principio de un profesor principal que enseña todas, o prácticamente todas, las asignaturas como forma de garantizar la aplicación de un enfoque de instrucción consistente. A partir del Tercer Grado, los niños trabajan cada vez más con profesores de asignaturas específicas que los preparan para hacer la transición a la educación secundaria, donde por regla general se cuenta con profesores especializados en una asignatura. A nivel internacional, la CINE 1 en Alemania se reporta con una duración de cuatro años (es decir, del Primer al Cuarto Grado). (CINE-P/CINE-A: 100)

Suiza - Primarschule, école primaire, scuola elementare (Escuela primaria). La edad de ingreso a la educación primaria varía según el cantón y puede ser 6 años (4 cantones), 6 1⁄2 años (2 cantones) o 7 años (17 cantones). En cada cantón la decisión de comenzar a los 6 o 7 años de edad la asumen los comunes (autoridades locales). Dado que la extensión 
combinada de los niveles de educación primaria y baja secundaria es siempre de nueve años, la diferencia de edad que pueda existir al momento de ingresar se mantendrá a lo largo de toda la trayectoria del alumno. La duración de la educación primaria fluctúa entre los cuatro y seis años (dependiendo del cantón). Actualmente se están implementando reformas que se espera reduzcan la proporción de alumnos que cursan programas de cuatro años. Para propósitos de comparabilidad, los primeros seis años de educación primaria/secundaria baja se asignan al nivel CINE1. (CINE-P/ CINE-A: 100)

Reino Unido - Primary school. En Inglaterra, Escocia y Gales la edad de inicio de la escuela primaria es 5 años y en Irlanda del Norte 4 años mientras que la duración fluctúa entre los seis (Inglaterra y Gales) y los siete años (Irlanda del Norte y Escocia). (CINE-P/CINE-A: 100)

\section{Ejemplos nacionales - Grupo 3: \\ Programas de educación primaria para niños con necesidades especiales de educación [CINE-P: 100; CINE-A: 100]}

Bélgica (Comunidad flamenca) - Buitengewoon lager onderwijs (Educación primaria especial). La educación primaria especial está destinada a niños que necesitan este tipo de ayuda ya sea en forma temporal o permanente. Esta condición puede deberse a una discapacidad física o mental o a serios problemas emocionales, conductuales o de aprendizaje. El ingreso a la educación primaria especial está determinado por la edad del alumno que debe cumplir 6 años de edad antes del 1 de enero del año escolar. También es factible ingresar a la edad de 5 años, decisión que cae en los padres y generalmente está basada en el asesoramiento del comité escolar y del centro de orientación estudiantil. En el caso de la educación especial, se redacta un documento específico que describe el tipo de educación que recibirá el alumno según el tipo de discapacidad que lo afecta. Tras la conclusión del programa de siete años de duración, el alumno recibe un certificado de educación primaria (Getuigschrift Basisonderwijs) que lo autoriza a avanzar al siguiente grado Gewoon secundair onderwijs - 1ste grad (primer grado de educación secundaria, CINE 2). (CINE-P/CINE-A: 100)

Eslovaquia ${ }^{3}$ - Špeciálna základná škola - 1 stupeň (Escuela básica especial - primera etapa) Existen diversos programas educativos para alumnos con necesidades especiales de educación que se ofrecen en forma paralela a las clases convencionales de educación primaria (Základná škola - 1, stupeň / escuela básica - primera etapa, CINE 1). La escuela básica especial atiende a niños con discapacidades físicas. También existen variantes de programas educativos para niños con discapacidades de aprendizaje o deficiencias mentales. A la edad de 6 años, que marca el comienzo de los diez años de educación obligatoria del país, los alumnos pueden ingresar al programa escolar básico de cuatro años de duración a tiempo completo. Tras la conclusión exitosa, los alumnos reciben el Vysvedčenie (certificado) y pueden avanzar a la segunda etapa de enseñanza básica (CINE 2). (CINE-P/CINE-A: 100)

\section{Ejemplos nacionales - Grupo 4: \\ Programas de educación primaria para niños que superan la edad típica para cursar educación primaria [CINE-P: 100; CINE-A: 100]}

Bélgica (Comunidad flamenca) - Basiseducatie (Educación básica de adultos). En la comunidad flamenca de Bélgica, la educación básica de adultos privilegia el mejoramiento del nivel general de alfabetismo, la utilización de números (numeracy), el holandés como segundo idioma, nociones básicas de inglés y francés, integración social y competencias TIC básicas. Solo los centros de educación básica de adultos están autorizados para organizar este tipo de instrucción. Estos cursos de competencias básicas se asignan al nivel de educación primaria y a la primera etapa de educación secundaria (CINE 1 y CINE 2) de acuerdo al nivel de sus contenidos. (CINE-P/CINE-A: 100)

Egipto - (Educación comunitaria). Este programa, liderado por el Ministerio de Educación y apoyado por comunidades locales y ONG nacionales e internacionales, está orientado a niños fuera de la escuela entre las edades de 6 y 14 años. Ofrece una segunda oportunidad a niños que nunca han recibido educación formal o abandonaron la escuela antes de finalizar la educación primaria. En las escuelas comunitarias, las clases generalmente están limitadas a 30 alumnos que integran un grupo multi-etario supervisado por dos facilitadores. Los alumnos se agrupan de acuerdo a la habilidad y rapidez para aprender que exhibe cada uno, aunque siempre dentro de la misma aula. Si bien el programa se ha diseñado siguiendo el modelo de educación primaria inicial (seis años de duración) los alumnos más aventajados pueden finalizar el curso en solo tres años. Tras la conclusión exitosa del programa, los alumnos reciben un certificado de educación primaria y pueden avanzar a la escuela preparatoria (CINE-P/CINE-A: 100) 
Hungría - Általános iskola 1-4, évfolyam, felnõttoktatás (Nivel primario de la escuela general, $1^{\text {er }}$ a $4^{\text {to }}$ Grado, educación a tiempo parcial, curso de alfabetización para adultos). Programa destinado a estudiantes de 16 años o más que imparte competencias de alfabetización y una educación similar a la del programa general de educación primaria de cuatro años de duración a tiempo completo (CINE 1). Tras la conclusión exitosa del programa, los estudiantes reciben un certificado (Bizonyitvány) y pueden ingresar a la escuela general a nivel de educación secundaria baja (CINE 2). (CINE-P/ CINE-A: 100)

Kuwait - (Educación primaria de adultos). El programa de educación primaria para adultos está diseñado para jóvenes de 15 años o más, que nunca han sido parte de la educación formal o que han abandonado la escuela prematuramente. El programa busca dar una segunda oportunidad a los jóvenes y reintégralos a la educación primaria formal previa al ingreso al mercado laboral. A diferencia del programa de educación primaria destinado a niños, que tiene una duración de cinco años, el programa de adultos se puede cursar en solo tres años. Tras la conclusión exitosa de este programa formal, los participantes reciben un certificado de educación primaria y pueden avanzar a la etapa intermedia para adultos (CINE 2). (CINE-P/CINE-A: 100)

Sudán del Sur - Programa de Aprendizaje Acelerado (ALP) a nivel primario. Este programa se ofrece en el marco del Sistema Alternativo de Educación y se ha diseñado con dos objetivos: ayudar a las personas (niños o adultos) que han abandonado la escuela en forma prematura, y acelerar su proceso de aprendizaje para reingresar al sistema educativo o para adquirir destrezas para una vida productiva. El programa ALP comprime ocho años de educación primaria en cuatro. La mayoría de los participantes son mayores de 10 años, en circunstancias que la edad oficial de ingreso a la educación primaria es de 6 años. Tras la conclusión exitosa de este programa, los participantes reciben un certificado de educación primaria y pueden avanzar a la educación secundaria. (CINE-P/CINE-A: 100)

España - Enseñanzas Iniciales de Educación Básica para personas en edad adulta. Estos son programas de segunda oportunidad para personas que han superado la edad de educación obligatoria. Entre sus principales objetivos se cuenta promover la alfabetización y consolidar los conocimientos básicos de los participantes. No se ha definido una duración teórica, ni se ha impuesto una duración máxima o mínima. La educación impartida es similar a la establecida para la educación primaria, es decir, seis años a tiempo completo (Educación primaria, CINE 1) y, por lo tanto, la duración teórica se considera equivalente a la educación primaria convencional. Tras la exitosa conclusión del programa, los estudiantes pueden avanzar a Educación secundaria (educación secundaria baja de acuerdo a la CINE 2011). (CINE-P/CINE-A: 100)

Suecia - Svenska för vuxna invandrare (Sueco para inmigrantes adultos). Este programa de un año de duración enseña el idioma sueco y ofrece información general sobre la vida en Suecia a inmigrantes de 16 años o más. En Suecia, se clasifica como educación primaria. Tras la conclusión del programa, los estudiantes conservan el mismo nivel de logro educativo que antes de ingresar. (CINE-P: 100; CINE-A: igual que antes de ingresar)

\section{Ejemplos nacionales - Grupo 5: Programa que abarcan los niveles CINE 1 y 2}

República Checa - Základni škola (Escuela básica). Las escuelas básicas imparten nueve años de educación básica y obligatoria que habitualmente comienza cuando el niño cumple 6 años de edad. Se ha dividido en dos etapas. La primera etapa de escuela básica cubre de Primer a Quinto Grado (educación primaria CINE 1) y la segunda etapa de Sexto a Noveno Grado (secundaria baja, CINE 2). En la primera etapa de educación básica (de Primer a Quinto Grado) el proceso de enseñanza y aprendizaje está orientado a facilitar la transición de los alumnos desde la educación preescolar (CINE 0) y el cuidado en el hogar, hacia una modalidad de educación obligatoria, regular y sistemática. A través de sus actividades y naturaleza práctica, el proceso educativo incentiva a los alumnos a aprender más, promueve el aprendizaje activo y enseña habilidades de resolución de problemas. La primera etapa del programa de educación básica está diseñada para enseñar conocimientos fundamentales de educación general, politécnica, física y estética. (Primer a Quinto Grado: CINE-P; CINE-A: 100; Sexto a Noveno Grado CINE-P; CINE-A: 244)

Dinamarca - Grundskole (Escuela polivalente). La grundskole incluye diez grados. Los diez años de estudio necesarios para la conclusión del nivel Grundskole son obligatorios. Sin embargo, no es obligatorio concretar este nivel en entornos formales de educación. La grundskole comprende una clase preescolar (bornehaveklasse) para niños de 6 años seguida de nueve años de educación básica. En la CINE 2011, la clase preescolar y los seis grados (Primer a Sexto Grado) de educación básica (grundskole, 1-6 klasse) se clasifican como educación primaria (nivel CINE 1), en tanto que los 
tres grados (Séptimo a Noveno Grado) de educación básica (grundskole, 7-9 klasse) se consideran como educación primaria baja (nivel CINE 2). Los diez años de escuela polivalente se han organizado en base a tres conglomerados de asignaturas (humanidades, prácticas/creativas y científicas), suplementadas en los últimos tres años (CINE 2) con asignaturas electivas que ofrecen al alumno la oportunidad de elegir asignaturas adicionales. (Educación preescolar hasta Sexto Grado: CINE-P; CINE-A: 100; Séptimo a Noveno Grado: CINE-P; CINE-A: 244)

Estonia - Põhidaridus, põhikooli (Educación básica). La educación básica es obligatoria para todos los niños a partir de los 7 años de edad y se extiende nueve años (Primer a Noveno Grado). Está dividida en tres etapas cada una de tres años de duración: Primer a Tercer Grado, Cuarto a Sexto Grado y Séptimo a Noveno Grado. A los estudiantes que cursan la tercera etapa también se les ofrece capacitación pretécnica en escuelas básicas. En la CINE 2011, las primeras dos etapas de educación básica (Primer a Sexto Grado) se clasifican como educación primaria (CINE 1) y la tercera etapa como educación secundaria baja (CINE 2). De acuerdo al currículo nacional, la escuela debe colaborar en la tarea de hacer de los jóvenes personas creativas y equilibradas que exhiban un comportamiento honorable tanto en su vida social como familiar. (Primer a Sexto Grado: CINE-P/CINE-A: 100; Séptimo a Noveno Grado: CINE-P/CINE-A: 244)

Fiji - Primary School. La escuela primaria comienza a la edad de 6 años y cubre ocho grados (Años 1 a 8). El programa no se ha dividido en etapas a nivel nacional. Para propósitos de reportar a nivel internacional, se considera que este programa abarca los niveles 1 y 2 de la CINE. Los primeros seis grados se clasifican como CINE 1 y los otros dos como CINE 2. (Primer a Sexto Grado: CINE-P/CINE-A: 100; Séptimo y Octavo Grado: CINE-P/CINE-A: 244) (...Grades 7 and 8: ISCED-P/ISCED-A: 244)

Finlandia - Peruskoulu (Escuela polivalente). La escuela polivalente imparte nueve años de educación básica (primaria y secundaria baja) de carácter general y obligatorio, a partir de la edad de 7 años. Se ha dividido en dos etapas: etapas inferiores (Primer a Sexto Grado) y etapas superiores (Séptimo a Noveno Grado). Durante los primeros 6 años la instrucción suele estar a cargo de un profesor principal. De acuerdo a la Ley de Educación Básica, el objetivo general de este nivel de educación es promover el crecimiento de los niños hacia una ciudadanía ética y responsable e impartirles a la vez los conocimientos y las destrezas esenciales para el diario vivir. Los alumnos que cursan los nueve años de escuela polivalente reciben un certificado de educación básica. En la CINE 2011, las etapas inferiores (Primer a Sexto Grado) se clasifican como educación primaria (CINE 1) y las etapas superiores (Séptimo a Noveno Grado) como educación secundaria baja (CINE 2). (Primer a Sexto Grado: CINE-P/CINE-A: 100; Séptimo a Noveno Grado: CINE-P/ CINE-A: 244)

Islandia - Grunnskolar (Educación obligatoria). En Islandia, la duración de la educación obligatoria es de diez años (Primer a Décimo Grado). A nivel nacional, no existe división entre la educación primaria y secundaria baja y, más bien, forman parte del mismo nivel e incluso normalmente se imparten en la misma institución. En general, los primeros siete grados (Primer a Séptimo Grado) son equivalentes a educación primaria (CINE 1) y los últimos tres (Octavo a Décimo Grado) a secundaria baja (CINE 2). Tras la conclusión de la educación obligatoria los alumnos reciben un certificado. (Primer a Séptimo Grado: CINE-P/CINE-A: 100; Octavo a Décimo Grado: CINE-P/CINE-A: 244)

Kenia - Primary education. La educación primaria del país está destinada a niños a partir de los 6 años de edad. Incluye ocho grados agrupados en dos etapas: la primera etapa cubre de Primer a Tercer Grado y la segunda de Cuarto a Octavo Grado. Los primeros seis grados (Primer a Sexto Grado) son equivalentes a educación primaria (CINE 1) y los últimos dos (Séptimo y Octavo Grado) a secundaria baja (CINE 2). (Primer a Sexto Grado: CINE-P/CINE-A: 100; Séptimo y Octavo Grado: CINE-P/CINE-A: 244)

Malawi - Primary education. La duración de la educación primaria es de ocho años. La edad oficial de ingreso es de 6 años. En la CINE 2011 los primeros seis grados (Primer a Sexto Grado) son equivalentes a educación primaria (CINE 1) y los últimos dos (Séptimo y Octavo Grado) a secundaria baja (CINE 2). (Primer a Sexto Grado: CINE-P/CINE-A: 100; Séptimo y Octavo Grado: CINE-P/CINE-A: 244)

Omán - (Educación básica). El programa de educación básica tiene una duración de diez años y comienza a la edad de 6 años. Se ha organizado en dos ciclos: el primer ciclo cubre de Primer a Cuarto Grado y el segundo de Quinto a Décimo Grado. A estos dos ciclos le siguen dos años de educación postbásica (educación secundaria). En la CINE 2011, los primeros seis grados se clasifican como CINE 1 y los otros cuatro como CINE 2. (Primer a Sexto Grado: CINE-P/ CINE-A: 100; Séptimo a Décimo Grado: CINE-P/CINE-A: 244) 
República Árabe Siria - (Educación básica). El programa de educación básica se extiende nueve años (Primer a Noveno Grado) a partir de la edad de 6 años. Se ha organizado en dos etapas: la primera etapa cubre los primeros cuatro grados (Primer a Cuarto Grado) y la segunda los otros cinco (Quinto a Noveno Grado). Tras su exitosa conclusión, los alumnos reciben un certificado de educación básica y tienen la opción de avanzar a la educación secundaria alta. En la CINE, la primera etapa se clasifica como CINE 1 y la segunda como CINE 2. (Primer a Cuarto Grado: CINE-P/ CINE-A: 100; Quinto a Noveno Grado: CINE-P/CINE-A: 244)

Timor-Leste - Ensino basico Filial (Educación básica). La educación básica representa los primeros nueve años de educación y comprende tres ciclos. El primer ciclo incorpora los primeros cuatro grados, el segundo ciclo incluye el Quinto y Sexto Grado y el tercer ciclo los últimos tres grados. Para efectos de comparabilidad internacional, los primeros dos ciclos (Primer a Sexto Grado) se clasifican como educación primaria y el tercer ciclo (Séptimo a Noveno Grado) como educación (general) secundaria baja. (Primer a Sexto Grado: CINE-P/CINE-A: 100; Séptimo a Noveno Grado: CINE-P/CINE-A: 244)

\section{Ejemplos nacionales - Grupo 6:}

Programas de nivel CINE 1 insuficientes para la conclusión del nivel, por lo tanto el logro educativo equivale a la conclusión parcial del nivel [CINE-P: 100; CINE-A: 030]

Etiopía - Alternative Basic Education programme (ABE). El programa Alternativo de Educación Básica (ABE) se ha desarrollado como una modalidad rápida para lograr la meta de educación primaria universal. El ABE exige la misma edad de ingreso que la educación primaria regular (6 años) pero su currículo comprime los cuatro primeros grados en tres. Tras la exitosa conclusión del Tercer Grado el estudiante puede postular al Quinto Grado de la educación primaria regular. (CINE-P: 100/CINE-A: 030)

\section{Notas}

1. Los números de los párrafos refieren al documento de clasificación CINE 2011. Para mayores detalles, sírvase consultar la Guía del Lector.

2. El Instituto de Estadística de la UNESCO (UIS) y la Unión Europea (UE) utilizan "República de Corea" como el nombre oficial de "Corea".

3. El Instituto de Estadística de la UNESCO (UIS) y la Unión Europea (UE) utilizan "Eslovaquia" como el nombre oficial de las "República Eslovaca". 


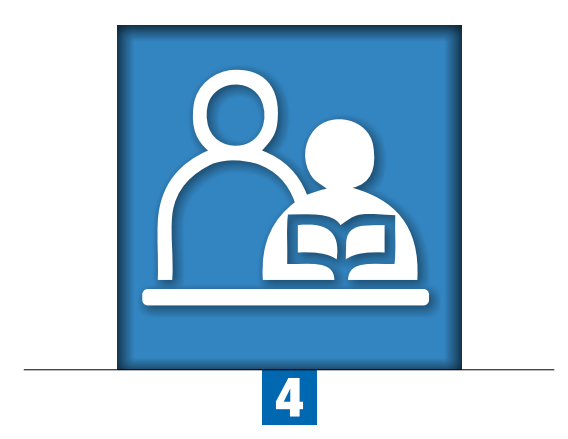

Capítulo 4

\section{Nivel 2 - CINE 2011:}

\section{Educación secundaria baja}

Los programas de secundaria baja están destinados a sentar las bases que propicien el desarrollo de una amplia gama de asignaturas y a preparar a los niños y jóvenes para estudios más especializados en educación secundaria alta y niveles más avanzados de educación. En el caso de los alumnos más jóvenes, el inicio, o finalización de la educación secundaria baja, con frecuencia implica un cambio de escuela así como un cambio en el estilo de instrucción.

Los programas clasificados en la nivel CINE 2 pueden recibir distintas denominaciones, por ejemplo: escuela secundaria (primera etapa/grados inferiores), escuela media, junior secondary school, middle school o junior high school. Si un programa abarca los niveles CINE 1 y 2 , se suelen utilizar los términos educación elemental o educación básica (segunda etapa/ grados superiores). Para propósitos de comparación a nivel internacional, se usa el término "secundaria baja" para denominar al nivel CINE 2. 


\section{DESCRIPCIÓN}

\section{Definición}

(§139)는 Los programas del nivel CINE2, o educación secundaria baja, suelen estar destinados a reforzar los resultados de aprendizaje del nivel CINE 1. En general, el objetivo que se persigue es sentar las bases para el desarrollo humano y el aprendizaje a lo largo de la vida sobre las cuales los sistemas educativos puedan expandir oportunidades de educación adicionales. Es probable que algunos sistemas educativos ya ofrezcan programas vocacionales en el nivel CINE 2 orientados a proporcionar a las personas destrezas relevantes para el acceso al mercado laboral.

(§140) En este nivel, los programas suelen aplicar un modelo más orientado por asignaturas con el fin de introducir conceptos teóricos sobre una amplia gama de temas. El personal docente se caracteriza por haber recibido formación pedagógica en asignaturas específicas en tanto que - con mayor frecuencia que en el nivel CINE 1 - una clase puede tener varios profesores especializados en las asignaturas que enseñan.

\section{Criterios de clasificación (\$143)}

\section{Criterios principales}

a) Transición a una instrucción más orientada por asignaturas

(§144) La línea divisoria entre los niveles CINE 1 y 2 coincide con el punto de transición en los sistemas educativos donde se privilegia la instrucción orientada por asignaturas.

b) Requisitos de ingreso

(§145) El ingreso a este nivel requiere la conclusión del nivel CINE 1 o la habilidad de manejar los contenidos del nivel CINE 2 a través de una combinación de estudios previos así como de experiencias prácticas y laborales. En determinados países, el ingreso a algunos o a todos los programas de nivel CINE 2 puede requerir la conclusión exitosa del nivel CINE 1 o un nivel específico de logros.

c) Duración acumulada a partir del inicio del nivel CINE 1.

(§146) El nivel CINE 2 finaliza tras 8 a 11 años de educación a partir del inicio del nivel CINE 1.

\section{Criterios subsidiarios}

a) Edad típica de ingreso

(§141) El nivel CINE 2 se inicia tras cuatro a siete años de educación en el nivel CINE 1. La edad típica de ingreso al nivel CINE 2 puede variar entre los 10 y 13 años.

b) Certificaciones del docente y organización de la instrucción por asignaturas

(§147) Respecto del tipo de certificación que se exige a los docentes, pueden existir diferencias entre los niveles CINE 1 y 2. En este último nivel, los profesores suelen estar certificados en una o más asignaturas, así como en pedagogía. Adicionalmente, la organización de la instrucción puede ser diferente a la que es habitual en el nivel CINE 1, ya que normalmente se cuenta con varios profesores para una clase que enseñan en uno o en varios campos de especialización.

c) Relación con la educación obligatoria

(§148) En muchos sistemas educativos que han adoptado la educación obligatoria, el fin de la educación secundaria baja coincide con el fin de la educación (general) obligatoria. 


\section{Dimensiones complementarias}

(§152) Dos dimensiones permiten diferenciar los programas educativos del nivel CINE 2.

(§153) Orientación del programa:

- General; y

- Vocacional.

(§154) Conclusión del nivel:

- Nivel CINE 2 inconcluso: programas terminales cortos (o secuencia de programas) de una duración inferior a dos años en el nivel CINE 2 o que finalizan después de menos de 8 años de educación acumulada a partir del comienzo del nivel CINE 1.

- Conclusión parcial del nivel CINE 2: programas que representan al menos 2 años en el nivel CINE 2, con una duración acumulada de al menos 8 años a partir del comienzo del nivel CINE 1 y que forman parte de una secuencia de programas en el nivel CINE 2, pero que no son el último programa de esta secuencia.

- Conclusión del nivel CINE 2 sin acceso directo a un nivel CINE más avanzado: programas de una duración mínima de 2 años en el nivel CINE 2 y que finalizan después de al menos 8 años de duración acumulada a partir del comienzo del nivel CINE 1, pero no dan acceso directo al nivel CINE 3.

- Conclusión del nivel CINE 2 con acceso directo a programas de un nivel CINE más avanzado: cualquier programa que otorgue acceso directo al nivel CINE 3 independientemente de la duración que pueda tener en este nivel o su duración acumulada desde el inicio del nivel CINE 1.

\section{CORRESPONDENCIA ENTRE LOS NIVELES CINE 2011 Y CINE 1997}

En las actualizaciones de la CINE 1997 y 2011, la cobertura del nivel CINE 2 es la misma.

No obstante, las dimensiones complementarias correspondientes al nivel CINE 2 son distintas en la versión más reciente. (§278)

a) Orientación de los programas

La CINE 1997 define tres tipos de orientación: general, pretécnica y vocacional. En la CINE 2011 se consideran solo dos orientaciones en el nivel CINE 2: general y vocacional. Los programas previamente clasificados como pretécnicos (en la CINE 1997) no otorgan certificaciones pertinentes al mercado laboral y en la actualidad se clasifican esencialmente bajo la denominación "educación general".

b) Conclusión de nivel y destino del programa

La CINE 1997 clasifica los programas en base a los programas y niveles a que finalmente conducen (destino de los programas). En el caso del nivel CINE 2, se han definido tres destinos:

Destino A: programas con acceso directo a la educación secundaria alta de nivel 3A o 3B, conforme a la CINE 1997, (es decir, programas que conducen directamente a la educación terciaria);

Destino B: programas con acceso directo a la educación secundaria alta aunque solo de nivel 3C, conforme a la CINE 1997 (es decir, programas que conducen directamente a la educación postsecundaria no terciaria o al mercado laboral); y

Destino C: programas sin acceso directo a la educación secundaria alta (es decir, programas terminales que conducen al mercado laboral).

La CINE 2011 clasifica sus programas de acuerdo al tipo de conclusión del nivel y acceso a otros programas y niveles. En la versión 2011, los destinos A y B de la CINE 1997 se combinan en una categoría única: conclusión del nivel 2 (CINE 2011) con acceso directo a la educación secundaria alta. El destino C de la CINE 1997 se subdivide en las siguientes categorías en la CINE 2011:

- conclusión del nivel 2 (CINE 2011) sin acceso directo a la educación secundaria alta;

- conclusión parcial del nivel 2 (CINE 2011) sin acceso directo a la educación secundaria alta; y

- insuficiente para conclusión del nivel o conclusión parcial del nivel 2 (CINE 2011). 


\section{DIRECTRICES PARA CLASIFICAR PROGRAMAS Y CERTIFICACIONES DE NIVEL CINE 2}

Los programas de secundaria baja están destinados a sentar las bases que propicien el desarrollo de una amplia gama de asignaturas y a preparar a los niños y jóvenes para estudios más especializados en educación secundaria alta y niveles más avanzados de educación. El inicio, o finalización, de la educación secundaria baja con frecuencia implica un cambio de escuela así como también un cambio en el estilo de instrucción. Los programas de secundaria baja refuerzan los conocimientos adquiridos en educación primaria y suelen aplicar un modelo más orientado por asignaturas. Típicamente, todos los alumnos se guían por el mismo currículo y tienen pocas opciones (en el caso de tenerlas) de elegir sus asignaturas de estudio. Se espera que tras la conclusión exitosa de la educación secundaria baja los jóvenes habrán adquirido una sólida base en asignaturas fundamentales (que generalmente incluyen lectura, escritura, matemática, historia, geografía, ciencia y a menudo un segundo idioma o un idioma extranjero. El arte, la música y la educación física también pueden formar parte del currículo.

En algunos sistemas de educación los programas se pueden distinguir por su orientación, aunque esto suele ser más común en la educación secundaria alta.

Los programas vocacionales, generalmente brindan opciones (de existir) a los jóvenes que desean insertarse directamente al mercado laboral desempeñándose como trabajadores poco calificados o semicalificados (Ejemplos nacionales Grupo 1). Estos programas también pueden representar el primer paso en la educación vocacional, dando acceso a programas vocacionales más avanzados a nivel de secundaria alta (Ejemplos nacionales - Grupo 2).

Sin embargo, en prácticamente todos los sistemas de educación, la gran mayoría se matricula en programas generales de educación secundaria baja que darán acceso al siguiente nivel (secundaria alta) (Ejemplos nacionales - Grupo 3).

El nivel CINE 2 también incluye programas de educación de adultos que tienen un contenido similar al impartido en las escuelas en este nivel (por ej., programas que imparten a los adultos las competencias necesarias para continuar su educación) y programas educativos para personas con necesidades especiales (por ej., discapacidades, dificultades o desventajas) (Ejemplos nacionales - Grupo 4).

También existen programas de segunda oportunidad o reintegración, destinados a reforzar las materias cubiertas en programas de educación secundaria baja o dar opciones a jóvenes que de otra manera abandonarían la escuela (Ejemplos nacionales - Grupo 5) sin certificación alguna. Asimismo, estos programas también pueden ofrecer a los jóvenes la oportunidad de cambiar su trayectoria académica o elegir una ocupación que requiera una certificación de nivel secundario menos avanzada, más acorde con la actual trayectoria de estudios. (§156).

En este nivel también se imparten programas destinados a la integración de inmigrantes, tanto jóvenes como adultos (Ejemplos nacionales - Grupo 6).

En el pasado, el final de este nivel a menudo coincidía con el final de la educación obligatoria, a pesar que en la actualidad la tendencia de los países es prolongar la educación obligatoria acercándose cada vez más al nivel de secundaria alta. La duración de los programas de educación secundaria baja fluctúa entre dos y cinco años, siendo tres años la más común. En algunos países donde puede existir una secuencia de programas dentro de un nivel, estos programas pueden tener una duración menor. Los programas secuenciales son más comunes en educación secundaria alta, si bien pueden darse en secundaria baja cuando se producen transferencias entre escuelas durante el desarrollo del nivel (por ej., el caso escuelas básicas que cubren ocho o más grados extendiéndose más allá del nivel primario).

\section{Programas que abarcan educación secundaria baja y otro nivel CINE}

Los programas que abarcan educación secundaria baja y un nivel inferior o superior, requieren especial atención. En estos casos, solo los grados, etapas o ciclos que reflejen los criterios de los respectivos niveles (niveles CINE 1, 2 o 3) deben asignarse a esos niveles. (\$149)

\section{LOGRO EDUCATIVO EN EL NIVEL CINE 2}

Al igual que en educación primaria, los programas de educación secundaria baja no siempre conducen a una certificación final reconocida, particularmente si la misma institución ofrece educación secundaria baja y alta o si el final de secundaria baja no coincide con el final de la educación obligatoria. De ser este el caso, se pueden utilizar otros tipos de reconocimiento formal de la exitosa conclusión del programa o nivel para determinar el nivel de logro educativo. 
Esto puede incluir confirmación formal de asistencia ininterrumpida durante el último año del programa o el derecho a avanzar a programas o niveles superiores.

Para propósitos de medición del logro educativo, la CINE 2011 establece una distinción entre la conclusión y la conclusión parcial de la educación secundaria baja, si bien en este nivel la conclusión parcial se da muy infrecuentemente.

Dentro de la CINE, los programas que conducen a la conclusión de la educación secundaria baja se subdividen en aquellos que conducen a la educación secundaria alta y aquellos que no lo hacen. Ambos tipos dan origen a un logro educativo equivalente a secundaria baja. Este último grupo suele incluir programas vocacionales a menudo destinados a estudiantes que han superado la edad teórica de cursar la educación secundaria baja.

La conclusión parcial del nivel tiene un significado muy específico y no es sinónimo con "estudios incompletos" o "algunos estudios" en el nivel. Un programa que conduce a la conclusión parcial del nivel cuenta con una certificación reconocida u otro tipo de confirmación formal otorgada por las autoridades nacionales competentes que avalan la exitosa conclusión del programa. El programa es uno dentro de una secuencia establecida en la CINE pero no es el último programa de la secuencia. Asimismo, el programa debe representar un mínimo de ocho años de estudios acumulados a partir del inicio de la educación primaria y al menos dos años de estudios (acumulados) en educación secundaria baja (Ejemplos nacionales - Grupo 7). Cabe destacar que también se debe hacer una distinción entre las subcategorías "conclusión parcial del nivel" y "sin conclusión de nivel". Esta última se refiere a programas que no cumplen los requisitos de duración establecidos para "conclusión" y "conclusión parcial” y por consiguiente el logro educativo al que de origen será inferior al nivel del programa (véanse Ejemplos nacionales - Grupo 8).

La conclusión parcial del nivel en educación secundaria baja ocurre con mayor frecuencia cuando se produce un cambio de escuelas durante el desarrollo del nivel. Como parte del proceso de transición entre escuelas, los países suelen administrar evaluaciones o exámenes formales del avance de los alumnos hacia la exitosa conclusión reconocida de un programa nacional determinado.

(§159) En términos de logro educativo, las certificaciones otorgadas por programas de nivel CINE 2 consideradas insuficientes para la conclusión o conclusión parcial de este nivel se clasifican en el nivel CINE 1.

(§160) En forma similar, las certificaciones otorgadas por programas de nivel CINE 3 consideradas insuficientes para la conclusión o conclusión parcial de este nivel se clasifican en el nivel CINE 2.

Si el programa no conduce a certificaciones reconocidas (o si la exitosa conclusión no cuenta con el reconocimiento formal de las autoridades nacionales competentes), el concepto de conclusión parcial no aplica. En esos casos, un logro educativo equivalente al nivel CINE 2 solo puede ser asignado al final de la secuencia de programas y una vez obtenida la certificación o confirmación formal correspondiente de exitosa conclusión.

Los programas de nivel CINE 2 que no dan acceso directo a la CINE 3 y que representan menos años de estudio desde el comienzo de la educación primaria (es decir, menos de ocho) o de la educación secundaria baja (menos de dos) o ambos, se consideran insuficientes para la conclusión o conclusión parcial de secundaria baja y dan origen a un logro educativo de nivel primario (Ejemplos nacionales - Grupo 8).

Los usuarios de la clasificación que deseen difundir resultados de acuerdo al conjunto simplificado de categorías de logro educativo establecidos en la CINE-A deberán decidir en qué forma abordar la conclusión parcial del nivel. Dos enfoques diferentes son posibles dependiendo del objetivo principal del análisis:

(i) Algunos usuarios podrían estar interesados en conocer el porcentaje de una población determinada que ha concluido exitosamente cada nivel CINE de educación. Esto haría necesario clasificar la conclusión parcial del nivel en un nivel inferior al que corresponde al estudio (por ej., a nivel primario, en el caso de conclusión parcial de educación secundaria baja).

(ii) Otros usuarios podrían estar interesados en medir un estudio ampliamente reconocido en un nivel determinado, particularmente si esto pudiese representar un punto potencial de salida del sistema educativo o una "primera graduación" dentro de un nivel CINE dado. Estas personas optarían por clasificar la conclusión parcial del nivel en el mismo nivel CINE que corresponde al estudio (es decir, en el nivel de secundaria baja en el caso de conclusión parcial de la educación secundaria baja). 
Ambos enfoque son válidos. El propio usuario o analista deberá determinar cuál es el método más adecuado a sus circunstancias. Se recomienda indicar en los metadatos que acompañan a las estadísticas la modalidad de conclusión parcial aplicada al cálculo de indicadores de logro.

\section{EJEMPLOS DE PROGRAMAS Y CERTIFICACIONES CLASIFICADOS EN EL NIVEL CINE 2}

(§142) Los programas clasificados en el nivel CINE 2 pueden recibir distintas denominaciones, por ejemplo: escuela secundaria (primera etapa/grados inferiores, de contar con un programa que abarque los niveles CINE 2 y 3), escuela media, junior secondary school, middle school o junior high school. Si un programa abarca los niveles CINE 1 y 2, se suelen utilizar los términos educación elemental o educación básica (segunda etapa/ grados superiores). Para propósitos de comparación a nivel internacional, se usa el término "secundaria baja" para denominar al nivel CINE 2.

\section{Ejemplos nacionales - Grupo 1:}

Programas vocacionales destinados a preparar a jóvenes para ingresar directamente al mercado laboral desempeñando ocupaciones de baja calificación o semicalificadas [CINE-P: 251 o 253; CINE-A: 100 o 253]

Túnez - (Certificado de competencia). El acceso a este programa requiere la conclusión de Séptimo Grado, es decir, el primer grado de educación secundaria baja. Este programa de carácter vocacional tiene una duración de dos años y conduce al Certificat de Compétence (certificado de competencia), que solo da acceso al mercado laboral. (CINE-P/ CINE-A: 253)

Ejemplos nacionales - Grupo 2:

Programas vocacionales destinados a preparar para el ingreso directo al mercado laboral que también dan acceso a programas de educación secundaria alta [CINE-P: 254; CINE-A: 254]

Bulgaria - Profesionalni programi- parva stepen na profesionalna kvalifikatsiya sled 6 ili 7 klas (Programa vocacional que otorga una certificación de primer nivel tras la conclusión del Sexto o Séptimo Grado). Los alumnos pueden ingresar a este programa después de completar dos años de estudio en el nivel CINE 2. La duración del programa fluctúa entre dos o tres años y conduce a dos certificaciones: logro equivalente a educación básica (con acceso al nivel CINE 3) y certificación vocacional de primer nivel. (CINE-P/CINE-A: 254)

Líbano - (Aptitud vocacional). Este programa vocacional de dos años de duración requiere finalizar el primer grado de educación secundaria baja como mínimo. Tras su exitosa conclusión los graduados reciben el (Certificate of vocational aptitude), que conduce al mercado laboral y a niveles más avanzados de educación. (CINE-P/CINE-A: 254)

Países Bajos - WEB-assistentenopleiding (Educación vocacional: capacitación para el nivel de asistente (nivel 1)). Estos programas educativos diseñados para estudiantes desde los 16 años de edad, pueden ser a tiempo completo o parcial, son impartidos en escuelas y pertenecen al sistema dual de educación. (Solo los estudiantes de 18 años o más son elegibles para participar en programas a tiempo parcial). Los programas a tiempo completo tienen una duración típica de un año y conducen al MBO niv. 1: assistant (Certificado de Educación Secundaria Vocacional). A los estudiantes que concluyen con éxito se les permite continuar sus estudios en secundaria alta aunque la mayoría ingresa al mercado laboral. (CINE-P/CINE-A: 254)

\section{Ejemplos nacionales - Grupo 3: \\ Programas generales que dan acceso a educación secundaria alta [CINE-P: 244; CINE-A: 244]}

Australia - Secondary school: 1st stage. La primera etapa de la escuela secundaria tiene una duración de tres o cuatro años, (según el largo de la educación primaria en cada estado) al cabo de los cuales los estudiantes reciben el Certificado del Décimo Año. Los estudiantes siguen un programa general que ofrece la posibilidad de continuar su educación en niveles más avanzados. (CINE-P/CINE-A: 244)

Egipto - (Educación preparatoria). Este es un programa general de educación post-primaria de tres años de duración. Tras su exitosa conclusión los graduados reciben el (Certificado de Educación Básica). Posteriormente, los estudiantes pueden cursar programas de educación general o vocacional a nivel de secundaria alta. (CINE-P/CINE-A: 244) 
Alemania - Sekundarbereich I mit Qualifikation für weiterführende Bildungsgänge (Escuelas de educación secundaria baja con acceso a programas generales de educación secundaria alta). Este programa (Quinto a Noveno o Décimo Grado) que se imparte después de cuatro años de educación primaria, marca el comienzo de un currículo más orientado a las asignaturas. Los estudiantes graduados pueden ingresar a escuelas de educación general a nivel de secundaria alta (Gymnasiale Oberstufe) que los preparan para postular a programas de nivel CINE 6 o 7. (CINE-P/CINE-A: 244)

India - Upper primary (Grades VI to VIII). El acceso a este programa de educación general de tres años de duración tiene como requisito un certificado de primaria que se otorga tras la exitosa conclusión del programa de educación primaria de seis años de duración (CINE 1). Los graduados de educación primaria alta reciben el certificado correspondiente que da acceso a programas de educación secundaria alta (CINE 3). (CINE-P/CINE-A: 244)

Eslovenia - Osnovnošolsko izobraževanje (7.-9. razred) (Educación básica (Séptimo a Noveno Grado)). Este programa de tres años de duración conduce al Zaključno spričevalo (osnovne šole) (Certificado de conclusión de educación básica obligatoria) que da acceso directo a programas de educación secundaria alta. Los estudiantes ingresan al programa tras la exitosa conclusión de educación primaria, típicamente a la edad de 12 años. (CINE-P/CINE-A: 244)

Islas Salomón - Junior Secondary Education (Forms 1-3) Este es un programa de educación general de tres años de duración que se inicia tras la exitosa conclusión de Standard 6 (que marca el final de la educación primaria). Una vez finalizado este programa los estudiantes rinden el examen National Form 3 Examination (NF3) que da acceso a educación secundaria alta. (CINE-P/CINE-A: 244)

\section{Ejemplos nacionales - Grupo 4: \\ Educación de adultos que proporciona las competencias básicas para continuar la educación y para acceder a programas de nivel CINE 2 en el caso de estudiantes con necesidades especiales [CINE-P: 243, 244, 253 o 254; CINE -A: 243, 244, 253 o 254]}

Bélgica (Comunidad flamenca) - Buitengewoon secundair onderwijs - opleidingsvorm 1 en 2 (Educación secundaria especial - tipos 1 y 2). Este programa está orientado a niños que necesitan ayuda especial en forma temporal o permanente. En la educación secundaria especial, la instrucción está organizada en función del tipo de discapacidad y las posibilidades del alumno. La educación tipo 1 provee educación social orientada a integrar al alumno a un entorno protegido. La educación tipo 2 imparte educación general y social así como capacitación laboral orientada a integrar al alumno a entornos de vida y trabajo protegidos. (CINE-P/CINE-A: 253)

Alemania - Sekundarbereich I, Abendschulen (Escuelas vespertinas de educación secundaria baja). Este programa (de uno a dos años de duración) está destinado a adultos que poseen escasas certificaciones (o ninguna) de nivel CINE 2 (por ej., Hauptschulabschluss) que aspiran a obtener una certificación más avanzada a nivel de secundaria baja (principalmente Mittlerer Schulabschluss). (CINE-P/CINE-A: 244)

Kuwait - (Etapa intermedia de adultos). Normalmente, este programa formal de educación de adultos está orientado a personas adultas de 15 o más años de edad que han finalizado la educación primaria. Al igual que la etapa intermedia inicial (secundaria baja), el programa tiene una duración teórica de cuatro años. Tras su exitosa conclusión, los graduados pueden optar por programas de educación de adultos a nivel de secundaria alta. (CINE-P/CINE-A: 244)

México - Capacitación para el trabajo (Capacitación ocupacional a nivel de secundaria baja). La duración típica de estos programas es de dos años, si bien existen programas más largos y más cortos. Habitualmente, los estudiantes matriculados en estos programas son adultos. El objetivo del programa es preparar a personas (de 15 años de edad o mayores) para su inserción en el mundo del trabajo. (CINE-P/CINE-A: 243)

\section{Ejemplos nacionales - Grupo 5:}

Programas de reintegración o segunda oportunidad para estudiantes que aún no han finalizado la educación secundaria baja [CINE-P: 243, 244, 253 o 254; CINE-A: 243, 244, 253 o 254]

Irlanda - Youthreach (Nivel básico). Este es un programa general de dos años de duración destinado a personas que abandonan la escuela sin certificaciones de ningún tipo. Es posible obtener diversas certificaciones incluyendo el Junior Certificate a nivel de educación secundaria baja. (CINE-P/CINE-A: 244)

Marruecos - (Capacitación vocacional: nivel de especialización). Todo estudiante que curse el Sexto Grado de educación primaria y tenga una edad mínima de 15 años tiene acceso a este programa, cuya duración es de dos años 
y su objetivo preparar al estudiante para ingresar al mercado laboral. También da acceso a niveles más avanzados de educación (nivel CINE 3).

Eslovaquia ${ }^{2}$ - Praktická škola (Escuela práctica). Este programa general, que ofrece educación y capacitación en actividades ocupacionales de baja complejidad, puede prolongarse entre uno y tres años. Está diseñado para dar una segunda oportunidad a jóvenes que ya han cursado el ciclo completo de educación secundaria baja. La edad de ingreso típica es de 15 años o más. El contenido de este programa no es lo suficientemente complejo como para ser clasificado en el nivel de secundaria alta. Conduce al certificado Vysvedčenie. (CINE-P/CINE-A: 243)

\section{Ejemplos nacionales - Grupo 6: \\ Programas diseñados para la integración de nuevos inmigrantes \\ [CINE-P: 241, 243, 244, 253 o 254; CINE-A: 100, 243, 244, 253 o 254]}

Bélgica (Comunidad flamenca) - Onthaalklas voor anderstalige nieuwkomers (Clases de recepción para inmigrantes). Este tipo de educación está orientada a estudiantes recién llegados a Bélgica que tiene un conocimiento muy básico del neerlandés. Su objetivo principal es que los participantes aprendan neerlandés y se integren al tipo de educación secundaria y disciplina (campo de estudio) que mejor se adapte a sus habilidades individuales. El currículo del año de recepción se centra primordialmente en la adquisición del neerlandés. Para ingresar a la clase de recepción la persona debe cumplir los siguientes criterios: 1) el 31 de diciembre después del inicio del año escolar debe haber cumplido 12 años de edad y no ser mayor de 18 años; 2) ser un inmigrante reciente (tener como máximo un año de residencia en Bélgica); 3) tener una lengua materna o hablar en el hogar un idioma distinto al neerlandés; 4) no tener el conocimiento necesario del neerlandés para entender las lecciones impartidas en escuelas convencionales; y 5) estar matriculado por no más de nueve meses en una escuela donde el neerlandés sea el idioma de instrucción. (CINE-P: 241; CINE-A: 100)

Luxemburgo - Classes d'accueil (ACCU) (12-15 ans) y Classes d'insertion pour jeunes adultes (CLIJA) (16-17 ans) (Clases de bienvenida para jóvenes de 12 a 15 años y de 16 y 17 años, respectivamente. Estos son programas generales de un año de duración destinados a preparar a jóvenes recién llegados del extranjero para ingresar al sistema regular de educación a nivel de educación secundaria baja (Classes d'accueil (ACCU) (12-15 ans) o educación secundaria alta (Classes d'insertion pour jeunes adultes (CLIJA) (16-17 ans). (CINE-P: 241/CINE-A: 100 y CINE-P/CINE-A: 244, respectivamente)

Noruega - Introduksjonsordning og opplæring I norsk og samfunnskunnskap for nyankomne innvandrere (Programa introductorio al idioma noruego y a las condiciones sociales para nuevos inmigrantes). Este programa de hasta dos años de duración conduce al Fullført introduksjonsprogram (Certificado de idioma noruego y de educación cívica para inmigrantes adultos). No da acceso a niveles más avanzados de educación. (CINE-P: 241/CINE-A: 100)

\section{Ejemplos nacionales - Grupo 7:}

Programas y certificaciones que derivan en conclusión parcial del nivel [CINE-P: 242 o 252; CINE-A: 242 o 252]

Lituania - Profesinio mokymo programa, skirta asmenims, neturintiems pagrindinio išsilavinimo (Programas de educación vocacional para personas sin educación básica). Tras la conclusión de educación primaria, los estudiantes pueden ingresar a este programa de dos años de duración que otorga un reconocimiento de certificación vocacional que permite a los estudiantes continuar su educación en otros programas de educación secundaria baja, que una vez finalizados dan acceso al nivel de secundaria alta. (CINE-P/CINE-A: 252)

\section{Ejemplos nacionales - Grupo 8: \\ Programas de nivel CINE 2 insuficientes para conclusión del nivel, en consecuencia otorgan un logro educativo de nivel CINE 1 [CINE-P: 2421 o 251; CINE-A: 100]}

Argelia - (Capacitación vocacional especial). Este programa de un año de duración prepara a adolescentes para tener acceso directo al mercado laboral. A partir de los 11 años de edad, toda persona que sepa leer y escribir tiene acceso al programa. Tras la conclusión del programa, los graduados reciben un certificado de estudios considerado más avanzado que educación primaria pero menos avanzado que educación secundaria baja. El programa se considera insuficiente para conclusión del nivel CINE 2. (CINE-P: 251/CINE-A: 100

Estonia - Põhihariduse nõudeta kutseõpe (Educación vocacional para personas sin educación básica que han superado la edad de cursar la educación obligatoria). La edad de ingreso a este programa es de 17 a 19 años y su duración fluctúa 
entre seis meses y dos años y medio. El requisito de ingreso a este programa es haber concluido el nivel CINE 1. Los graduados reciben un certificado de estudios otorgado por una institución de educación vocacional considerado más alto que el nivel CINE 1 pero insuficiente para clasificar como certificación de nivel CINE 2. (CINE-P: 251/CINE-A: 100)

\section{Notas}

1. Los números de los párrafos refieren al documento de clasificación CINE 2011. Para mayores detalles, sírvase consultar la Guía del Lector.

2. El Instituto de Estadística de la UNESCO (UIS) y la Unión Europea (UE) utilizan "Eslovaquia" como el nombre oficial de las "República Eslovaca". 



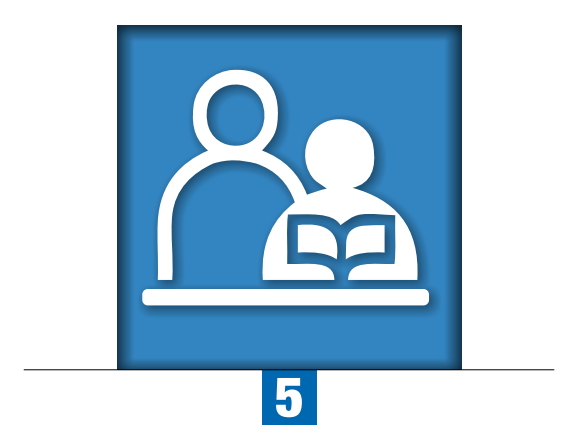

Capítulo 5

\section{Nivel 3 - CINE 2011:}

\section{Educación secundaria alta}

Los programas de educación secundaria alta son más especializados que los impartidos en educación secundaria baja y ofrecen a los estudiantes un espectro más amplio de opciones y ramificaciones para finalizar su educación secundaria. El número de asignaturas que un estudiante debe tomar tiende a ser menor que en los niveles inferiores de educación, aunque el contenido es más complejo y se requieren estudiar con mayor profundidad. Los programas se distinguen por su orientación y con frecuencia en base a grupos amplios de asignaturas.

Los programas clasificados en el nivel CINE 3 pueden recibir distintas denominaciones, por ejemplo: escuela secundaria (segunda etapa/grados superiores), senior secondary school o (senior) high school. Para propósitos de comparación a nivel internacional, se usa el término "secundaria alta" para denominar al nivel CINE 3. 


\section{DESCRIPCIÓN}

\section{Definición}

(§162)1 Los programas del nivel CINE 3, o educación secundaria alta, suelen tener como principal objetivo consolidar la educación secundaria como preparación a la educación terciaria, o bien proporcionar destrezas pertinentes al empleo o ambos.

(§163) Los programas de este nivel se caracterizan por impartir a los estudiantes un tipo de instrucción más diversificada, especializada y avanzada que los programas del nivel CINE 2. Asimismo, presentan un mayor grado de diferenciación y ofrecen un espectro más amplio de opciones y ramificaciones dentro del mismo nivel. Con frecuencia, los docentes han recibido una sólida formación en las asignaturas o campos de especialización que enseñan, particularmente en los grados superiores.

\section{Criterios de clasificación (§166)}

\section{Criterios principales}

a) Contenido

(§167) Los programas correspondientes a la segunda etapa o la etapa final de la educación secundaria pueden ser programas generales o vocacionales del nivel CINE 3. Algunos de estos programas dan acceso directo al nivel CINE 4 y/o al nivel 5, 6 o 7.

b) Requisitos de ingreso

(§168) El ingreso a este nivel requiere la conclusión de la educación secundaria baja (nivel CINE 2) o la habilidad de manejar los contenidos del nivel CINE 3 a través de una combinación de estudios previos, así como de experiencias prácticas y laborales. El ingreso a algunos o a todos los programas de nivel CINE 3 puede requerir una certificación de nivel CINE 2 o bien un nivel específico de logros.

c) Duración acumulada a partir del inicio del nivel CINE 1

(§164) El nivel CINE 3 comienza después de 8 a 11 años de educación a partir del inicio del nivel CINE 1. La edad típica de ingreso de estos estudiantes fluctúa entre los 14 y 16 años. Los programas comprendidos en este nivel suelen tener una duración de doce o trece años a partir del inicio del nivel CINE 1 (es decir, cuando el estudiante tiene aproximadamente 17 o 18 años de edad), siendo 12 años la duración acumulada más común. Sin embargo, el egreso de la educación secundaria alta suele fluctuar entre 11 y 13 años a partir del inicio del nivel CINE 1.

\section{Criterios subsidiarios}

a) Punto de transición del programa

(§169) La transición del nivel CINE 2 al nivel CINE 3 coincide con el punto de transición en el sistema educativo en el cual los programas ofrecidos a los alumnos son más variados, especializados y avanzados y con una instrucción más profunda en asignaturas o campos específicos. Normalmente, estos programas presentan un mayor grado de diferenciación y ofrecen a los participantes un espectro más amplio de opciones y ramificaciones.

b) Certificaciones de los docentes

(§170) Las certificaciones que se exigen a los docentes en este nivel pueden ser distintas a las requeridas en el nivel CINE 2. Además de su formación pedagógica, los docentes suelen tener una mayor especialización en las materias que enseñan. 


\section{Dimensiones complementarias}

(§174) Dos dimensiones permiten diferenciar los programas educativos del nivel CINE 3.

(§175) Orientación del programa

- General; y

- Vocacional.

(§176) Conclusión del nivel:

- Nivel CINE 3 inconcluso: programas terminales cortos (o secuencia de programas) de una duración inferior a 2 años en este nivel o que finalizan después de menos de 11 años de duración acumulada a partir del comienzo del nivel CINE 1.

- Conclusión parcial del nivel CINE 3: programas que representan al menos 2 años en el nivel CINE 3, con una duración acumulada de al menos 11 años a partir del nivel CINE 1 y que forman parte de una secuencia de programas de nivel CINE 3, pero que no son el último programa de la secuencia.

- Conclusión del nivel CINE 3 sin acceso directo a programas de primer título de educación terciaria de nivel CINE 5, 6 o 7: programas de una duración mínima de 2 años en el nivel CINE 3 y que finalizan después de al menos 11 años de educación acumulada a partir del comienzo del nivel CINE 1. Estos programas pueden ser terminales o dar acceso directo al nivel CINE 4.

- Conclusión del nivel CINE 3 con acceso directo a programas de primer título de educación terciaria de nivel CINE 5, 6 o 7: cualquier programa que de acceso directo a dichos programas en el nivel CINE 5, 6 ० 7 , independientemente de su duración en el nivel CINE 3 o de su duración acumulada a partir del comienzo del nivel CINE 1.

(§178) Este nivel puede incluir algunos programas vocacionales de segundo ciclo en aquellos casos donde los puntos de transición al final del segundo ciclo corresponden a los puntos de transición entre los niveles de otras trayectorias (mayormente de orientación general) ofrecidas en el sistema.

(§179) Asimismo, este nivel incluye programas de educación secundaria alta de segunda oportunidad o de reintegración. Normalmente, estos programas están destinados a personas que abandonaron la escuela antes de finalizar la educación secundaria alta (estos programas facilitan el reingreso al sistema educativo con el fin de completar este nivel), o han completado la educación secundaria alta pero han optado por cursar un programa o desempeñar un oficio para el cual no se encuentran lo suficientemente preparados.

\section{CORRESPONDENCIA ENTRE LOS NIVELES CINE 2011 Y CINE 1997}

La cobertura del nivel CINE 3 es prácticamente la misma en las versiones 1997 y 2011 de la CINE, con la siguiente excepción que involucra al nivel 4 de la CINE 1997:

(\$190) Los programas destinados a actualizar los contenidos de programas de nivel CINE 3 - por ejemplo, con el fin de preparar a los estudiantes para rendir exámenes de ingreso a la educación terciaria - se deben incluir en el nivel CINE 3.

En la versión CINE más reciente, las dimensiones complementarias del nivel CINE 3 son diferentes. (§278)

a) Orientación del programa

La CINE 1997 define tres tipos de orientación: general, pretécnica y vocacional. En la CINE 2011 se consideran solo dos orientaciones en el nivel CINE 3: general y vocacional. Los programas previamente clasificados como pretécnicos (en la CINE 1997) no otorgan certificaciones pertinentes al mercado laboral y en la actualidad se clasifican esencialmente bajo la denominación "educación general". 
b) Conclusión de nivel y destino del programa

La CINE 1997 clasifica los programas en base a los programas y niveles a que finalmente conducen (destino de los programas). En el caso del nivel CINE 3, se han definido tres destinos:

Destino A: programas con acceso directo a la educación terciaria de nivel 5A, conforme a la CINE 1997, (es decir, programas que conducen directamente a un doctorado o programa equivalente);

Destino B: programas con acceso directo a la educación terciaria de nivel 5B (pero no de nivel 5A) conforme a la CINE 1997 (es decir, programas que dan acceso a una educación terciaria más orientada al campo profesional); y

Destino C: programas sin acceso directo a la educación terciaria (es decir, programas terminales o programas que solo dan acceso a otros programas de nivel 3 o 4 de la CINE 1997).

La CINE 2011 clasifica sus programas de acuerdo al tipo de conclusión del nivel y acceso a otros programas y niveles. En la versión 2011, los destinos A y B de la CINE 1997 se combinan en una categoría única: conclusión del nivel 3 (CINE 2011) con acceso directo a la educación terciaria. El destino C de la CINE 1997 se subdivide en las siguientes categorías en la CINE 2011:

- conclusión del nivel 3 (CINE 2011) sin acceso directo a la educación terciaria;

- conclusión parcial del nivel 3 (CINE 2011) sin acceso directo a la educación postsecundaria; e

- insuficiente para conclusión o conclusión parcial del nivel 3 (CINE 2011).

\section{DIRECTRICES PARA CLASIFICAR PROGRAMAS Y CERTIFICACIONES DE NIVEL CINE 3}

Los programas de educación secundaria alta son más especializados que los impartidos en educación secundaria baja y ofrecen a los estudiantes un espectro más amplio de opciones y ramificaciones para finalizar su educación secundaria (§163). El número de asignaturas que un estudiante debe tomar tiende a ser menor que en los niveles inferiores de educación, aunque el contenido es más complejo y se requieren estudiar con mayor profundidad.

Los programas se distinguen por su orientación $(\S 167)$ y con frecuencia en base a grupos amplios de asignaturas.

Los programas generales suelen estar diseñados para estudiantes que proyectan continuar sus estudios académicos o profesionales a nivel terciario. Con frecuencia, los estudiantes comienzan a especializarse en campos específicos, como la ciencia, las humanidades o las ciencias sociales, pese a que deben continuar tomando cursos en asignaturas básicas tales como el idioma nacional, matemática y quizás un idioma extranjero. La exitosa conclusión de estos programas es prácticamente siempre el requisito de ingreso a los primeros años de estudios de nivel universitario o equivalente (Ejemplos nacionales - Grupo 1). También pueden haber programas generales de nivel CINE 3 que no den acceso a la educación terciaria aunque estos son relativamente escasos. No obstante, en los Ejemplos nacionales - Grupo 10 se presenta un caso.

En algunos países los requisitos de ingreso a programas del nivel 6 son distintos a los del nivel CINE 5. Cuando este sea el caso, ambas certificaciones deben clasificarse en el nivel CINE 3.

Los programas vocacionales cumplen el objetivo doble de ofrecer opciones a jóvenes que de lo contrario abandonarían la escuela sin haber obtenido certificación alguna a nivel de secundaria alta (Ejemplos nacionales - Grupo 2), y de preparar a estudiantes que aspiran a trabajar como obreros calificados o técnicos. (Ejemplos nacionales - Grupo 3).

Los programas de segunda oportunidad o de reintegración, destinados a reforzar las materias cubiertas en programas de educación secundaria alta (Ejemplos nacionales - Grupo 4) u ofrecer a los jóvenes la oportunidad de cambiar su trayectoria académica o insertarse en una ocupación que requiera una certificación o logro educativo de educación secundaria alta que no podrían obtener de continuar su actual trayectoria, se clasifican en el nivel CINE 3 (§179).

En contraste, los programas accesibles tras la exitosa conclusión de educación secundaria alta que han sido diseñados para ampliar las opciones de avance hacia el nivel terciario o constituyen programas vocacionales de segundo ciclo, deben clasificarse en el nivel CINE 4 (\$185). Los programas vocacionales de segundo ciclo que se imparten en forma paralela a otros programas de educación secundaria alta (en su mayoría programas generales) normalmente deberían clasificarse en el nivel CINE 3 (§179).

La duración de los programas de educación secundaria alta fluctúa entre dos y cinco años, siendo tres años la más común. Los programas de este nivel pueden ser más cortos en países donde un nivel consiste en una secuencia 
de programas cada uno de los cuales conduce a una certificación distinta reconocida a nivel nacional. En el nivel de secundaria alta se pueden dar programas secuenciales cuando el final de la educación obligatoria se produce dentro de este nivel o donde existen puntos comunes de salida de la educación en el nivel que requiere ser documentado por una certificación reconocida (por ej., para buscar empleo o acceder a niveles de educación más avanzados). Si tal secuencia llegara a existir, probablemente sería una secuencia de programas generales, si bien también existe la posibilidad de que sea una secuencia vocacional (Ejemplos nacionales - Grupo 7).

\section{Programas que abarcan educación secundaria alta y otro nivel CINE}

Los programas que abarcan educación secundaria alta y un nivel inferior o superior, requieren especial atención. En estos casos, solo los grados, etapas o ciclos que reflejen los criterios de los respectivos niveles (niveles CINE 2, 3, 4 o 5) deben asignarse a esos niveles. (\$171)

(§173) Si la duración teórica de un programa vocacional de nivel CINE 3 excede en dos o más años la duración teórica de un programa general de nivel CINE 3 del mismo sistema educativo, se debe considerar que dicho programa abarca educación secundaria alta (nivel CINE 3) y la educación postsecundaria no terciaria (nivel CINE 4) o la educación terciaria de ciclo corto (nivel CINE 5). Los grados, etapas o ciclos con una duración superior a la de los programas generales de nivel CINE 3 se deben clasificar en los niveles CINE 4 o 5 de acuerdo a la complejidad de sus contenidos. (Ejemplos nacionales - Grupo 6).

\section{LOGRO EDUCATIVO EN EL NIVEL CINE 3}

Para propósitos de medición del logro educativo, la CINE 2011 establece una distinción entre la conclusión y la conclusión parcial de la educación secundaria alta.

La conclusión parcial del nivel tiene un significado muy específico y no es sinónimo con "estudios incompletos" o "algunos estudios" en el nivel. Un programa que conduce a la "conclusión parcial del nivel" es uno que otorga una certificación reconocida por las autoridades nacionales competentes a los estudiantes que completan el programa hasta un punto determinado de la secuencia de programas, pero no es equivalente a la certificación conferida por la exitosa conclusión de toda la secuencia. El programa es uno dentro de una secuencia establecida por la CINE aunque no es el último programa de la secuencia. Asimismo, el programa debe representar un mínimo de once años de estudios acumulados a partir del inicio de la educación primaria y al menos dos años de estudios (acumulados) en educación secundaria alta (Ejemplos nacionales - Grupo 7). Cabe hacer presente que también se debe diferenciar entre las subcategorías "conclusión parcial del nivel" y "sin conclusión de nivel". Esta última se refiere a programas que no cumplen los requisitos de duración establecidos para "conclusión" o "conclusión parcial” y por consiguiente el logro educativo al que de origen será inferior al nivel del programa (véanse Ejemplos nacionales - Grupo 9).

(§182) En términos de logro educativo, las certificaciones otorgadas por programas de nivel CINE 3 consideradas insuficientes para la conclusión de este nivel se clasifican en el nivel CINE 2.

(§183) En forma similar, las certificaciones otorgadas por programas de nivel CINE 4 consideradas insuficientes para la conclusión de este nivel se deben clasificar en el nivel CINE 3.

Si el programa no conduce a certificaciones reconocidas (o si la exitosa conclusión no cuenta con el reconocimiento formal de las autoridades nacionales competentes), el concepto de conclusión parcial no aplica. En esos casos, un logro educativo equivalente al nivel CINE 3 solo puede ser asignado al final de la secuencia de programas y una vez obtenida la certificación.

Los programas de nivel CINE 3 que no dan acceso directo a un nivel CINE más avanzado y que representan menos años de estudio desde el comienzo de la educación primaria (es decir, menos de once) o de la educación secundaria alta (menos de dos) o ambos, se consideran insuficientes para la conclusión o conclusión parcial de secundaria alta y dan origen a un logro educativo equivalente al nivel de secundaria baja (Ejemplos nacionales - Grupo 8). 
Dentro de la CINE, los programas vocacionales que conducen a la conclusión de la educación secundaria alta se subdividen en los que conducen a la educación terciaria (Ejemplos nacionales - Grupo 9) y los que no lo hacen (Ejemplos nacionales - Grupo 10). Ambos tipos dan origen a un logro educativo a nivel de secundaria alta. Este último grupo de programas puede, o no, dar acceso a la educación postsecundaria no terciaria.

En algunos casos un programa puede conducir a varias certificaciones distintas. El programa debe ser clasificado de acuerdo a las características de la certificación que, en adelante, otorgue el mayor acceso a estudios más avanzados. El logro educativo de las personas que han completado un programa de estas características debe determinarse respecto de la certificación más alta otorgada a la persona (Ejemplos nacionales - Grupo 11).

Los usuarios de la clasificación que desean difundir resultados de acuerdo al conjunto simplificado de categorías de logro educativo establecidos en la CINE-A (por ej., en el nivel CINE de 1 dígito) deberán decidir en qué forma abordar la conclusión parcial del nivel. Dos enfoques diferentes son posibles dependiendo del objetivo principal del análisis:

i) Algunos usuarios podrían estar interesados en conocer el porcentaje de una población determinada que ha concluido exitosamente cada nivel CINE de educación. (Esto haría necesario clasificar la conclusión parcial del nivel a un nivel inferior que el correspondiente al estudio (por ej., a nivel primario, en el caso de conclusión parcial de educación secundaria baja).

ii) Otros usuarios podrían estar interesados en medir un estudio ampliamente reconocido en un nivel determinado, particularmente si esto pudiese representar un punto potencial de salida del sistema educativo o una "primera graduación" dentro de un nivel CINE dado. Estas personas optarían por clasificar la conclusión parcial del nivel en el mismo nivel CINE que corresponde al estudio (es decir, en el nivel de secundaria alta en el caso de conclusión parcial de la educación secundaria alta).

Ambos enfoque son válidos. El propio usuario o analista deberá determinar cual es el método más adecuado a sus circunstancias. Se recomienda indicar en los metadatos que acompañan a las estadísticas la modalidad de conclusión parcial aplicada al cálculo de indicadores de logro.

\section{EJEMPLOS DE PROGRAMAS Y CERTIFICACIONES CLASIFICADAS EN EL NIVEL CINE 3}

(§165) Los programas clasificados en el nivel CINE 3 pueden recibir distintas denominaciones, por ejemplo: escuela secundaria (segunda etapa/grados superiores), senior secondary school o (senior) high school. Para propósitos de comparación a nivel internacional, se usa el término "secundaria alta" para denominar al nivel CINE 3.

\section{Ejemplos nacionales - Grupo 1: \\ Programas generales que dan acceso a programas de primer título de educación terciaria (Niveles 6 o 7 de la CINE 2011) [CINE-P: 344; CINE-A: 344]}

Egipto - (Secundaria general). Este programa general de educación secundaria requiere estar en posesión del certificado de educación básica otorgado tras la exitosa conclusión de educación básica (CINE 2). El programa general de secundaria tiene una duración de tres años y sus graduados reciben el certificado de secundaria general que da acceso a niveles más avanzados de educación incluyendo programas de educación terciaria y no terciaria. (CINE-P/ CINE-A: 344)

Estonia - Üldkeskharidus (Educación general de nivel secundario). Este programa de tres años de duración conduce al certificado de estudios generales de secundaria alta que da acceso directo a programas Bakalaureuseõpe (programa de estudios de grado en educación terciaria). Los estudiantes ingresan al programa tras la exitosa conclusión de educación secundaria baja generalmente a la edad de 16 años. (CINE-P/ CINE-A: 344)

Francia - Enseignement de second cycle général du second degré conduisant au baccalauréat général ou technologique ou au brevet de technicien Educación secundaria general (segundo ciclo) que prepara para Bac général, technologique o Brevet de technicien. Este programa, cuyo requisito es la exitosa conclusión de educación secundaria baja, tiene una duración de tres años y representa la ruta típica que conduce a la educación terciaria. De hecho, prácticamente todas las personas que han logrado estas certificaciones cursan este tipo de programas de estudio. CINE-P/ CINE-A: 344) 
Alemania - Allgemeinbildende Programme im Sekundarbereich II (Escuelas de secundaria alta, general). Estos programas de educación general de nivel de secundaria alta (Gymnasiale Oberstufe), que comprende dos combinaciones de grados (del Décimo al Décimo Primero, o del Décimo Primero al Décimo Tercero), conducen a la Hochschulreife (certificación de admisión a la universidad). Los estudiantes que cursan programas tales como Gymnasium (incluyendo Berufliches Gymnasium), Integrierte Gesamtschule o Freie Waldorfschule (escuelas de gramática, polivalentes o escuelas Waldorf), han obtenido el certificado Mittlerer Schulabschluss (certificado de educación secundaria baja con acceso a secundaria alta). Los graduados de estos programas pueden ingresar a programas de nivel CINE 6 o 7. (CINE-P/ CINE-A: 344).

Arabia Saudita - (Educación general de nivel secundario). Este programa de educación general tiene una duración de tres años a tiempo completo y requiere la conclusión de la educación intermedia (CINE 2). Los graduados de estos programas reciben el certificado nacional de educación secundaria general que conduce a la educación terciaria. (CINE-P/ CINE-A: 344)

Swazilandia - Senior Secondary Certificate. Este programa de educación secundaria alta con una duración de dos años, se ofrece a graduados de educación secundaria baja y da acceso directo a todos los programas postsecundarios. La edad oficial de ingreso es de 19 años. (CINE-P/ CINE-A: 344)

Suiza - Gymnasiale Maturität, maturité gymnasiale, maturità (Escuelas que conducen al certificado de estudios). Estos programas generales, que tienen una duración de tres años y medio, están destinados a jóvenes que han concluido con éxito la educación secundaria baja y desean continuar sus estudios a nivel universitario. Los programas preparan a estos estudiantes para rendir su examen de admisión a la universidad. (CINE-P/ CINE-A: 344)

Ejemplos nacionales - Grupo 2:

Programas vocacionales diseñados para jóvenes que aspiran a insertarse directamente en el mercado laboral o de lo contrario abandonarían la escuela sin haber obtenido una certificación otorgada por un programa de secundaria alta [CINE-P: 351 o 353; CINE-A: 254 o 353]

Bulgaria - Profesionalni programi - parva stepen na profesionalna kvalifikatsiya sled 8 klas (Programas EFTV impartidos tras la conclusión de Octavo Grado que otorgan una certificación vocacional de primer nivel). Estos son programas vocacionales de dos años de duración ofrecidos a estudiantes que han concluido la educación secundaria baja, que conducen a la Profesionalni programi- parva stepen na profesionalna kvalifikatsiya (Certificación vocacional de primer nivel). Estos programas no conducen a un certificado de estudios de secundaria alta - Sredno obrazovanie - que da acceso directo a educación terciaria. Dado que el programa solo representa diez años de estudio a partir del comienzo de la educación primaria, se considera insuficiente para conclusión o conclusión parcial del nivel CINE 3. (CINE-P 351; CINE-A: 254)

Eslovenia - Nižje poklicno izobraževanje (Programas vocacionales cortos de secundaria alta). Estos programas vocacionales de dos a tres años de duración están diseñados para jóvenes que han finalizado con éxito nueve años de educación básica (obligatoria) o, en su defecto, un programa educativo modificado para niños con necesidades especiales de educación. El programa también está disponible para personas que asistieron nueve años a la escuela básica pero no lograron concluirla con éxito (es decir, cumplieron la "obligación de cursar la escuela básica"). De acuerdo a la ley, estos programas tienen dos a tres años de duración y finalizan con la rendición de un examen. Sus objetivos principales son reforzar los conocimientos generales adquiridos por los estudiantes en los últimos años de educación básica, impartir nuevos conocimientos generales y vocacionales, y otorgar certificaciones para ocupaciones de baja complejidad. (CINE-P/ CINE-A: 353)

\section{Ejemplos nacionales - Grupo 3: \\ Programas vocacionales que preparan para ocupaciones calificadas o técnicas [CINE-P: 353 o 354; CINE-A: 353 o 354]}

Australia - Certificate III. Estos son cursos vocacionales avanzados diseñados para técnicos, trabajadores especializados y oficios reconocidos. No se establecen requisitos formales mínimos de ingreso aunque los jóvenes que participan en el programa suelen tener entre 15 y 16 años. La duración típica de estos programas es de uno a dos años en el nivel CINE 3 o entre catorce y quince años a partir del comienzo del nivel CINE 1. Las personas que concluyen exitosamente estos programas si bien no tienen acceso a la educación terciaria pueden optar por los programas de Certificado IV a nivel 4 (CINE 2011) o ingresar al mercado laboral. (CINE-CINE-P/ CINE-A: 353) 
Francia - Enseignement de second cycle professionnel des écoles sociales conduisant aux diplômes de moniteurs éducateurs et équivalents (Educación secundaria vocacional (segundo ciclo) para escuelas especializadas en el cuidado y la salud que otorgan certificaciones de Moniteur éducateur (y equivalente). Estos son programas vocacionales en el área de servicios sociales (por ej., moniteur éducateur, technicien de l'intervention sociale et familiale - instructoreducador, técnicos en intervenciones en el ámbito social y familiar) diseñados para estudiantes de mayor edad que han concluido con éxito la educación secundaria baja. Suelen tener dos años de duración. Las certificaciones otorgadas son equivalentes al baccalauréat y dan acceso a programas de nivel terciario. (CINE-P/ CINE-A: 354)

Francia - Enseignement de second cycle professionnel du second degré conduisant au Baccalauréat Professionnel ou équivalent (Educación secundaria vocacional (segundo ciclo) que prepara para el Bac Professionnel). Este programa de tres años de duración se imparte principalmente en instituciones de formación y capacitación, si bien incluye períodos de capacitación en el empleo, y prepara a los participantes para ingresar al mundo del trabajo. También existe la opción de adquirir el Bac Professionnel a través de programas para el aprendizaje de oficios, donde el tiempo de instrucción se divide entre la institución educadora o capacitadora y el lugar de trabajo. La certificación da acceso directo al mercado laboral. Una minoría de los graduados continúa a estudios más avanzados fundamentalmente para recibir el Brevet de technicien supérieur (BTS) (Diploma de Técnico Avanzado) de nivel CINE 5. (CINE-P/ CINE-A: 354)

Alemania - Berufsschulen (Dual System) Erstausbildung (Capacitación en Escuelas Vocacionales (Sistema dual)). Esta es una modalidad especial de aprendizaje, que puede tener una duración de dos, tres (la mayoría de los casos), o tres años y medio, que requiere formación y capacitación tanto en escuelas vocacionales como en el lugar de trabajo. Para tener acceso a estos programas los estudiantes deben haber cursado el nivel CINE 2. El programa conduce a la certificación Lehrabschluss (Certificación del Sistema Dual). Los graduados pueden optar por ingresar al Fachoberschulen (un año) o al mercado laboral. (CINE-P/ CINE-A: 354)

Líbano - (Educación vocacional de nivel secundario). Este programa, que tiene una duración de tres años a tiempo completo, requiere la conclusión del nivel CINE 2 (general o vocacional). Generalmente, la edad de los participantes fluctúa entre los 15 y 17 años. Este programa vocacional de nivel secundario no da acceso directo a un nivel CINE más avanzado, a pesar de considerarse equivalente a la conclusión del nivel CINE 3. (CINE-P/ CINE-A: 353)

Eslovaquia ${ }^{2}$ - Stredá odborná škola - štúdium s maturity (Escuela secundaria especializada que conduce a maturita). Este es un programa de cuatro años de duración que ofrece educación general y vocacional orientada a mejorar el desempeño en actividades ocupacionales más exigentes. Tras su exitosa conclusión los participantes reciben una certificación general - Vysvedčenie o maturitnej skúške (maturita) - y una certificación vocacional Výučný list (certificado de aprendiz) - y pueden optar por la educación terciaria o por el mercado laboral. (CINE-P/ CINE-A: 354)

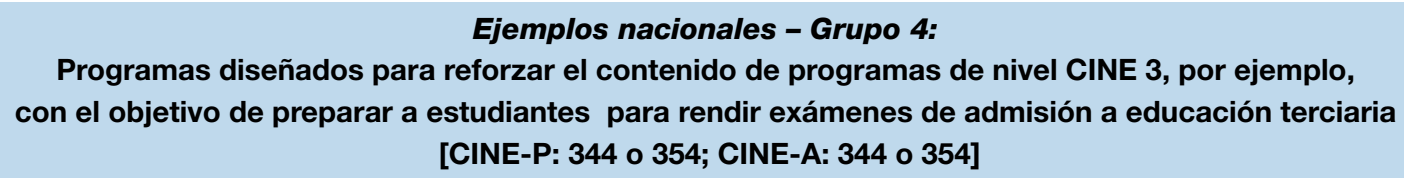

Australia - Enabling courses. Estos son programas suplementarios cortos (menos de un año de duración) impartidos por universidades a estudiantes desaventajados que necesitan mayor preparación antes de comenzar un curso que otorgue un reconocimiento formal, o a estudiantes universitarios que deben reforzar sus conocimientos en un campo específico de estudio. Los programas se han diseñado para reforzar estudios previos de educación secundaria alta para asegurar que los participantes están suficientemente preparados para iniciar sus estudios de educación terciaria. (CINE-P/ CINE-A: 344)

\section{Ejemplos nacionales - Grupo 5:}

Programas de reintegración o segunda oportunidad para estudiantes que aún no han finalizado educación secundaria alta [CINE-P: 343, 344, 353 o 354; CINE-A: 343, 344, 353 o 354]

Marruecos - (Capacitación vocacional: nivel de técnico). Este programa vocacional de dos años de duración se ofrece a estudiantes durante el último año de educación general de secundaria alta. Está orientado a ofrecer una segunda oportunidad a personas que han optado por cambiar su orientación de general a vocacional. Al finalizar el programa, los graduados reciben un diploma técnico que solo da acceso directo al mercado laboral. (CINE-P/ CINE-A: 353) 
Países Bajos - VAVO-HAVO en VAVO-VWO (Educación secundaria general para adultos). Estos programas de uno a tres años de duración a tiempo parcial conducen a las certificaciones oger algemeen voortgezet onderwijs (HAVO) y voorbereidend wetenschappelijk onderwijs (MWO) que dan acceso directo a programas de nivel terciario. Representan programas de segunda oportunidad y las contrapartes a tiempo parcial de los programas iniciales HAVO y WWO de dos y tres años de duración a tiempo completo, respectivamente. El requisito de ingreso es haber concluido la educación secundaria baja. Los programas de adulto conducen a las mismas certificaciones que los programas iniciales excepto que la edad típica de ingreso es de 18 años en lugar de 16. (CINE-P/ CINE-A: 344)

Eslovenia - Poklicni tecaj in poklicna matura (Curso vocacional que conduce a Matura vocacional). Este es un curso vocacional de un año de duración que hace las veces de puente entre la educación general y vocacional. Permite que estudiantes provenientes de escuelas secundarias superiores de orientación clásica, general u otras (o personas que han finalizado el último año de estos programas sin haber aprobado el examen general Matura), obtengan una certificación vocacional inicial. Por regla general, los cursos vocacionales que conducen al examen vocacional Matura conducen a las mismas certificaciones que los programas técnicos de secundaria alta de cuatro años de duración que dan acceso a la educación terciaria y al mercado laboral. (CINE-P/ CINE-A: 344)

\section{Ejemplos nacionales - Grupo 6: Programas que abarcan el nivel CINE 3 y otro nivel CINE}

Austria - Berufsbildende höhere Schule (Instituto superior técnico y vocacional). Programa vocacional de cinco años de duración que abarca los niveles CINE 3 (años 1 a 3) y CINE 5 (años 4 y 5). El requisito de ingreso a este programa es haber concluido la educación secundaria baja. La exitosa conclusión del tercer año otorga una certificación secundaria de orientación vocacional (nivel CINE 3) en tanto que la certificación final (después de cinco años) equivale directamente a otras certificaciones de nivel CINE 5. También da crédito para transferencias a programas de nivel CINE 6 y 7 en campos de estudio relacionados. El programa prepara a los estudiantes para desempeñarse en ocupaciones de nivel más alto en la areas de ingeniería, comercio, artes y oficios, turismo, servicios domésticos, enseñanza en jardines infantiles y otros. (Años 1 a 3: (CINE-P/ CINE-A: 354; Años 3 y 4: (CINE-P; 554; CINE-A: 550)

Kazajstán - Техническое и профессиональное образование по подготовке кадров по массовым профессиям технического и обслуживающего труда (Capacitación técnica y vocacional en ocupaciones técnicas). Estos programas tienen una duración de tres a cuatro años y establecen como requisito la conclusión de la educación secundaria baja. Están diseñados para capacitar trabajadores calificados confieréndoles el certificado de conclusión de educación secundaria alta (аттестат об общем среднем образовании) tras los dos primeros años de estudio y un diploma téncnicovocacional que incluye una certificación técnica (диплом о техническом и профессиональном образовании с присвоением технической квалификации) tras la conclusión del tercer o cuarto año. Estos programas abarcan los niveles CINE 3 (en el caso de los primeros dos años) y CINE 4 (en el caso del tercer y cuarto año). (Años 1 y 2: CINE-P/ CINE-A: 353; Años 3 y 4: CINE-P/ CINE-A: 454)

Kazajstán - Техническое и профессиональное образование по подготовке специалистов среднего звена и предусматривающие овладение сложными (смежными) профессиями и практическими навыками выполнения работ во всех отраслях экономики, связанными с высокими технологиями и профессиональной деятельностью (Сарасіtación técnica y vocacional de directivos intermedios que incluye el dominio de oficios y destrezas de alta complejidad que implican el uso de tecnología de alto nivel). Estos programas de cuatro a cinco años de duración tienen como requisito la conclusión de educación secundaria baja y su objetivo es impartir conocimientos y desarrollar destrezas para ocupaciones que requieren algún grado de estudios de nivel terciario. Los programas otorgan el certificado de conclusión de educación secundaria alta y un diploma técnico-vocacional que incluye una certificación técnica (диплом о техническом и профессиональном образовании с присвоением профессиональной классификации) al finalizar el cuarto o quinto año. Estos programas abarcan los niveles CINE 3 (en el caso de los dos primeros años) y CINE 5 (en el caso del tercer a quinto año). (Años 1 y 2: CINE-P/ CINE-A: 354; Años 3 a 5: CINE-P: 554; CINE-A: 550)

Ejemplos nacionales - Grupo 7:

Programas que conducen a la conclusión parcial del nivel (o certificaciones derivadas de la conclusión parcial del nivel) [CINE-P: 342 o 352; CINE-A: 342 o 352 ]

Ex República Yugoeslava de Macedonia ${ }^{3}$ - Strucno osposobuvanje (Capacitación vocacional). Este es un programa vocacional de dos años de duración que se imparte una vez finalizada la educación secundaria baja. Confiere un 
diploma que da acceso a los egresados a programas vocacionales de tres o cuatro años de duración a nivel de secundaria alta (Sredno obrazovanie - redovno or Sredno obrazovanie - redovno strucno). Estos últimos, dan acceso directo a la educación terciaria. Por su parte, el programa de capacitación de dos años de duración está diseñado para dar acceso a otros programas a nivel de secundaria alta y por consiguiente forma parte de la secuencia de programas dentro del nivel CINE. (CINE-P/CINE-A: 352)

Lituania - Profesinio mokymo programa, skirta asmenims, turintiems pagrindinị išsilavinimą ir nesiekiantiems vidurinio išsilavinimo (Programas de educación vocacional para personas con educación básica que no proyectan obtener el certificado otorgado al finalizar la educación secundaria (Brandos atestatas)). Estos son programas de dos años de duración diseñados para personas que han concluido educación secundaria baja y solo conducen a un reconocimiento formal de certificación vocacional (Profesinès kvalifikacijos pažyméjimas). Los egresados de estos programas tienen acceso al programa vocacional (Profesinio mokymo programa, skirta asmenims, turintiems pagrindini išsilavinimą ir siekiantiems vidurinio išsilavinimo) de tres años de duración, que también conduce al certificado Brandos atestatas. Si bien las personas que finalizan con éxito el programa vocacional de dos años podrían ingresar al mercado laboral, el objetivo principal del programa es dar acceso a otro programa que permita concluir la educación secundaria alta. Por lo tanto, este último programa puede ser considerado como parte de la secuencia de programas dentro del nivel CINE. (CINE-P/CINE-A: 352)

Malasia - Menengah Atas (Secundaria alta). Este es un programa general de educación secundaria alta de dos años de duración que se imparte tras la conclusión de educación secundaria baja. Al final del último grado de este programa (Form 5), los estudiantes rinden un examen que otorga el certificado de educación malasio (Sijil Pelajaran Malaysia (SPM)) que, a su vez, conduce al programa de educación secundaria alta Pra Universiti de dos años de duración, que conduce a la educación terciaria. El examen SPM se rinde tras haber cursado once años de educación a partir del comienzo del nivel CINE 1. (CINE-P/CINE-A: 342)

Reino Unido - General Certificate of Secondary Education (GCSE). Este es un programa general de dos años de duración que se imparte al final de educación secundaria baja. Hasta hace poco, marcaba el final de la educación obligatoria en el país, y por consiguiente representaba el primer punto importante de salida del sistema educativo. Los estudiantes cursan varios programas GCSE, típicamente de ocho a diez, en distintas asignaturas cada una de las cuales se evalúa en forma separada en base al rendimiento en los cursos y el puntaje en el examen final. A cada asignatura se le asigna una calificación desde $A^{*}$ (la más alta) hasta G (la más baja) o U (no especificada) en caso de no aprobación. Las autoridades nacionales consideran que la aprobación de 5 o más asignaturas con calificaciones $A^{*}$-C representa la conclusión parcial de secundaria alta. Típicamente, este constituye el requisito mínimo de ingreso a estudios más avanzados a nivel de secundaria alta (vocacional o general) y da acceso a la educación terciaria y/o al mercado laboral en ocupaciones específicas. El programa GCSE, representa una secuencia dentro del nivel CINE no siendo el programa final de la secuencia. Esencialmente, representa once años de estudio a partir del comienzo de la educación primaria y dos años más en secundaria alta. Cinco o más aprobaciones en grados avanzados/con calificaciones altas cubren un rango razonable del currículo de secundaria alta y por consiguiente se considera un certificación reconocida. Esta certificación no da acceso a la educación postsecundaria no terciaria ni a la educación terciaria. (CINE-P/CINE-A: 342)

\section{Ejemplos nacionales - Grupo 8: \\ Programas de nivel CINE 3 insuficientes para conclusión o conclusión parcial del nivel que por lo tanto conducen a un logro educativo de nivel CINE 2 [CINE-P: 341 o 351; CINE-A: 244 o 254]}

Bangladesh - Secondary school vocational certificate. Este es un programa vocacional de dos años de duración que requiere la aprobación de Junior Secondary (Nivel CINE 2). Al finalizar el programa, que se imparte en escuelas e institutos técnicos de educación superior tanto públicos como no gubernamentales, los graduados reciben el certificado Secondary School Vocational Certificate (SSC-Voc). La duración acumulada a partir del comienzo del nivel CINE 1 es de solo diez años. Por lo tanto, el programa es insuficiente para conclusión o conclusión parcial del nivel CINE 3. (CINE-P: 351; CINE-A: 254)

Bulgaria - Profesionalno obuchenie za vazrastni - treta stepen PK (Capacitación técnica para adultos - certificación ocupacional de tercer nivel). Este programa vocacional para adultos tiene un año y medio de duración. Está diseñado para conducir directamente el mercado laboral. (CINE-P: 351; CINE-A: 254) 
Nueva Zelanda - Year 11 - National Certificate of Educational Achievement 1 (NCEA 1). Este es el primero de una secuencia de tres programa generales de un año de duración que conforman la trayectoria típica de educación secundaria alta. El NCEA 1 representa el primer punto importante de salida del sistema educativo. El NCEA 1 forma parte de una secuencia de programas que representan once años de estudio a partir del comienzo de la educación primaria pero solo un año de estudio a nivel de secundaria alta. Esta certificación no da acceso a la educación postsecundaria no terciaria ni a la educación terciaria. (CINE-P: 341; CINE-A: 244)

Zambia - Trade Test Level Il Certificate. Este programa vocacional se ofrece a personas que han finalizado la educación secundaria baja y tienen por lo menos un año de experiencia laboral o a personas que han obtenido un certificado de educación primaria y acumulan por lo menos tres años de experiencia laboral. La duración de este programa puede fluctuar entre seis meses y un año, tiempo considerado insuficiente para la conclusión del nivel CINE 3. (CINE-P: 351; CINE-A: 254)

\section{Ejemplos nacionales - Grupo 9:}

Programas /certificaciones vocacionales que dan acceso a la educación terciaria [CINE-P: 354; CINE-A: 354]

Japón - Koutou senmon gakko (Instituto Superior de Tecnología, primer a tercer año). Ingreso al Koutou senmon gakko tiene como requisito la conclusión de educación obligatoria. El propósito de este programa es desarrollar ingenieros que muestren potencial e impartir cinco años de educación general (los primeros tres años equivalen al nivel CINE-P 354 y el cuarto y quinto al nivel CINE-P 554). La mayoría de los estudiantes que han finalizado los primeros tres años, además de tener acceso al cuarto año (CINE-P 554), obtendrán una certificación que les permite postular a estudios universitarios (CINE 6 o 7). (Los primeros tres años en el Koutou senmon gakko: CINE-P/CINE-A: 354)

Kuwait - (Diploma de enfermería). Este programa vocacional requiere la exitosa conclusión del Noveno Grado, el último grado de educación secundaria baja, como mínimo. Pese a que la edad teórica de ingreso es de 15 años, en la práctica se aproxima a los 17 años debido a múltiples repeticiones. La exitosa conclusión de este programa de tres años de duración se considera equivalente a la conclusión del nivel. Los egresados pueden continuar sus estudios a nivel de educación terciaria. (CINE-P: 354; CINE-A: 354)

Países Bajos - WEB-middenkaderopleiding, voltijd bol en bbl (Educación vocacional, capacitación de personal directivo intermedio, (nivel 4); programas educativos pertenecientes al sistema dual, ofrecidos en escuelas bajo la modalidad tiempo completo). Este programa vocacional de tres años de duración se imparte, típicamente, tras la exitosa conclusión de un programa pre-vocacional de secundaria baja de cuatro años de duración (Voorbereidend middelbaar beroepsonderwijs (VMBO) (beroepsgerichte, gemengde en theoretische leerwegen)). El país también cuenta con un programa a tiempo parcial que conduce a la misma certificación (MBO niv.4: middenkaderfunctionaris), si bien sus participantes suelen ser mayores que los matriculados a tiempo completo. (CINE-P/CINE-A: 354)

Ejemplos nacionales - Grupo 10:

Programas /certificaciones que conducen a la conclusión de educación secundaria alta pero no dan acceso a educación terciaria [CINE-P: 343 o 353; CINE-A: 343 o 353]

Afganistán - Talimate Takhniki wa Maslaki (Educación técnica y vocacional (Décimo a Decimocuarto Grado)). La duración teórica de este programa vocacional es de cinco años tras la exitosa conclusión del Noveno Grado (CINE 2). Los graduados de este programa reciben el certificado Shahadat Naama que da acceso directo al mercado laboral y a programas de nivel terciario. Los tres primeros grados del programa se clasifican a nivel de secundaria alta. (Décimo a Duodécimo Grado: CINE-P/CINE-A: 353; Décimo tercero y Decimocuarto Grado; CINE-P/CINE-A: 454)

Alemania - Beamtenausbildung (mittlerer Dienst) (Capacitación para funcionarios públicos (nivel intermedio)). Este programa tiene una duración de dos años y ofrece capacitación a futuros funcionarios públicos que aspiran a cargos directivos de nivel intermedio. La admisión a este programa requiere el certificado de educación media o una certificación reconocida equivalente. El programa se ofrece en instituciones de administración pública en todos los niveles regionales (Bund, Länder, Regierungsbezirke, Kreise, Gemeinden) y en escuelas especializadas en administración pública. Los graduados de este programa son elegibles a cargos en la administración pública. El programa no da acceso a la educación terciaria. (CINE-P/CINE-A: 353) 
Israel - Batey sefer taasiyatiim le hanihim, misrad ha-kalkala, tlat shnati (Escuelas industriales y para el aprendizaje de oficios, Ministerio de Economía, tres años de duración). Este es un programa vocacional de tres años de duración cuyo ingreso requiere la exitosa conclusión de educación secundaria baja. Los egresados de estas escuelas pueden continuar su educación participando en programas preparatorios cortos (entre siete y diez meses) diseñados para ingenieros o profesiones afines (Mechina kdam handasaim) si bien la mayoría ingresa directamente al mercado laboral. Un número reducido de egresados continúa sus estudios en educación postsecundaria no terciaria. (CINE-P/CINE-A: 353)

Seychelles - Upper secondary education programme. Este es un programa general de secundaria alta de dos años de duración que tiene como requisito la conclusión de educación secundaria baja. Los egresados de este programa reciben el certificado Secondary Five National Examination Certificate o IGCSE (Cambridge) o DELF Scolaire (Diplôme d'Études en Langue Française), que da acceso directo a la educación postsecundaria no terciaria, aunque no a la educación terciaria. (CINE-P/CINE-A: 343)

\section{Ejemplos nacionales - Grupo 11: \\ Programas que conducen a más de una certificación (y sus respectivos logros académicos) [Cualquier código CINE-P o CINE-A de nivel CINE 3]}

Polonia - Trzyletnie liceum ogólnokształcące (General upper secondary school). (Educación general de secundaria alta). Este programa de tres años de duración requiere la conclusión de educación secundaria baja y conduce al certificado de estudios (Świadectwo ukończenia liceum ogólnokształcącego (wykształcenie średnie)) conferido a todos los estudiantes que finalizan el programa. Los estudiantes que desean seguir estudios universitarios deben optar por el certificado de matrícula (Matura - świadectwo dojrzałości), requisito de admisión indispensable para este nivel. Sin embargo, el logro educativo conferido a los egresados dependerá de las certificaciones acumuladas al final del programa. El certificado de estudios no es suficiente para ingresar a la educación terciaria de manera que se clasifica como CINE-A 343, en tanto que al certificado Matura se le asigna el código CINE-A 344. (CINE-P: 344 CINE -A: 343 o 344)

\section{Notas}

1. Los números de los párrafos refieren al documento de clasificación CINE 2011. Para mayores detalles, sírvase consultar la Guía del Lector.

2. El Instituto de Estadística de la UNESCO (UIS) y la Unión Europea (UE) utilizan "Eslovaquia" como el nombre oficial de la "República Eslovaca".

3. El Instituto de Estadística de la UNESCO (UIS) utiliza "La Ex República Yugoslava de Macedonia" como el nombre oficial de "Ex República Yugoslava de Macedonia". 


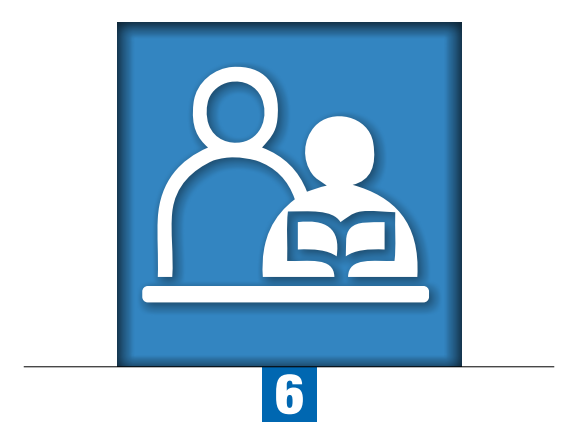

Capítulo 6

\section{Nivel 4 - CINE 2011:}

\section{Educación postsecundaria no terciaria}

Los programas de educación postsecundaria no terciaria no suelen ser mucho más avanzados que los programas de educación secundaria alta. Estos programas se caracterizan por ampliar - en lugar de profundizar los conocimientos, las destrezas y competencias de personas que han exitosamente concluido la educación secundaria alta. Pueden tener la finalidad de mejorar las probabilidades de inserción de los participantes en el mercado laboral o de acceso al nivel terciario, o ambas.

Generalmente, los programas clasificados en el nivel CINE 4 tienen una orientación vocacional. Estos pueden recibir distintas denominaciones, por ejemplo: diploma técnico, préparation aux carriéres administratives y primary professional education. Para propósitos de comparación a nivel internacional, se usa el término "postsecundaria no terciaria" para denominar al nivel CINE 4. 


\section{DESCRIPCIÓN}

\section{Definición}

$(\$ 185)^{1}$ La educación postsecundaria no terciaria refuerza los conocimientos adquiridos en educación secundaria, prepara para el mercado laboral y para la educación terciaria. Las destrezas, competencias y conocimientos impartidos en este nivel se encuentran debajo del nivel de complejidad que caracteriza a la educación terciaria. Los programas de nivel CINE 4, o educación postsecundaria no terciaria están generalmente diseñados para proporcionar a las personas que han concluido el nivel CINE 3 las certificaciones no terciarias requeridas para avanzar a la educación terciaria, o bien para insertarse en el mercado laboral en el caso que sus certificaciones de nivel CINE 3 no otorgaran acceso a este nivel. Por ejemplo, los graduados de programas generales de nivel CINE 3 pueden optar por una certificación vocacional no terciaria. Por su parte, los graduados de programas vocacionales de nivel CINE 3 pueden optar por mejorar su nivel de certificación o perfeccionar su especialización. El contenido de los programas de nivel CINE 4 no es lo suficientemente complejo para ser considerado como educación terciaria; sin embargo claramente forma parte de la educación postsecundaria.

(\$187) Generalmente, los programas de este nivel están destinados a proporcionar acceso directo al mercado laboral. Algunos sistemas educativos ofrecen programas generales de este nivel que normalmente están dirigidos a estudiantes que han concluido el nivel CINE 3, pero que desean mejorar sus posibilidades de ingreso a la educación terciaria.

\section{Criterios de clasificación (\$189)}

\section{Criterios principales}

a) Orientación

(§190) Los programas de nivel CINE 4 no forman parte de la educación terciaria, siendo más bien programas vocacionales y terminales que preparan para el mercado laboral. Algunos sistemas educativos ofrecen programas generales de este nivel. Los programas destinados a actualizar los contenidos de programas de nivel CINE 3 por ejemplo, con el fin de preparar a los estudiantes para rendir exámenes de ingreso a la educación terciaria - se deben incluir en el nivel CINE 3.

b) Complejidad del contenido superior a la del nivel CINE 3 e inferior a la del nivel de educación terciaria

(§191) Con frecuencia, los programas de nivel CINE 4, se caracterizan por ampliar - en lugar de profundizar conocimientos, destrezas y competencias de las personas que han finalizado un programa de nivel CINE 3 . Si bien estos programas no suelen ser mucho más avanzados que los programas de nivel CINE 3 , su contenido se caracteriza por ser más especializado o detallado que los impartidos a nivel de educación secundaria alta. Claramente, estos programas son menos avanzados que los impartidos a nivel terciario en tanto que pueden impartirse en diversos entornos institucionales y, por lo tanto, no solamente en aquellas instituciones consideradas exclusivamente de educación postsecundaria no terciaria.

c) Requisitos de ingreso

(§186) El ingreso a programas de nivel CINE 4 requiere la conclusión de un programa de nivel CINE 3 . Sin embargo, estos requisitos de ingreso pueden ser menores que los exigidos para ingresar a programas terciarios de los niveles CINE 5, 6 o 7.

\section{Criterios subsidiarios}

Ninguno. 


\section{Dimensiones complementarias}

(§193) Dos dimensiones permiten diferenciar los programas educativos del nivel CINE 4:

(§194) Orientación del programa:

- General; y

- Vocacional

(§195) Conclusión del nivel y acceso a niveles CINE más avanzados;

- Nivel CINE 4 inconcluso: módulos o etapas de programas considerados demasiado cortos para la conclusión del nivel. Estos no dan acceso a programas de primer título de educación terciaria de niveles CINE 5, 6 o 7. La conclusión exitosa de dichos módulos o etapas no equivale a la conclusión del nivel CINE 4.

- Conclusión del nivel CINE 4 sin acceso directo a programas de primer título de educación terciaria de niveles CINE 5, 6 o 7 (programas esencialmente destinados a preparar al estudiante para el mercado laboral).

- Conclusión del nivel CINE 4 con acceso directo a programas de primer título de educación terciaria de nivel CINE 5, 6 o 7: programas destinados principalmente a ampliar el acceso a la educación terciaria.

(§198) En términos de logro educativo, las certificaciones intermedias otorgadas por la conclusión de una etapa de un programa de nivel CINE 5 que no se consideran suficientes para la conclusión de la educación terciaria se clasifican en el nivel CINE 4.

\section{CORRESPONDENCIA ENTRE LOS NIVELES CINE 2011 Y CINE 1997}

(§279) El nivel 4 de la CINE 2011, educación postsecundaria no terciaria, corresponde mayormente al nivel 4 de la CINE 1997. Sin embargo, en la CINE 2011 los programas que otorgan una certificación equivalente a la educación secundaria alta general se clasifican en el nivel 3 en circunstancias que en la CINE 1997 con frecuencia se clasificaban en el nivel 4. Asimismo, debido a la clarificación de los criterios principales y subsidiarios, es posible que la CINE 2011 y la CINE 1997 difieran respecto de sus implementaciones. En el caso de algunos países, estas diferencias podrían afectar los datos de series de tiempo.

En la versión CINE más reciente, las dimensiones complementarias del nivel CINE 4 son diferentes.

a) Orientación del programa

La CINE 1997 define tres tipos de orientación: general, pretécnica y vocacional. En la CINE 2011 se consideran solo dos orientaciones en el nivel CINE 4: general y vocacional. Los programas previamente clasificados como pretécnicos (en la CINE 1997) no otorgan certificaciones pertinentes al mercado laboral y en la actualidad se clasifican esencialmente bajo la denominación "educación general".

b) Conclusión del nivel y destino del programa

La CINE 1997 clasifica los programas en base a los programas y niveles a que finalmente conducen (destino de los programas). En el caso del nivel CINE 4, se han definido tres destinos:

Destino A: programas que preparan para ingresar a la educación terciaria (nivel 5 de la CINE 1997);

Destino B: programas que no dan acceso a la educación terciaria (diseñados principalmente para inserción directa al mercado laboral).

La CINE 2011 clasifica sus programas de acuerdo al tipo de conclusión del nivel y acceso a otros y niveles. El destino A de la CINE 1997 es directamente equivalente a la subcategoría "conclusión" del nivel 4 de la CINE 2011 que otorga acceso directo a la educación terciaria. El destino B de la CINE 1997 se divide en las siguientes subcategorías de la CINE 2011:

- conclusión del nivel 4 (CINE 2011) sin acceso directo a la educación terciaria; e

- insuficiente para conclusión del nivel 4 (CINE 2011). 


\section{DIRECTRICES PARA CLASIFICAR PROGRAMAS Y SUS CERTIFICACIONES RELACIONADAS RECONOCIDAS EN EL NIVEL 4 DE LA CINE}

Los programas de educación postsecundaria no terciaria no suelen ser mucho más avanzados que los programas de educación secundaria alta. Estos programas se caracterizan por ampliar - en lugar de profundizar - los conocimientos, las destrezas y competencias de personas que han exitosamente concluido la educación secundaria alta. Pueden tener la finalidad de mejorar las probabilidades de inserción de los participantes en el mercado laboral o de acceso al nivel terciario, o ambas.

Los programas diseñados para conducir a certificaciones adicionales de secundaria alta o dar acceso a un espectro más amplio de ocupaciones que las contempladas en este nivel deben clasificarse en el nivel CINE 4. Esto incluye programas vocacionales de segundo ciclo cuya duración total de estudios (acumulada) a partir del comienzo del nivel CINE 3 es significativamente mayor que la un programa general de secundaria alta que da acceso directo a los primeros títulos del nivel CINE 6 o 7. Los programas vocacionales que se imparten en forma paralela a otros programas de educación secundaria alta, normalmente deben clasificarse en el nivel CINE 3.

Generalmente, los programas de nivel CINE 4 tienen una orientación vocacional y ofrecen a las personas que han concluido la educación secundaria alta, la oportunidad de adquirir los conocimientos, las destrezas y competencias que una ocupación específica requiere. En muchos casos estos programas vocacionales postsecundarios no terciarios han sido diseñados exclusivamente para conducir al mercado laboral y no dan acceso a la educación terciaria. Estos programas se clasifican como CINE-P: 453; CINE-A: 453 (véanse Ejemplos nacionales - Grupo 1).

Algunos sistemas educativos también ofrecen programas generales postsecundarios no terciarios. Generalmente, estos están destinados a estudiantes que han concluido la educación secundaria alta pero desean mejorar sus posibilidades de ingreso a la educación terciaria (§187). Es posible que un estudiante haya finalizado un programa vocacional de educación secundaria alta con anterioridad y, en consecuencia, desee obtener la certificación de educación secundaria general. Por otra parte, la persona puede haber completado su educación secundaria general pero desea ampliar sus conocimientos en asignaturas o campos específicos para mejorar sus probabilidades en el proceso de admisión a la educación terciaria. Estos programas se clasifican como CINE-P: 444; CINE-A: 444 (véanse Ejemplos nacionales - Grupo 2).

Los programas de segunda oportunidad o de reintegración, han sido diseñados para personas que no concluyeron con éxito la educación secundaria alta, o desean mejorar las calificaciones obtenidas en certificaciones ya adquiridas en secundaria alta, o intentan cambiar de trayectoria académica - generalmente de general a vocacional - con el fin de ingresar a programas u ocupaciones de secundaria alta para los cuales las certificaciones existentes de este nivel no dan acceso, deben clasificarse en el nivel CINE 3 (El capítulo sobre el nivel CINE 3 presenta algunos ejemplos).

Es probable que algunos programas vocacionales de nivel CINE 4 también hayan sido diseñados para dar acceso a la educación terciaria a estudiantes que previamente carecían de este acceso, o para mejorar y ampliar las oportunidades de estudio en el nivel terciario pese a que la certificación anterior de secundaria alta ya le daba acceso a la educación terciaria. Asimismo, otros programas de nivel CINE 4 pueden dar acceso tanto al mercado laboral como a la educación terciaria. Asumiendo que todos los demás criterios del nivel CINE 4 se han cumplido, todos estos programas se pueden considerar equivalentes a la conclusión del nivel CINE 4 con acceso a la educación terciaria (véanse Ejemplos nacionales - Grupo 3).

En ocasiones puede ser difícil determinar si un programa de postsecundaria no terciaria da acceso a la educación terciaria por primera vez, o si mejora las oportunidades de acceso en circunstancias que el estudiante ya tiene acceso al nivel terciario, o si el programa no se ha diseñado para dar acceso más amplio a programas de educación terciaria incluso si la certificación anterior requerida para ingresar al programa ya le daba acceso a este nivel (véanse Ejemplos nacionales - Grupo 4). A continuación se presenta un cuadro ilustrativo de casos posibles.

\begin{tabular}{l|l|l}
\hline $\begin{array}{l}\text { Se requiere acceso desde } \\
\text { programas CINE } 3 \text { para ingresar }\end{array}$ & Acceso desde programas CINE 4 & $\begin{array}{l}\text { Codificación de tercer dígito CINE-P y } \\
\text { CINE-A) }\end{array}$ \\
\hline $\begin{array}{l}\text { Sin acceso directo a educación } \\
\text { terciaria }\end{array}$ & $\begin{array}{l}\text { Acceso directo a educación terciaria } \\
\text { por primera vez }\end{array}$ & $\begin{array}{l}444 / 454-\text { conclusión con acceso directo a } \\
\text { educación terciaria }\end{array}$ \\
\hline Acceso directo a educación terciaria & $\begin{array}{l}\text { Acceso directo más amplio a } \\
\text { educación terciaria }\end{array}$ & $\begin{array}{l}444 / 454-\text { conclusión con acceso directo a } \\
\text { educación terciaria }\end{array}$ \\
\hline Acceso directo a educación terciaria & $\begin{array}{l}\text { Sin acceso más amplio a educación } \\
\text { terciaria }\end{array}$ & $\begin{array}{l}\text { CINE-P: 443/453 - conclusión sin acceso } \\
\text { directo a educación terciaria } \\
\text { CINE-A: 444/454 - dado que el estudiante ya } \\
\text { tenía acceso a educación terciaria }\end{array}$ \\
\hline
\end{tabular}


El requisito de ingreso a programas de nivel CINE 4 es la exitosa conclusión del nivel CINE 3. Esto significa la exitosa conclusión de un programa de educación secundaria alta cuya clasificación corresponde a la conclusión de este nivel de educación (es decir, CINE-P/CINE-A: 343, 353, 344 o 354). Los programas que siguen a uno de nivel CINE 3 pero no conducen a la conclusión del nivel deben clasificarse en el nivel CINE 3.

Los programas de nivel CINE 4 suelen estar destinados a personas que han superado la edad de ingreso a la educación secundaria alta. Los requisitos de ingreso pueden incluir certificaciones educativas y un período de experiencia laboral pertinente (véanse Ejemplos nacionales - Grupo 5).

Típicamente, los programas de nivel CINE 4 tienen una duración equivalente a tiempo completo que fluctúa entre 6 meses y dos años. Los programas de más de dos años de duración deben clasificarse en el nivel CINE 4. Sin embargo, en el caso de programas que se prolongan bastante más de dos años, es aconsejable realizar algún tipo de evaluación sobre el nivel de complejidad. Se debe tener especial rigurosidad al momento de clasificar programas muy largos de nivel CINE 4. En estos casos, el criterio clave para establecer la distinción entre la educación postsecundaria no terciaria (nivel CINE 4) y la educación terciaria de ciclo corto (nivel CINE 5) es el grado de complejidad del programa (véanse Ejemplos nacionales - Grupo 6).

Normalmente, si programas de distintas duraciones conducen a la misma certificación, o a certificaciones reconocidas como equivalentes, se deben clasificar en el mismo nivel CINE. Sin embargo, considerando que el nivel CINE 4 no es significativamente más avanzado que algunos programas de nivel CINE 3 - en particular los programas de segundo ciclo, o los que conducen a certificaciones distintas a las ya obtenidas en secundaria alta - esto podría dar origen a certificaciones otorgadas a otras personas que participan en programas de educación secundaria alta. La equivalencia de las certificaciones no es motivo suficiente para clasificar un programa en el nivel CINE 3. Por otra parte, a nivel nacional algunas certificaciones de nivel CINE 4 son reconocidas como "más avanzadas" que las ofrecidas en el nivel CINE 3. Cuando este es el caso, se debe considerar que todos los programas que conducen a esta certificaciones "más avanzadas" son programas que abarcan los niveles CINE 3 y 4 o programas de nivel CINE 4.

Los programas de educación postsecundaria no terciaria pueden recibir distintas denominaciones (véase §188). No obstante, es importante clasificar los programas no en base a su denominación o institución que los imparte sino por el nivel de complejidad, $x x$ desde una perspectiva internacional. Asimismo, cabe destacar que los programas de nivel CINE 4 pueden ser impartidos en una variedad de entornos institucionales, no solo en las instituciones tradicionalmente consideradas de educación postsecundaria no terciaria $(\$ 191,52)$. Por consiguiente, el tipo de institución o proveedor de educación nunca debe utilizarse como criterio principal para hacer la distinción entre el nivel CINE 4 y la educación terciaria o secundaria (véanse Ejemplos nacionales - Grupo 7).

\section{Distinción entre el nivel CINE 4 y el nivel CINE 5}

El criterio clave para distinguir entre la educación postsecundaria no terciaria y la educación terciaria de ciclo corto es la complejidad del contenido del programa. Los programas de ambos niveles tiene como requisito de ingreso la conclusión de la educación secundaria alta. Los programas de nivel CINE 4 amplían los conocimientos del estudiante en algunos campos de estudio. Sin embargo, estos no son significativamente más avanzados que los programas de nivel CINE 3. El nivel CINE 5 es bastante más avanzado que el nivel CINE 3. Los programas de nivel CINE 5 profundizan los conocimientos, destrezas y competencias de los participantes en un dominio determinado.

Las certificaciones de nivel CINE 5 se consideran de un nivel superior a las otorgadas por el nivel CINE 4. Los programas de educación terciaria de ciclo corto pueden dar créditos para transferir al primer título de educación terciaria programas de nivel CINE 6 o 7. Tras la conclusión del nivel CINE 5, las personas pueden tener acceso directo a estos programas terciarios de primer título y quedar liberados de tomar algunos cursos o módulos impartidos en este nivel. Los programas de nivel CINE 4 conducen a certificaciones que son levemente más avanzadas que las certificaciones de nivel CINE 3 y que en algunos casos conducen a las mismas certificaciones que otorga el nivel CINE 3. Estos programas no dan crédito para estudios de nivel terciario.

\section{LOGRO EDUCATIVO EN EL NIVEL CINE 4}

El logro educativo en el nivel CINE 4 requiere la exitosa conclusión (que conduzca a una certificación reconocida) de un programa que represente una duración acumulada mínima de 6 meses en el nivel CINE 4. 
El nivel CINE 4 también incluye módulos o etapas de programas con una duración inferior a seis meses y son, por lo tanto, demasiado cortos para determinar la conclusión del nivel. En términos de logro educativo, la exitosa conclusión de estos módulos o etapas de programas se clasificarían en el nivel CINE 3.

En igual forma, el logro educativo asignado a las certificaciones derivadas de la exitosa conclusión de programas de nivel CINE 5 que sin embargo no cumplen los criterios de conclusión del nivel, debe corresponder al nivel CINE 4, incluso si el país no contara con este nivel (véanse Ejemplos nacionales - Grupo 7 en el capítulo nivel CINE 5).

\section{EJEMPLOS DE PROGRAMAS Y CERTIFICACIONES CLASIFICADAS EN EL NIVEL CINE 4}

(§188) Los programas clasificados en el nivel CINE 4 pueden recibir distintas denominaciones, por ejemplo: diploma técnico, préparation aux carriéres administratives y primary professional education. Para propósitos de comparación a nivel internacional, se usa el término "postsecundaria no terciaria" para denominar al nivel CINE 4.

Ejemplos nacionales - Grupo 1:
Programas vocacionales de nivel CINE 4 suficientes para conclusión del nivel, diseñados para dar acceso
al mercado laboral (sin acceso directo a la educación terciaria) [CINE-P: 453; CINE-A: 453]

Egipto - (Últimos dos años del programa técnico de cinco años de duración) Este programa vocacional largo requiere la conclusión del nivel de educación preparatoria (CINE 2). Al final del programa, los graduados reciben un primer diploma técnico que solo conduce al mercado laboral. Un diploma similar se otorga tras la conclusión de otro programa vocacional postsecundaria de dos años de duración (ya clasificado en el nivel CINE 4). Para efectos de reportar a nivel internacional, se considera que este programa largo abarca los niveles CINE 3 y 4 . Los primeros tres grados se clasifican como conclusión de educación secundaria alta sin acceso a la educación terciaria (CINE-P/CINE-A: 453)

Irlanda - Teagasc Advanced Certificate in Agriculture. La duración de este programa de capacitación de orientación vocacional puede fluctuar de un año y medio a tres años, existiendo también programas de tres años. El requisito mínimo de ingreso es la conclusión de educación secundaria alta. Los egresados del programa reciben el Certificado Avanzado de Agricultura otorgado por la Teasgasc (Autoridad Irlandesa para el Desarrollo de la Agricultura y la Alimentación), que conduce directamente al mercado laboral. (CINE-P/CINE-A: 453)

España - Certificados de Profesionalidad de nivel 3. Estos programas preparan para el mercado laboral y tienen como requisito de ingreso la conclusión de la educación secundaria alta. Las personas que puedan demostrar aptitudes para cursar estos programas o que hayan recibido la certificación Certificado de Profesionalidad de nivel 2 en el mismo campo de estudio también tienen acceso a ellos. La duración del programa fluctúa entre seis meses y un año (entre 350 y 1.110 horas de estudio y enseñanza y/o capacitación supervisada). (CINE-P/CINE-A: 453)

\section{Ejemplos nacionales - Grupo 2:}

Programas generales de nivel CINE 4 suficientes para conclusión del nivel, diseñados para mejorar las probabilidades de ingresar a la educación terciaria [CINE-P: 444; CINE-A: 444]

Canadá - Post-secondary short general pre-university diploma programmes. Estos programas, que requieren la conclusión de educación secundaria alta, tienen una duración de hasta dos años. Se consideran programas acreditables orientados a preparar a estudiantes en estudios de pre-grado a nivel universitario. Tras la conclusión de estos programas que otorgan diplomas, los estudiantes pueden aplicar a programas de grado en educación terciaria (nivel CINE 6). (CINE-P/CINE-A: 444)

Alemania - Sekundarbereich II, Berufsoberschule (Educación técnico-vocacional de secundaria alta). En la Berufsoberschule, los conocimientos, destrezas y competencias adquirida por los estudiantes durante su educación técnico-vocacional y educación formal previa al ingreso al mercado laboral se toman como la base sobre la cual desarrollar una educación general teórica, profunda, extensa y orientada a las asignaturas, que permitirá a los estudiantes cursar programas de educación superior. Los cursos de tres a cuatro años de duración conducen a una certificación doble: una certificación vocacional (por ej., ocupaciones para auxiliares o certificaciones vocacionales para diversas ocupaciones reconocidas que requieren formación en el sistema formal) y una certificación de ingreso a la educación superior. La Berufsoberschule, que imparte educación a tiempo completo de dos años de duración, conduce a la Fachgebundene 
Hochschulreife. Los estudiantes pueden obtener la Allgemeine Hochschulreife demostrando sus conocimientos en un segundo idioma extranjero. (CINE-P/CINE-A: 444)

Israel - Mechina kdam akademit (Programa preparatorio pre-académico). Estos son programas generales de un año de duración diseñados para estudiantes que han finalizado programas de educación secundaria alta que no dan acceso a educación terciaria y desean mejorar sus posibilidades de ingresar a este nivel. La exitosa conclusión de estos programas otorga el certificado Mechina que reemplaza el certificado de matriculación para efectos de admisión a estudios de nivel terciario. (CINE-P/CINE-A: 444)

Israel - Mechina kdam handasaim (Programa preparatorio para ingenieros prácticos). Estos programas de siete a diez meses de duración están destinados a estudiantes que han finalizado educación secundaria alta y desean estudiar ingeniería a nivel terciario. La exitosa conclusión de estos programas otorga la certificación Teudat Sium Mechinat Handesaim (conclusión de educación postsecundaria no terciaria) que da acceso a programas terciarios de ciclo corto de ingeniería (Mahat) creados por el Ministerio de Economía. (CINE-P/CINE-A: 444)

Omán - (Año básico). Este programa general postsecundario se ofrece a estudiantes que han concluido la educación secundaria alta (con acceso a educación terciaria) pero desean ampliar sus opciones de estudio a nivel terciario. La edad típica de ingreso a este programa de un año de duración, es de 19 años. Tras la conclusión del programa, los graduados reciben el certificado básico que también da acceso a la educación terciaria. (CINE-P/CINE-A: 444)

Qatar - (Programa básico). Este es un programa general postsecundario que se ofrece a estudiantes que han concluido la educación secundaria alta (con acceso a educación terciaria) pero desean ampliar sus opciones de estudio a nivel terciario. El programa impartido en universidades tiene una duración de un año. Tras finalizar el programa los graduados reciben un certificado de conclusión que también da acceso a la educación terciaria. (CINE-P/CINE-A: 444)

Suiza - Passerellenlehrgang/passerelle/passerella (Preparatory course for university for holders of the vocational baccalaureate). (Curso preparatorio universitario para personas que han obtenido el grado en educación terciaria de orientación vocacional). Estos programas generales de un año de duración preparan a los graduados de programas vocacionales de secundaria alta para postular a programas de estudio de nivel terciario. Tras la exitosa conclusión del programa, los estudiantes reciben una certificado de aptitud para estudios universitarios (Passerellenzeugnis/Certificate de passerelle/Certificado de passerella) que les da acceso a programas de grado en educación terciaria. (CINE-P/ CINE-A: 444)

\section{Ejemplos nacionales - Grupo 3: \\ Programas vocacionales de nivel CINE 4 suficientes para conclusión del nivel, diseñados para dar acceso directo a la educación terciaria y al mercado laboral con certificaciones ocupacionales más avanzadas que las otorgadas por el nivel CINE 3 [CINE-P: 454; CINE-A: 454]}

Canadá - Career, technical or professional training programmes. La edad típica de ingreso a estos programas de uno a dos años de duración que se imparten a estudiantes que han concluido la educación secundaria alta es de 18 años. Estos programas vocacionales conducen a certificados para ocupaciones específicas. La conclusión de estos programas también da acceso a programas terciarios de ciclo corto. (CINE-P/CINE-A: 454)

Estonia - Kutseõpe keskariduse basil (Educación vocacional basada en la educación secundaria). Estos programas vocacionales (education based on secondary education). Están destinados a estudisantes que han concluido la educación secundaria alta. La edad típica de ingreso es de 19 años y la duración del programa puede fluctuar entre un año y dos años y medio. Tras su conclusión, los estudiantes reciben el certificado de Educación Vocacional Basada en Educación Secundaria. Este programa también da acceso a programas de grado en educación terciaria. (Bakalaureuseõpe). (CINE-P/CINE-A: 454)

Francia - Préparation à l'entrée d'une formation sélective de niveau BTS (Diferentes programas terciarios incluyendo cursos que preparan para rendir exámenes de admisión competitivos). Estos programas de un año de duración están diseñados para estudiantes que han finalizado la educación secundaria alta y desean cursar programas vocacionales de educación terciaria de ciclo corto. Los programas ofrecen formación en una serie de campos profesionales y preparan a estudiantes para ingresar a escuelas especializadas en estudios paramédicos y servicio social (écoles paramédicales et sociales) de alto nivel, equivalentes al Brevet de technicien supérieur (BTS) (es decir, de nivel CINE 5). (CINE-P/ CINE-A: 454) 
Alemania - Berufsschulen/Duales System (Programas de segundo ciclo del sistema dual). Esta es una forma especial de aprendizaje de oficios (segundo ciclo) que incorpora formación y capacitación tanto en escuelas vocacionales como en el lugar de trabajo. Los estudiantes que desean ingresar a este programa de tres o tres años y medio de duración deben haber concluido un programa general que otorga una certificación de admisión a la universidad o, en su defecto, un programa vocacional (del sistema dual que conduzca al Lehrabschluss, o un programa de formación vocacional en una escuela vocacional especializada) a nivel de secundaria alta. Los graduados pueden optar por continuar sus estudios (Fachschulen) o ingresar directamente al mercado de trabajo. (CINE-P/CINE-A: 454)

Marruecos - (Técnico especializado). Este es un programa postsecundario de dos años de duración que requiere la exitosa conclusión de educación secundaria alta. Está orientado a preparar técnicos en diversas ocupaciones especializadas. Tras finalizar el programa, los participantes reciben el Diploma de Técnico Especializado Diplôme de Technicien Spécialisé (DTS), que da acceso al mercado laboral y además a la educación terciaria. (CINE-P/CINE-A: 454)

Países Bajos - WEB-specialistenopleiding, bol en bbl (Educación vocacional, formación de especialistas, nivel 4). Estos programas vocacionales de nivel postsecundario se imparten a tiempo completo, en escuelas, y pertenecen al sistema dual de educación. Típicamente, los estudiantes ingresan a estos programas de un año de duración a la edad de 19 años tras haber concluido la educación secundaria alta (sin acceso a terciaria). Tras la exitosa conclusión del programa, los estudiantes reciben una certificación de educación secundaria vocacional, nivel de especialista (MBO niv.4: specialist) que también da acceso a la educación terciaria (CINE-P/CINE-A: 454)

Seychelles - Programas que confieren diplomas. Estos programas vocacionales de tres años de duración se ofrecen a personas que han finalizado el primer año de estudio del programa de dos años denominado Certificado de Nivel $A$ (CINE 344). Los estudiantes graduados reciben un diploma que da acceso directo a la educación terciaria. (CINE-P/ CINE-A: 454)

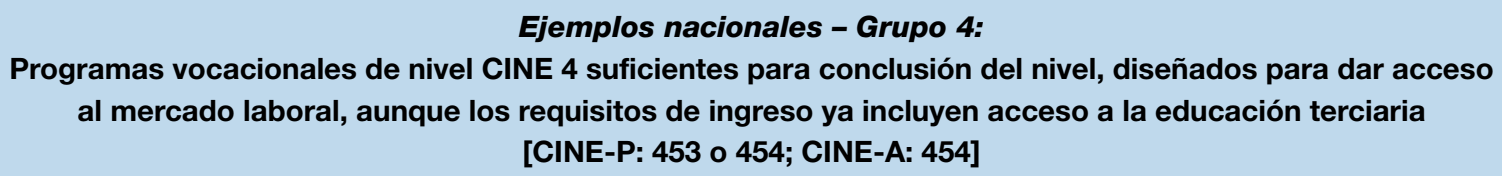

Brasil - Educação profissional de ensino médio (subsequente) (Educación vocacional de secundaria alta (educación posterior)). Estos programas están destinados a estudiantes que han concluido un programa de nivel CINE 3 y desean cursar programas de educación vocacional diseñados para ingresar el mercado laboral. La duración del programa es de 800 horas (entre 8 y 18 meses). En estos programas los estudiantes suelen tener más edad que los estudiantes de nivel CINE 3 y buscan una educación vocacional específica con el fin de mejorar su posición en el mercado laboral. Muchos estudiantes cuentan con empleos pero intentan especializarse en su campo de estudio. Los estudiantes que ingresan a este programa ya han obtenido acceso a la educación terciaria a través de sus certificaciones CINE 3 (educación secundaria alta - ensino médio). Sin embargo, este programa vocacional está diseñado específicamente para el mercado laboral y no prepara ni da acceso al nivel terciario más allá de la preparación recibida en el nivel CINE 3. (CINE-P: 453; CINE-A: 454)

Grecia - Diploma epagematikis katartisis epipedou metadefterovathmias epagelmatikis katarisis (Diploma de formación vocacional. Estos programas vocacionales de cinco semestres de duración (cuatro semestres teóricos y un semestre de trabajo práctico) se ofrecen en Institutos de Formación Vocacional (Institouto Epagelmatikis Katartisis - IEK) y establecen como requisito de ingreso la conclusión de educación secundaria alta. El diploma otorgado a los graduados no da acceso a la educación terciaria ni a la universidad. Estos programas se han diseñado para dar ingreso al mercado laboral en calidad de técnico especializado de un nivel más alto. Entre los requisitos de ingreso se incluye la exitosa conclusión de educación secundaria alta (lyceia), de orientación general o vocacional, que da acceso al nivel CINE 6 (sujeto a la aprobación de un examen general de admisión a la universidad). (CINE-P: 453; CINE-A: 453 o 454)

Portugal - Ensino pós-secundário não superior, Curso de Especialização Tecnológica (Curso de especialización tecnológica postsecundario no terciario). Estos programas vocacionales tienen una duración que fluctúa entre un año y un año y medio y conducen al diploma Especialização Tecnológica. La especialización tecnológica comprende cursos de formación de nivel postsecundario no terciario que preparan a jóvenes y adultos para desempeñar trabajos calificados con el fin de facilitar su ingreso al mercado laboral. Estos cursos tienen componentes de formación en la escuela y capacitación en el lugar de trabajo. El requisito de ingreso mínimo definido para estos programas es la exitosa 
conclusión de educación secundaria alta. La conclusión de estos programas da acceso a programas terciarios de primer título de CINE 6 y 7 . (CINE-P/CINE-A: 454)

\section{Ejemplos nacionales - Grupo 5:}

Programas vocacionales de nivel CINE 4 suficientes para conclusión del nivel, que contemplan experiencia laboral pertinente entre sus requisitos de ingreso [CINE-P: 453 o 454; CINE-A: 453 o 454]

Finlandia - Erikoisammattitutkinto (Programas vocacionales que preparan para certificaciones vocacionales de especialistas). Estos programas preparan para exámenes de certificaciones o destrezas basadas en competencias, que generalmente se rinden después de algunos años de experiencia laboral (por ej,. en oficios o destrezas técnicas). Si bien es cierto que los estudiantes generalmente participan en estos programas como una manera de prepararse para la certificación, no es menos cierto que esta certificación también puede obtenerse sobre la base de destrezas laborales ya adquiridas, y no dependen necesariamente de estudios previos. Los participantes en estos programas generalmente han concluido la educación secundaria alta o han adquirido destrezas equivalentes. Tras la exitosa conclusión de estos programas los estudiantes también tienen acceso a la educación terciaria. (CINE-P/CINE-A: 454)

Noruega - Halårig til ettårig fagskoleutdanning (Programas vocacionales de seis meses a un año de duración, impartidos por institutos de educación superior). Estos programas están diseñados para ingresar directamente al mercado laboral y satisfacer necesidades vocacionales especializadas. A menudo, representan una especialización más avanzada que los certificados de artesanos. Sin embargo, en algunos casos, se ofrecen en campos de estudio no considerados en el nivel CINE 3. El requisito de ingreso es la exitosa conclusión de programas de formación o capacitación en educación secundaria alta. (Nivel CINE 3). (CINE-P/CINE-A: 453)

\section{Ejemplos nacionales - Grupo 6: \\ Programas vocacionales de nivel CINE 4 de más de dos años de duración pero con contenido inferior al de educación terciaria [CINE-P: 453 o 454; CINE-A: 453 o 454]}

Guinea-Bissau - Treinamento (formação) de professores de ensino secundário geral (Formación de profesores de enseñanza secundaria general). Este programa tiene una duración de tres años tras la conclusión de la educación secundaria alta. Está orientada a preparar a profesores calificados de educación secundaria alta. Una vez finalizado el programa los participantes reciben un diploma de enseñanza secundaria general (Diploma de ensino secundário geral) que da acceso al mercado laboral y a la educación terciaria. El programa se clasifica a nivel de educación postsecundaria no terciaria (CINE 4) ya que en el país se considera menos avanzado que un programa de educación terciaria. (CINE-P/CINE-A: 454).

Polonia - Policealne studium wokalno-aktorskie (Escuela postsecundaria para el desarrollo de la voz y la actuación). Este es un programa vocacional de nivel CINE 4 que prepara a los estudiantes para ocupaciones artísticas específicas y culmina con la entrega del certificado de estudios postsecundarios. De acuerdo a las regulaciones del Ministerio de Cultura y Patrimonio Nacional, del año escolar 2014/2015 en adelante, la educación ofrecida en la policealne studium wokalno-aktorskie se organizará en un ciclo de estudio de tres años de duración. (CINE-P/CINE-A: 453).

\section{Ejemplos nacionales - Grupo 7:}

Programas de nivel CINE 4 ofrecidos en instituciones no típicas de educación postsecundaria no terciaria [Cualquier código CINE-P o CINE-A de nivel CINE 4]

República Checa - Další vzdělávání na vysoké škole: pro absolventy SŠ (Universidades: la segunda certificación para graduados de educación secundaria alta). Estos son cursos generales postsecundarios diseñados para estudiantes que han concluido la educación secundaria alta (con acceso a la educación terciaria) y se imparten en universidades. Los estudiantes ingresan a partir de los 19 años y la duración de los cursos es un año. Tras su conclusión los estudiantes reciben un certificado (osvědsčeni). El programa también da acceso a la educación terciaria. (CINE-P/CINE-A: 444).

República Checa - Pomaturitní studium (Cursos de educación postsecundaria de tipo vocacional). Estos cursos vocacionales postsecundarios están diseñados para estudiantes que han concluido educación secundaria alta (con acceso a la educación terciaria). El programa se ofrece en escuelas secundarias. La edad típica de ingreso es de 19 años y la duración del programa es un año. Tras su conclusión los estudiantes reciben un certificado (osvědsčenî). El programa también da acceso a la educación terciaria. (CINE-P/CINE-A: 454). 
España - Títulos propios de Universidad de menos de 2 años. Estos programas postsecundarios cortos y variados se ofrecen en universidades y no conducen a títulos universitarios reconocidos a nivel nacional. Su duración fluctúa entre seis meses y un año. Los estudiantes que desean ingresar a estos programas vocacionales deben haber concluido la educación secundaria alta. (CINE-P/CINE-A: 453)

\section{Note}

1. Los números de los párrafos refieren al documento de clasificación CINE 2011. Para mayores detalles, sírvase consultar la Guía del Lector. 


\section{TERCERA PARTE \\ NIVELES CINE 5 A 8: EDUCACIÓN TERCIARIA}

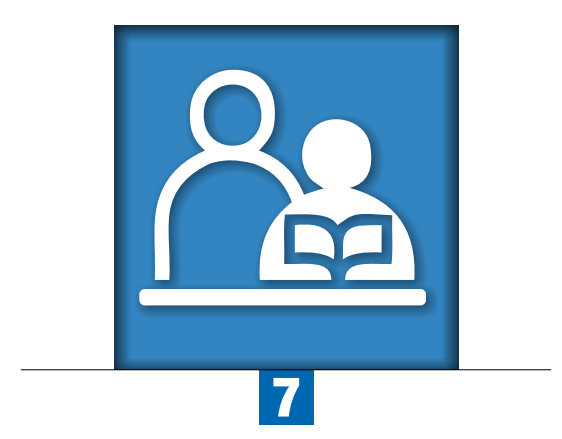

Capítulo 7

\section{Aspectos generales de los niveles CINE de educación terciaria}

La educación terciaria se basa en parte de los conocimientos adquiridos en la educación secundaria, proporcionando actividades de aprendizaje en campos especializados de estudio. Está destinada a impartir aprendizaje a un alto nivel de complejidad y especialización. La educación terciaria comprende lo que se conoce como "educación académica", pero también incluye la educación profesional o vocacional avanzada.

Generalmente, existe una clara jerarquía entre las certificaciones otorgadas por los programas de educación terciaria. Consta de los niveles CINE 5 (educación terciaria de ciclo corto), CINE 6 (título en educación terciaria o equivalente), CINE 7 (nivel de maestría, especialización o equivalente) y CINE 8 (nivel de doctorado o equivalente). El contenido de los programas de este nivel es más complejo y avanzado que los programas de niveles inferiores. 


\section{DESCRIPCIÓN}

\section{Definición}

$(\S 200)^{1}$ La educación terciaria se basa en parte de los conocimientos adquiridos en la educación secundaria, proporcionando actividades de aprendizaje en campos especializados de estudio. Está destinada a impartir aprendizaje a un alto nivel de complejidad y especialización. La educación terciaria comprende lo que se conoce como "educación académica", pero también incluye la educación profesional o vocacional avanzada. Consta de los niveles CINE 5, 6, 7 y 8, denominados educación terciaria de ciclo corto, grado en educación terciaria o equivalente, nivel de maestría, especialización o equivalente y nivel de doctorado o equivalente, respectivamente.

El contenido de los programas de este nivel es más complejo y avanzado que los programas de niveles inferiores.

(§201) Los programas de primer título de nivel CINE 5, 6 o 7 requieren la conclusión exitosa de programas de nivel CINE 3 que den acceso directo a programas de primer título de educación terciaria. A su vez, este acceso también es posible desde el nivel CINE 4. Además de los requisitos de certificación, el ingreso a programas impartidos en estos niveles puede depender de la selección de materias de estudio y/o las calificaciones obtenidas en los niveles CINE 3 o 4. Asimismo, podría ser necesario aprobar un examen de admisión.

(§205) El ingreso al nivel CINE 8 normalmente requiere la conclusión exitosa del nivel CINE 7. (Véase el Gráfico 1)

(§203) Generalmente, existe una clara jerarquía entre las certificaciones otorgadas por los programas de educación terciaria. Sin embargo, a diferencia de los programas que corresponden a los niveles CINE 1, 2, 3 y 4, los programas nacionales de nivel CINE 5, 6 y 7 pueden existir en forma paralela, en lugar que un nivel siga en forma secuencial a otro.

El Gráfico 7.1 ilustra las categorías de programas de educación terciaria, que serán descritas en mayor detalle en los capítulos siguientes, y las trayectorias entre ellos.

Estas categorías son:

- Programas de educación terciaria de ciclo corto de nivel CINE 5 (véase el grupo 5);

- Programas de primer título del grado en educación terciaria o nivel equivalente con una duración teórica acumulada (en el nivel terciario) de tres a cuatro años en el nivel CINE 6 (grado en educación terciaria o nivel equivalente) (véase el grupo 665);

- Programas largos de primer título del grado en educación terciaria o nivel equivalente con una duración teórica acumulada (en el nivel terciario) de más de cuatro años en el nivel CINE 6 (grado en educación terciaria o nivel equivalente) (véase el grupo 666);

- Programas de segundo o siguiente título, tras cursar un programa del grado en educación terciaria o equivalente en el nivel CINE 6 (véase el grupo 667);

- Programas largos de primer título, nivel maestría, especialización o equivalente con una duración teórica acumulada (en el nivel terciario) de al menos cinco años (que no requiere estudios previos de educación terciaria) en el nivel CINE 7 (nivel de maestría, especialización o equivalente) (véase el grupo 767);

- Programas de segundo o siguiente título, nivel maestría, especialización o equivalente tras cursar un programa del grado en educación terciaria o equivalente, en el nivel CINE 7 (nivel de maestría, especialización o equivalente) (véase el grupo 767);

- Programas de segundo o siguiente título, nivel maestría, especialización o equivalente (tras cursar otro programa de maestría, especialización o equivalente), en el nivel CINE 7 (véase el grupo 768); y

- Programas de doctorado o nivel equivalente, en el nivel CINE 8 (véase el grupo 8). 
- Gráfico 7.1 .

Trayectorias de educación terciaria de acuerdo a la CINE 2011
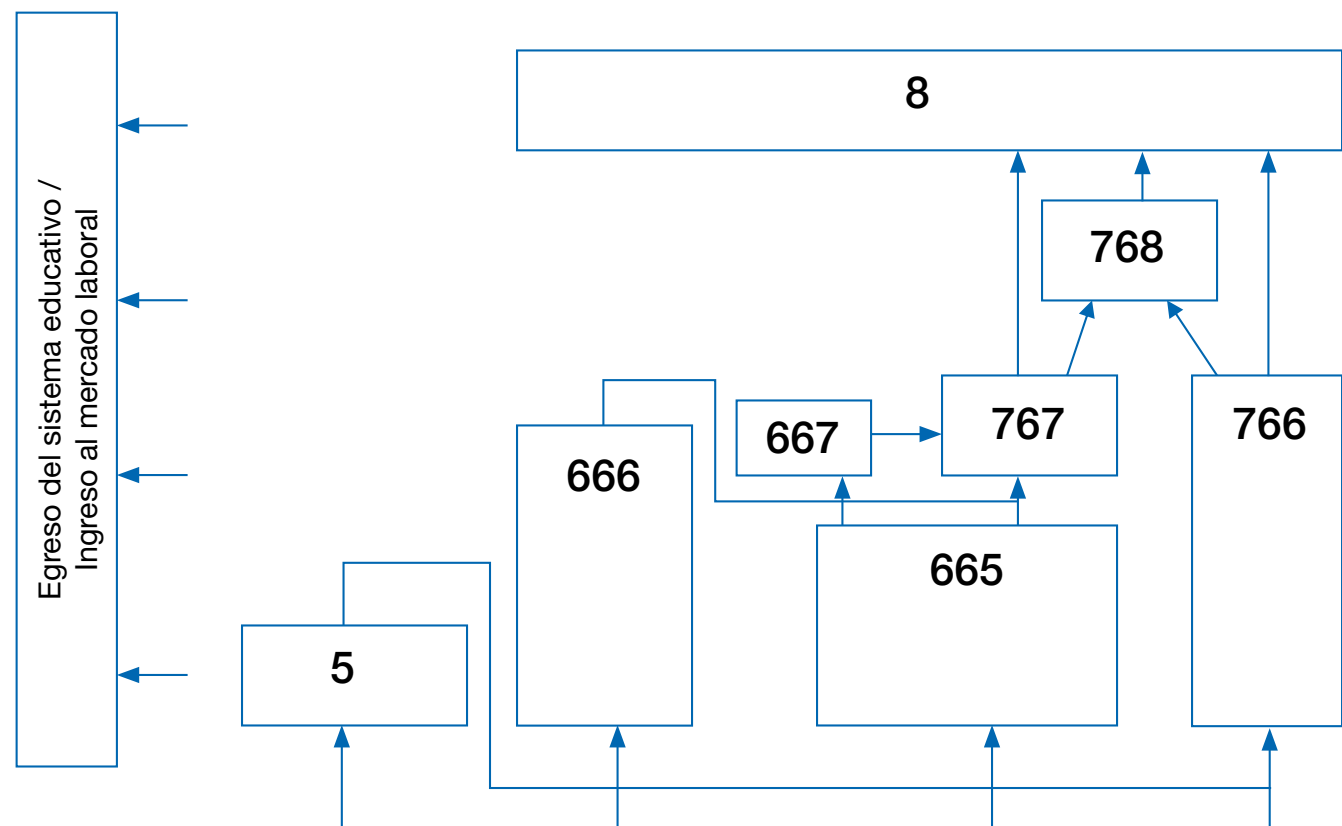

Conclusión del nivel CINE 3 o 4 con acceso directo a programas de primer título de educación terciaria de nivel CINE 5, 6 o 7

\section{CORRESPONDENCIA ENTRE LOS NIVELES CINE 2011 Y CINE 1997}

(§281) La CINE 2011 considera cuatro niveles de educación terciaria, en comparación con los dos niveles que figuran en la CINE 1997. Los niveles 5, 6 y 7 de la CINE 2011 corresponden, en conjunto, al nivel 5 de la CINE 1997. El nivel 8 de la CINE 2011 corresponde al nivel 6 de la CINE 1997.

Los nuevos niveles facilitan la identificación de la estructura actual de los programas de educación terciaria, en particular, estableciendo la distinción entre los programas de grado en educación terciaria o programa equivalente y los programas de maestría, especialización o equivalente.

(§282) En comparación con la CINE 1997, la CINE 2011 simplifica las dimensiones complementarias de los niveles CINE terciarios. Respecto del nivel 5 de la CINE 2011, el segundo dígito del código permite distinguir entre los programas de orientación vocacional y general, distinción que no era posible en la CINE 1997. Adicionalmente, una vez que se cuente con definiciones internacionalmente consensuadas también será posible distinguir entre programas de orientación académica y profesional en los niveles 6, 7 y 8 de la CINE 2011. En los niveles 6 y 7 de la CINE 2011, el tercer dígito de clasificación establece una distinción entre los programas en función de su duración y posición en la estructura nacional de títulos y certificaciones, facilitando de esta forma el cálculo de estadísticas tales como tasas de ingreso y graduación. En la CINE 1997 se utilizó la orientación "tipo de programa" con el fin de subclasificar el nivel CINE 5A en programas de primer título y programas de segundo y siguiente título (lo que en la CINE 2011 corresponde a los niveles 6 y 7 combinados).

\section{Nota}

1. Los números de los párrafos refieren al documento principal de la clasificación CINE 2011. Para mayores detalles, sírvase consultar la Guía del Lector. 



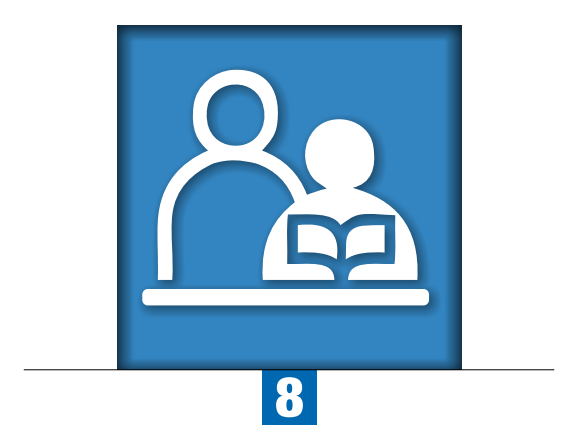

Capítulo 8

\section{Nivel 5 - CINE 2011:}

\section{Educación terciaria de ciclo corto}

El contenido de los programas de nivel CINE 5 es bastante más complejo que el de los programas de educación secundaria alta cuya exitosa conclusión es un requisito de acceso. El propósito de los programas de nivel CINE 5 es profundizar el conocimiento impartiendo técnicas, conceptos e ideas generalmente no cubiertos en la educación secundaria alta. Si bien el objetivo de los programas de nivel CINE 4 es ampliar la base de conocimientos, en términos de complejidad no suelen ser mucho más avanzados que los de nivel CINE 3.

Los programas clasificados en el nivel CINE 5 pueden recibir distintas denominaciones, por ejemplo: educación técnica (superior), (higher) technical education, junior college education, technician o advanced/ higher vocational training, associate degree o bac +2 . Para propósitos de comparación a nivel internacional, se usa el término "terciaria de ciclo corto" para denominar al nivel CINE 5. 


\section{DESCRIPCIÓN}

\section{Definición}

(§207) $)^{1}$ Los programas de nivel CINE 5, o educación terciaria de ciclo corto, suelen estar destinados a impartir al participante conocimientos, habilidades y competencias profesionales. Estos programas se caracterizan por estar basados en un componente práctico, estar orientados a ocupaciones específicas y preparar al estudiante para el mercado laboral. Sin embargo, también pueden facilitar el ingreso a otros programas de educación terciaria (niveles CINE 6 o 7). Los programas académicos de un nivel inferior al grado en educación terciaria o nivel equivalente también se clasifican en el nivel CINE 5.

(§208) El ingreso a programas de nivel CINE 5 requiere la conclusión exitosa de programas de nivel CINE 3 o 4 que den acceso a la educación terciaria. En este nivel CINE, los programas suelen tener un contenido más complejo que el de los niveles CINE 3 y 4, si bien son más cortos y generalmente menos teóricos que los programas de nivel CINE 6.

\section{Criterios de clasificación (\$211)}

\section{Criterios principales}

a) Contenido

(§212) El nivel CINE 5 comprende o capta el nivel más bajo de la educación terciaria. En este nivel, el contenido de los programas es más complejo que el de los programas de educación secundaria (nivel CINE 3) o postsecundaria no terciaria (nivel CINE 4), pero menos complejo que el de los programas de nivel CINE 6 (grado en educación terciaria o nivel equivalente).

b) Requisitos de ingreso

(§208) El ingreso a programas de nivel CINE 5 requiere la conclusión exitosa de programas de nivel CINE 3 o 4 que den acceso a la educación terciaria.

c) Duración mínima del nivel

(§213) El nivel CINE 5 tiene una duración mínima de dos años.

\section{Criterios subsidiarios}

a) Punto de transición entre instituciones educativas

(§214) El punto de transición entre instituciones educativas no terciarias y terciarias puede ayudar a identificar la línea divisoria entre la educación secundaria alta (nivel CINE 3), la educación postsecundaria no terciaria (nivel CINE 4) y la educación terciaria. Con frecuencia, los programas de nivel CINE 5 se imparten en instituciones educativas distintas a las instituciones que ofrecen programas de nivel CINE 6, 7 y 8.

b) Duración típica del nivel

(§213) El nivel CINE 5 tiene una duración mínima de dos años y suele tener (aunque no siempre) una duración inferior a tres años. 


\section{Dimensiones complementarias}

(§216) Dos dimensiones permiten diferenciar los programas educativos del nivel CINE 5.

(§217) Orientación del programa:

- General; y

- Vocacional2.

(§218) Conclusión de nivel:

- Nivel CINE 5 inconcluso: programas de menos de 2 años de duración, por lo tanto, considerados insuficientes para la conclusión de este nivel; y

- Conclusión del nivel CINE 5: programas de 2 o más años de duración, es decir, considerados suficientes para la conclusión de este nivel.

\section{CORRESPONDENCIA ENTRE LOS NIVELES CINE 2011 Y CINE 1997}

Consulte esta sección en el capítulo de educación terciaria.

\section{DIRECTRICES PARA CLASIFICAR PROGRAMAS DE NIVEL CINE 5 Y CERTIFICACIONES RECONOCIDAS RELACIONADAS}

El contenido de los programas de nivel CINE 5 es significativamente más complejo que el de los programas de educación secundaria cuya exitosa conclusión da acceso a este nivel. Los programas de nivel CINE 5 están orientados a profundizar el conocimiento a través de la enseñanza de nuevas técnicas, conceptos e ideas generalmente no cubiertos en la educación secundaria alta. En cambio, los programas de nivel CINE 4 se caracterizan por ampliar el conocimiento si bien no suelen ser más avanzados que los programas de nivel CINE 3 (§191). (Ejemplos nacionales - Grupo 1)

Los programas que tienen como requisito de ingreso la exitosa conclusión de un programa de nivel CINE 6 o 7 no deben ser clasificados en el nivel CINE 5, independientemente de su duración.

Normalmente, los programas de menos de dos años de duración que se encuentran inmediatamente después de educación secundaria alta, debería clasificarse en el nivel CINE 4, a menos que claramente sean directamente equivalente a la primera etapa, o etapas, de otros programas clasificados en el nivel CINE 5 (que cumplan los criterios de clasificación definidos para el nivel CINE 5 incluyendo una duración mínima acumulada de dos años). (Ejemplos nacionales - Grupo 2)

En algunos casos, una secuencia de programas cortos pueden sumar el equivalente a dos o tres años de estudios que cumplen los criterios de clasificación establecidos para el nivel CINE 5. Asimismo, es posible que al final de cada programa de la secuencia se otorgue una certificación. En consecuencia, el primer programa de la secuencia sería clasificado en el nivel CINE 5 de la CINE-P ("insuficiente para conclusión del nivel", siempre que toda la secuencia sea elegible para clasificar en el nivel 5) y en el nivel CINE 4 de la CINE-A en términos de logro educativo (incluso si no existiera un programa de nivel CINE 4 en el país).

Los programas de nivel CINE 5 pueden otorgar créditos transferibles a programas de nivel CINE 6 o 7 (\$209), lo que en la práctica significa liberar a los participantes de la obligación de asistir a ciertos cursos o módulos del programa de nivel CINE 6 o 7 al cual se transfirieron como resultado de la conclusión exitosa del programa de nivel CINE 5. (Ejemplos nacionales - Grupo 3)

La clasificación de programa largos o segundos programas de nivel terciario se debe realizar con especial atención, incluso si en la CINE 1997 se hubieran clasificado en el nivel 5B. Normalmente, segundos programas que representen al menos 5 años de estudios acumulados en el nivel CINE 5 se deben clasificar en el nivel CINE 6 (salvo que la certificación reconocida otorgada sea claramente inferior al grado en educación terciaria o nivel equivalente). En general, el logro educativo correspondiente se asignaría al nivel CINE 6, incluso si la duración de los estudios de nivel CINE 6 representa menos de 3 años. Lo anterior encuentra explicación en el hecho que el tiempo total de estudio en el nivel terciario es de cinco años como mínimo, por lo tanto el contenido adquirido por el estudiante al finalizar el programa debería ser equivalente en complejidad al cubierto en los programas más cortos de primer título del nivel CINE 6. 
Del mismo modo, se debería considerar la posibilidad de abordar los programas muy largos (que representan al menos 5 años de estudio) que cumplen los demás criterios de clasificación en el nivel CINE 5, como programas que abarcan los niveles CINE 5 y 6. La primera etapa de estos programas debería clasificarse en el nivel CINE 5 y las etapas posteriores en el nivel CINE 6. Dentro de lo posible, la línea divisoria entre los dos niveles debería basarse en una evaluación de la complejidad del contenido de las distintas etapas del programa. Así como en el caso de segundos programas, si la certificación derivada del programa largo es claramente inferior al grado en educación terciaria o nivel equivalente, la totalidad del programa debería clasificarse en el nivel CINE 5 independientemente de su duración.

\section{LOGRO EDUCATIVO EN EL NIVEL CINE 5}

A nivel CINE 5, el logro educativo requiere la exitosa conclusión de un programa - que otorgue una certificación reconocida - que represente una duración acumulada mínima de dos años en el nivel CINE 5. En los países integrantes del Espacio Europeo de Educación Superior, esto sería equivalente a un mínimo de 120 créditos del Sistema Europeo de Transferencia y Acumulación de Créditos.

La exitosa conclusión de programas que representan menos de dos años de estudio a nivel CINE 5, normalmente da origen a un logro educativo de nivel CINE 4 (incluso en países que no tienen programas de nivel CINE 4). (Ejemplos nacionales - Grupo 4)

En el caso de programas de distinta duración que conducen a certificaciones reconocidas como equivalentes, se recomienda clasificarlos en el mismo nivel CINE. ${ }^{3}$ Del mismo modo, dos o más certificaciones diferentes pero equivalentes, normalmente darían origen a un logro educativo del mismo nivel CINE aunque no necesariamente al mismo código (por ej., si uno es general y el otro vocacional los códigos CINE-A serían 540 y 550 respectivamente). Adicionalmente, si la duración de un programa educativo es inferior a dos años (por ej., si forma parte de una secuencia de programas) pero la certificación obtenida es equivalente a otras certificaciones clasificadas en el nivel CINE 5, el programa y la certificación deben ser clasificados en el nivel CINE 5. (Ejemplos nacionales - Grupo 5)

(\$221) En términos de logro educativo, las certificaciones intermedias otorgadas tras la conclusión de una etapa (o programa) de nivel CINE 5 considerados insuficientes para concluir este nivel, se clasifican en el nivel CINE 4.

(§222) Las certificaciones intermedias otorgadas tras la conclusión exitosa de una etapa de un programa de nivel CINE 6 (anterior a un primer título) que a su vez son consideradas insuficientes para la conclusión de este nivel, para los efectos de logro educativo se clasifican en el nivel CINE 5.

La exitosa conclusión de los primeros programas de educación terciaria con una duración menor a tres años en el nivel CINE 6, da lugar a un logro educativo de nivel CINE 5 (incluso en el caso de no existir programas de nivel CINE 5 en el país). Véanse los Ejemplos nacionales - Grupo 4, presentados en el capítulo correspondiente al nivel CINE 6.

\section{EJEMPLOS DE PROGRAMAS Y CERTIFICACIONES CLASIFICADAS EN EL NIVEL CINE 5}

(\$210) Los programas clasificados en el nivel CINE 5 pueden recibir distintas denominaciones, por ejemplo: educación técnica (superior), (higher) technical education, junior college education, technician o advanced/higher vocational training, associate degree o bac +2 . Para propósitos de comparación a nivel internacional, se usa el término "terciaria de ciclo corto" para denominar al nivel CINE 5.

\section{Ejemplos nacionales - Grupo 1: \\ Programas que cumplen todos los criterios de clasificación del nivel CINE 5 [CINE-P: 544 o 554; CINE-A: 540 o 550]}

Australia - Para-professional/Technician courses. Estos cursos están diseñados para impartir formación y capacitación inicial con el propósito de desarrollar todo el espectro de destrezas especializadas requeridas en ocupaciones paraprofesionales. Los reconocimientos más comunes son el Associate Diploma o Advanced Certificate, y de acuerdo a los 
requisitos de ingreso el postulante generalmente debe tener un Certificado (CINE 3) en el campo pertinente. Los cursos suelen tener una duración de dos años equivalente a tiempo completo. (CINE-P: 554; CINE-A: 550)

Brunei Darussalam - Higher National Diploma (HND). Este es un programa vocacional de dos años y medio de duración que requiere la conclusión de un programa de educación secundaria alta con acceso a la educación terciaria, tal como el nivel-A, un Diploma Nacional (ND) o el Sijil Tinggi Pelajaran Ugama (STPU) impartido en escuelas religiosas. (CINE-P: 554; CINE-A: 550)

Camboya - Associate degree. Este es un programa de dos años de duración que requiere la conclusión del Décimo Segundo Grado o de un certificado 3 técnico-vocacional (ambos de nivel CINE 3). El programa conduce a un associate degree en turismo y hospitalidad, enfermería y tecnología computacional. (CINE-P: 554; CINE-A: 550)

Francia - Enseignement conduisant aux Brevets de techniciens supérieurs et équivalent (Educación terciaria que conduce al Brevet de techniciens supérieurs (BTS) y equivalente). El requisito de admisión es el baccalauréat o el brevet de technicien complementado con calificaciones suficientes y recomendaciones de los profesores. Bajo ciertas condiciones, las personas que posean un BTS pueden continuar sus estudios en universidades o instituciones de educación superior. Esta certificación tiene el mismo nivel que el diplôme universitaire de technologie (DUT - diploma universitario de tecnología), si bien es más especializada y ofrece un menor número de posibilidades de cursar estudios más avanzados. (CINE-P: 554; CINE-A: 550)

Japón - Koutou senmon gakko (Institutos Superiores de Tecnología, cuarto y quinto años). Estos son los dos últimos años del programa de educación profesional Koutou senmon gakko cuyos estudiantes se especializan en el campo de la ingeniería. Tras la exitosa conclusión del programa y una vez aprobado el examen de admisión, los estudiantes se puede transferir al tercer año de programas universitarios o continuar su educación en el Koutou senmon gakko Senkoka (curso de ingeniería avanzado). (CINE-P: 554; CINE-A: 550)

Mauritania - Brevet de technicien supérieur (Certificado de técnico senior). Este programa de tres años de duración requiere la conclusión del Baccalauréat nacional (educación secundaria alta). Al finalizar el programa, los graduados reciben el certificado de técnico senior. (CINE-P: 554; CINE-A: 550)

México - Técnico Superior (Educación técnica y profesional). Estos programas se ofrecen en institutos tecnológicos y conducen al Certificado Asociado Profesional. Los graduados de estos programas de dos años de duración se consideran técnicos calificados. (CINE-P: 554; CINE-A: 550)

Noruega - Toårige fagskoleutdanning (Educación terciaria vocacional). Estos programas vocacionales de dos años de duración impartidos en institutos superiores están diseñados para cumplir los requisitos establecidos para maestros artesanos, técnicos calificados o para-profesionales, y dan acceso directo al mercado laboral. Los graduados en estudios técnicos, que representan la mayoría de los graduados en este nivel, pueden eximirse de cursar el grado en educación terciaria en ingeniería hasta por un año. El requisito de admisión es la exitosa conclusión de educación o capacitación a nivel de secundaria alta (CINE 3). (CINE-P: 554; CINE-A: 550)

Arabia Saudita - (Programas de diploma general de nivel intermedio). Estos programas se ofrecen en institutos superiores comunitarios a los graduados de educación secundaria alta en diversos campos de estudio. Al finalizar estos programas de dos años de duración, los graduados reciben el diploma general de nivel intermedio en el correspondiente campo de estudio. (CINE-P: 544; CINE-A: 540)

España - Ciclos Formativos de Formación Profesional de Grado Superior (Formación profesional - nivel superior). Estos programas de dos años de duración están incluidos en el Marco de Educación Superior Español. La certificación obtenida tras la conclusión de este programa Técnico Superior (Formación profesional - certificado y título de nivel superior) es equivalente a la de un técnico calificado en una ocupación determinada. El requisito de admisión es la exitosa conclusión del bachiller (nivel CINE 3). CINE-P: 544; CINE-A: 550)

Ucrania - Неповна вищза освіта (Conclusión parcial de la educación superior). Estos programas de dos a tres años de duración se ofrecen en instituciones de educación superior. El requisito mínimo de ingreso es el certificado de conclusión de la educación secundaria alta. Los graduados de estos programas reciben el diploma диплом молодиого спеціаліста (especialista junior). CINE-P: 554; CINE-A: 550) 


\section{Ejemplos nacionales - Grupo 2:}

\section{Programas de corta duración pero equivalentes a la primera etapa (o etapas) de otro programa de nivel CINE 5} [CINE-P: 541 o 551; CINE-A: 444 o 454]

Reino Unido - Higher National Certificate (HNC). La admisión a este programa requiere una edad mínima de 18 años y la correspondiente certificación nacional otorgada por el Consejo de Educación Comercial y Técnica (BTEC) o equivalente o el GCE nivel A (certificaciones de nivel CINE 3). El objetivo de estos programas es desarrollar destrezas e impartir capacitación que conduzca a diversas actividades profesionales. Se ofrecen en institutos de educación superior y en algunas universidades y centros profesionales. Los certificados HNC tienen una duración inferior a los diplomas HND (Higher National Diplomas) y suelen prolongarse por solo un año a tiempo completo. Las personas que han obtenido un HNC pueden ingresar al segundo año de programas HND en tanto que otros certificados HNC dan acceso al segundo año de un programa de grado en educación terciaria. Este programa se clasifica en el nivel CINE 5. El logro educativo asociado con esta certificación equivale a la conclusión del nivel CINE 4 (considerando que el programa es demasiado corto - un año - para ser equivalente a la conclusión del nivel CINE 5). CINE-P: 551; CINE-A: 454)

\section{Ejemplos nacionales - Grupo 3: \\ Programas clasificados en el nivel CINE 5 que transfieren créditos a niveles más avanzados (CINE 6 o 7) [CINE-P: 544 o 554; CINE-A: 540 o 550]}

Francia - Enseignement en institut universitaire de technologie (IUT) (Enseñanza en un instituto universitario de tecnología). Este programa de tecnología de dos años de duración conduce al Diplôme universitaire de technologie (DUT). Los estudiantes que han logrado el DUT pueden continuar sus estudios a nivel universitario para obtener la licencia (una certificación de nivel CINE 6), a pesar que el objetivo principal del programa es preparar a los estudiantes para ingresar directamente al mercado laboral. El requisito de ingreso es el baccalauréat, complementado con calificaciones lo suficientemente altas y recomendaciones de los profesores. CINE-P: 554; CINE-A: 550)

Japón - Senmon gakko (Instituto de formación profesional). Este programa está orientado principalmente a impartir formación profesional. El requisito mínimo de ingreso es la exitosa conclusión de educación secundaria alta (nivel CINE 3). Una vez finalizado el programa y después de cumplir con otros requisitos específicos, el estudiante puede obtener un Diploma (tras aproximadamente dos años de estudio) o un Diploma Avanzado (requiere por lo menos cuatro años de estudio). En general, al estudiante se le otorgarían simultáneamente las certificaciones para ingresar a la universidad (nivel CINE 6 o 766) o para graduarse (nivel CINE 7). (CINE-P: 554; CINE-A: 550)

Líbano - (Programas técnicos de excelencia). Estos programas de dos años de duración se ofrecen en institutos técnicos y profesionales a personas que han finalizado el baccalaureate general o vocacional (educación secundaria alta). Los estudiantes graduados de estos programas reciben el certificado de excelencia técnica (T.S.) orientado a preparar a técnicos calificados para el mercado laboral. Esta certificación también se considera requisito de ingreso al programa Technical License programme, clasificado al nivel de grado en educación terciaria (nivel CINE 6). (CINE-P: 554; CINE-A: 550)

Sudán - (Programas técnicos que confieren diplomas). Estos programas de tres años de duración se ofrecen en distintas universidades nacionales y en diversos campos de estudio. Tras su finalización, los participantes reciben el certificado de diploma técnico. Este certificado, diseñado principalmente para el mercado laboral, junto con la experiencia laboral (pertinente) del postulante, puede aportar créditos hacia estudios más avanzados a nivel de grado en educación terciaria. (CINE-P: 554; CINE-A: 550)

Timor-Leste - Politecnic Diploma 2 (Programas profesionales, Diploma politécnico 2). Estos programas de dos años de duración tienen como requisito la conclusión de la educación secundaria alta (con acceso a educación terciaria). Tras su finalización, los graduados reciben el Diploma 2 que también aporta créditos hacia programas educativos más avanzados, algunos de los cuales están al nivel de grado en educación terciaria. (CINE-P: 554; CINE-A: 550)

Reino Unido - Higher National Diploma (HND). Entre los requisitos de admisión a este programa se destacan una edad mínima de 18 años y la correspondiente certificación nacional otorgada por el Consejo de Educación Comercial y Técnica (BTEC) o equivalente o el GCE nivel A (certificaciones de nivel CINE 3). El objetivo de estos programas es desarrollar destrezas e impartir capacitación que conduzca a diversas actividades profesionales. Se ofrecen en institutos de educación superior, en algunas universidades y centros profesionales y generalmente conducen al nivel de técnico 
senior o de gerencia junior. Los programas pueden tener una duración de dos años a tiempo completo o tres años a tiempo parcial. Las personas que han obtenido un HND pueden ingresar al segundo o tercer año de un programa de título en educación terciaria. (CINE-P: 554; CINE-A: 550)

\section{Ejemplos nacionales - Grupo 4: \\ Programas de nivel CINE 5 considerados insuficientes para conclusión del nivel y que en consecuencia conducen a un logro educativo de nivel CINE 4 [CINE-P: 541 o 551; CINE-A: 444 o 454]}

Dinamarca - Merkonom, teknonom, datanom, revision (Educación superior de ciclo corto, educación de adultos abierta). El requisito de ingreso a este programa vocacional es haber finalizado la educación secundaria alta (nivel CINE 3) con acceso a la educación terciaria. Este programa tiene una duración de un año y su contenido es similar al del primer año de programas de educación terciaria de ciclo corto de dos años de duración, clasificados por el país en el nivel CINE 5. Dado que es más corto que estos programas, da origen a un logro educativo de nivel CINE 4. (CINE-P: 551; CINE-A: 454)

Reino Unido - Higher National Certificate (HNC). Este programa se clasifica en el nivel CINE 5 (insuficiente para conclusión del nivel) por las razones descritas en el Ejemplos nacionales - Grupo 2. El logro educativo asociado con la certificación a que da origen equivale a la conclusión del nivel CINE 4. (CINE-P: 551; CINE-A: 454)

\section{Ejemplos nacionales - Grupo 5: \\ Programas de una duración inferior a dos años que conducen a un logro educativo de nivel CINE 5 [CINE-P: 544 o 554; CINE-A: 540 o 550]}

Eslovaquia ${ }^{4}$ - Tančné konzervatórium - 8 ročné štúdium (Conservatorio de danza - ocho años). Este programa de 8 años de duración, que comienza a la edad de 10 años, tiene como objetivo formar bailarines profesionales y otorgarles, tras su finalización, el certificado de estudios (maturita, certificación de nivel CINE 3) - vysvedčenie o maturitnej skúške - y el diploma de graduado - absolventský diplom - equivalente a una certificación de nivel CINE 5, que permite a los graduados enseñar danza en la escuela de artes básicas. El programa abarca los niveles CINE 2 , 3 y 5, con cada nivel integrado por grados de la siguiente manera: Primero a Cuarto Grado, nivel CINE 2; Quinto a Séptimo Grado, nivel CINE 3; y Octavo Grado, nivel CINE 5. La certificación absolventský diplom también se otorga al finalizar otros dos programas que cumplen los criterios para el nivel CINE 5: pomaturitné špecializačné štúdium (estudios postsecundarios especializados) y vyššie odborné štúdium (estudios profesionales superiores), programas de dos y tres años respectivamente, impartidos tras la conclusión de educación secundaria alta. La exitosa conclusión de Octavo Grado del tanečné konzervatórium conduce a un logro educativo de nivel CINE 5. Mientras que solo un año del programa está clasificado en el nivel CINE 5, este conduce a la misma certificación otorgada por otros programas de nivel CINE 5. (CINE-P: 554; CINE-A: 550)

\section{Notas}

1. Los números de los párrafos refieren al documento de clasificación CINE 2011. Para mayores detalles, sívase consultar la Guía del Lector.

2. Si se lograra elaborar definiciones internacionales para programas "académicos" y "profesionales", estas reemplazarán a "general” y "vocacional" como categorías de orientación en el nivel CINE 5.

3. Cabe destacar que certificaciones con el mismo nombre no son necesariamente equivalentes particularmente cuando se otorgan en campos de estudio muy diversos o cuando el nombre de la certificación es más bien genérico (por ej., certificado, diploma, etc.).

4. El Instituto de Estadística de la UNESCO (UIS) y la Unión Europea (UE) utilizan "Eslovaquia" como el nombre oficial de la "República Eslovaca". 



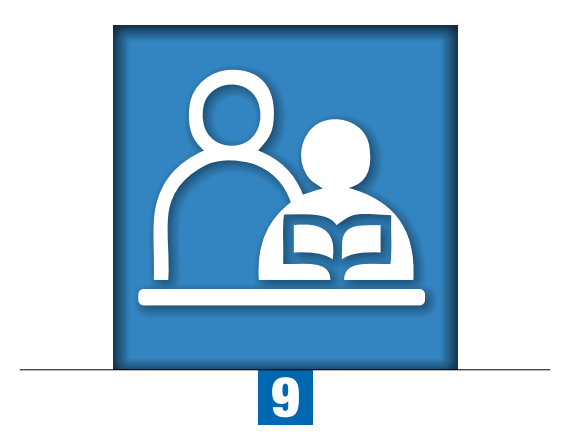

Capítulo 9

\section{Nivel 6 - CINE 2011:}

\section{Grado en educación terciaria o nivel equivalente}

Los programas de nivel CINE 6, o grado en educación terciaria o nivel equivalente, son más largos y generalmente más teóricos que los programas de nivel CINE 5. Con frecuencia están destinados a impartir conocimientos, destrezas y competencias académicas o profesionales intermedias que conducen a un primer título o a una certificación equivalente.

Normalmente, requieren de tres a cuatro años de estudio a tiempo completo en el nivel terciario y pueden incluir un componente práctico y/o requerir, además de estudios teóricos, un período de experiencia laboral. Tradicionalmente, estos programas son ofrecidos por universidades y otras instituciones de educación superior.

Los programas clasificados en el nivel CINE 6 pueden recibir distintas denominaciones, por ejemplo: Bachelor, licence o primer ciclo universitario. Para propósitos de comparación a nivel internacional, se usa el término "grado en educación terciaria o nivel equivalente" para denominar al nivel CINE 6. 


\section{DESCRIPCIÓN}

\section{Definición}

(§224) $)^{1}$ Los programas de nivel CINE 6, o grado en educación terciaria o nivel equivalente, son más largos y generalmente más teóricos que los programas de nivel CINE 5. Con frecuencia están destinados a impartir conocimientos, destrezas y competencias académicas o profesionales intermedias que conducen a un primer título o a una certificación equivalente. Los programas de este nivel son esencialmente teóricos, si bien pueden incluir un componente práctico, y están basados en investigación que refleja los últimos avances en el campo o las mejores prácticas profesionales. Estos programas no requieren necesariamente desarrollar una tesis o proyecto de investigación.

(§226) Una vez cursados los programas de nivel CINE 6, el estudiante puede continuar su educación en el nivel CINE 7 (nivel de maestría, especialización o equivalente), si bien no todos los programas de nivel CINE 6 dan acceso al nivel CINE 7. Normalmente, los programas de nivel CINE 6 no dan acceso directo al nivel CINE 8 (nivel de doctorado o equivalente).

\section{Criterios de clasificación (§228)}

\section{Criterios principales}

a) Contenido esencialmente teórico y/o profesional

(§224) Los programas de este nivel son esencialmente teóricos, si bien pueden incluir un componente práctico, y están basados en investigación que refleja los últimos avances en el campo o las mejores prácticas profesionales.

b) Requisitos de ingreso

(§226) Habitualmente, el ingreso a estos programas requiere la conclusión exitosa de un programa de nivel CINE 3 o 4 que otorgue acceso a la educación terciaria.

c) Duración acumulada mínima del programa (primer título)

(§229) Normalmente, los programas de primer título del nivel CINE 6 requieren de tres a cuatro años de estudio a tiempo completo. En el caso de los sistemas educativos que otorgan títulos en base a la acumulación de créditos, se requerirá un período comparable de duración y similar grado de intensidad.

d) Posición en la estructura nacional de títulos y certificaciones

(§230) Usualmente, los programas de este nivel conducen a un primer título académico. Los programas que conduzcan a un segundo o siguiente título pueden incluirse en el nivel CINE 6 siempre que la complejidad de sus contenidos sea equivalente a programas ya clasificados en este nivel dentro del mismo sistema educativo y que estos cumplan los demás criterios principales.

\section{Criterios subsidiarios}

a) Certificaciones del personal docente

(§225) En este nivel, la instrucción suele ser impartida bajo la modalidad de exposiciones orales por un personal docente que normalmente ha concluido un programa de nivel CINE 7 u 8 o ha adquirido vasta experiencia profesional.

(§231) En aquellos sistemas educativos donde se requiere que parte del personal docente haya obtenido certificaciones de nivel CINE 8, esta exigencia puede ser un buen criterio de aproximación para clasificar los programas educativos de este nivel. Lo anterior permite establecer una distinción entre los programas de nivel CINE 5 y de nivel CINE 6. 
b) Sin acceso directo a programas de nivel CINE 8

(§225) Los programas de este nivel no requieren necesariamente desarrollar una tesis (o proyecto de investigación) aunque de darse el caso esta no sería tan avanzada como una del nivel CINE 7 u 8, y el estudiante recibiría más orientación o tendría un menor grado de independencia que aquellos en programas de nivel CINE 7 u 8.

(§226) Normalmente, los programas de nivel CINE 6 no dan acceso directo al nivel CINE 8 (nivel de doctorado o equivalente).

\section{Dimensiones complementarias}

(§233) Dos dimensiones permiten diferenciar los programas educativos de nivel CINE 6.

(§234) Orientación del programa:

- Académica; y

- Profesional2.

(§235) Duración del programa y posición en la estructura nacional de títulos y certificaciones:

- Etapa (o programa) dentro del primer título del grado en educación terciaria o nivel equivalente con una duración teórica acumulada (en el nivel terciario) inferior a tres años; por lo tanto, considerada insuficiente para la conclusión del nivel CINE 6;

- Programa de primer título del grado en educación terciaria o nivel equivalente con una duración teórica acumulada (en el nivel terciario) de tres a cuatro años;

- Programa largo de primer título del grado en educación terciaria o nivel equivalente con una duración teórica acumulada (en el nivel terciario) de más de cuatro años; y

- Programa de segundo o siguiente título del grado en educación terciaria nivel o equivalente (tras la conclusión exitosa de un programa del grado en educación terciaria o programa equivalente).

\section{CORRESPONDENCIA ENTRE LOS NIVELES CINE 2011 Y CINE 1997}

Consulte esta sección en el capítulo de educación terciaria.

\section{DIRECTRICES PARA CLASIFICAR PROGRAMAS DE NIVEL CINE 6 Y CERTIFICACIONES RECONOCIDAS RELACIONADAS}

Los programas de este nivel son esencialmente teóricos, si bien pueden incluir un componente práctico, y están basados en investigación que refleja los últimos avances en el campo o las mejores prácticas profesionales. Los programas de nivel CINE 6, o grado en educación terciaria o nivel equivalente, suelen ser más largos y teóricos que los programas de nivel CINE 5. Con frecuencia, están destinados a impartir conocimientos, destrezas y competencias académicas o profesionales intermedias que conducen a un primer título o a una certificación equivalente (\$224).

Pueden incluir un componente práctico y/o requerir, además de estudios teóricos, un período de experiencia laboral (\$230).

Tradicionalmente, los programas de este nivel son ofrecidos por universidades y otras instituciones de educación superior (§224).

Es importante destacar que los programas con nombres similares a "licenciatura" deben incluirse en el nivel CINE 6 solo si son equivalentes en términos de complejidad del contenido y cumplen los demás criterios principales (\$227).

Habitualmente, el ingreso a estos programas requiere la conclusión exitosa de un programa de nivel CINE 3 o 4 que otorgue acceso a la educación terciaria. El ingreso puede depender de la selección de materias de estudio y/o las calificaciones obtenidas en los niveles CINE 3 y/o 4. Asimismo, podría ser necesario aprobar un examen de admisión. En 
ocasiones es factible ingresar o realizar una transferencia de créditos a un programa de nivel CINE 6 tras la conclusión exitosa del nivel CINE 5 (§226) (véase Ejemplos Nacionales - Grupo 4 en el nivel CINE 5).

Usualmente, los programas de este nivel conducen a un primer título académico y a certificaciones equivalentes de educación terciaria (aunque la persona puede haber obtenido una certificación de nivel CINE 5 con anterioridad a la matrícula en un programa de nivel CINE 6) (\$230). Normalmente, requieren de tres a cuatro años de estudio a tiempo completo en el nivel terciario. En el caso de los sistemas educativos que otorgan títulos en base a la acumulación de créditos, se requerirá un período comparable de duración y similar grado de intensidad (§229). (Ejemplos nacionales - Grupo 1)

En este nivel se deben incluir programas (largos) de primer título de más de 4 años de duración siempre que la complejidad de sus contenidos sea equivalente a programas del grado en educación terciaria (\$230). Ejemplos nacionales - Grupo 2. Sin embargo, los programas largos de primer título característicos de estudios profesionales altamente especializados (por ejemplo, medicina, odontología, ciencias veterinarias y, en algunos casos, derecho o ingeniería) habitualmente se clasifican en el nivel CINE 7 (§247). Estos son, típicamente, bastante más largos que otros programas de primer título clasificados en el nivel CINE 6 e incorporan un contenido más amplio y complejo, similar al nivel de maestría o equivalente.

Los programas que exigen un grado en educación terciaria o nivel equivalente como requisito de ingreso deben ser clasificados como segundo o siguiente título (incluso si no conducen a un título). Estos programas se caracterizan por tener una duración de 1 a 2 años, suelen tener una orientación profesional y ofrecen un grado de especialización superior a los programas de primer título, aunque su contenido no es significativamente más complejo (\$230). Ejemplos nacionales - Grupo 3. En general, los programas de nivel más avanzado que un título en educación terciaria y que además incluyen un importante componente de investigación deberían ser clasificados en el nivel CINE 7.

Una vez cursados los programas de nivel CINE 6, el estudiante puede continuar su educación en el nivel CINE 7 (nivel de maestría, especialización o equivalente), si bien no todos los programas de nivel CINE 6 dan acceso al nivel CINE 7 (§226). Los programas que requieren como requisito de ingreso la exitosa conclusión de un programa de nivel CINE 7 no deben ser clasificados en el nivel CINE 6, independientemente de su duración.

\section{LOGRO EDUCATIVO EN EL NIVEL CINE 6}

El logro educativo en el nivel CINE 6 tiene como requisito la conclusión exitosa de un programa que conduzca a una certificación reconocida de una duración mínima de 3 años en el nivel CINE 6. En los países integrantes del Espacio Europeo de Educación Superior, esto sería equivalente a un mínimo de 180 créditos del Sistema Europeo de Transferencia y Acumulación de Créditos.

(§238) En términos de logro educativo, las certificaciones intermedias otorgadas tras la conclusión exitosa de etapas de programas de nivel CINE 6 (previo a la obtención del primer título) que son consideradas insuficientes para concluir este nivel, se clasifican en el nivel CINE 5.

La conclusión exitosa de un programa que represente menos de 3 años de estudio en el nivel CINE 6, generalmente da origen a un logro educativo de nivel CINE 5 (incluso en países que no cuentan con programas de nivel CINE 5). Ejemplos Nacionales - Grupo 4.

(§239) Las certificaciones intermedias otorgadas tras la conclusión exitosa de programas (en forma previa a la obtención del primer título) consideradas insuficientes para la conclusión del nivel CINE 7 , se clasifican en el nivel CINE 6 respecto del logro educativo.

Los doctorados honoris causa otorgados por universidades aunque no necesariamente por motivos relacionados con la investigación, no son reconocidos para propósitos de logro educativo. 


\section{EJEMPLOS DE PROGRAMAS Y CERTIFICACIONES CLASIFICADAS EN EL NIVEL CINE 6}

(§227) Los programas clasificados en el nivel CINE 6 pueden recibir distintas denominaciones, por ejemplo: Bachelor, licence o primer ciclo universitario. Cabe destacar, sin embargo, que los programas con nombres similares a "licenciatura" deben incluirse en el nivel CINE 6 solo si cumplen los criterios reseñados en la clasificación CINE 2011 (párrafo 228). Para propósitos de comparación a nivel internacional, se usa el término "grado en educación terciaria o nivel equivalente" para denominar al nivel CINE 6.

\section{Ejemplos nacionales - Grupo 1: \\ Programas de primer título del grado en educación terciaria o nivel equivalente (entre 3 y 4 años) [CINE-P: 645, 655 o 665; CINE-A: 640, 650 o 660]}

Djibouti - Enseignement supérieur de cycle long (Educación terciaria de ciclo largo). Este es un programa terciario de cuatro años de duración que requiere la conclusión de educación secundaria alta (con acceso a educación terciaria) como condición mínima de admisión. Tras su conclusión, los graduados reciben un título equivalente a un grado de educación terciaria (Licence o Maitrise) en el campo de estudio pertinente. (CINE-P: 665; CINE-A: 660)

Finlandia - Ammattikorkeakoulututkinnot (Programa politécnico de grado en educación terciaria). Estos programas, de tres o cuatro años de duración, preparan para ocupaciones que exigen destrezas de alto nivel. Se caracterizan por combinar estudios (básicos y profesionales) con un componente de trabajo y capacitación práctica. Los programas requieren la presentación de un proyecto de investigación o tesis. Los estudiantes deben haber finalizado la educación secundaria alta como condición de admisión. (CINE-P: 665; CINE-A: 660)

Alemania - Fachhochschulen (Universidades de ciencias aplicadas). Este programa universitario de cuatro años de duración prepara para ocupaciones que requieren la aplicación de observaciones y métodos científicos. Para ser elegibles los estudiantes deben haber completado como mínimo Fachoberschule (CINE 3 o 4) o equivalente. Conduce a un primer título terciario, Diplom (FH). (CINE-P: 645; CINE-A: 640)

Japón - Koutou senmon gakko Senkoka, Tokurei Tekiyou Senkoka (Instituto Superior de Tecnología, NIAD-UE curso avanzado validado). Este programa se ofrece tras la conclusión exitosa del programa de cinco años de duración Koutou senmon gakko (Institutos superiores de tecnología) (tres primeros años: CINE-P 354, dos últimos años CINE-P554). Si bien la ley establece una duración mínima de un año para estos programas, todos los programas Koutou senmon gakko Senkoka se prolongan por más de dos años e imparten una educación avanzada y especializada en ingeniería. Los estudiantes que concluyen con éxito Tokurei Tekiyou Senkoka (Instituto Superior de Tecnología, NIAD-UE curso avanzado validado) reconocido como equivalente a un programa de pre-grado por la Institución Nacional de Títulos Académicos y Evaluación Universitaria (NIAD-UE), pueden recibir un grado en educación terciaria o continuar su educación participando en estudios universitarios superiores. (CINE-P: 665; CINE-A: 660)

Kirguistán - Высмее профессиональное образование, ведущее к поступлению в программы продвинутых научных исследований и получению диплома бакалавра (Programa de grado en educación terciaria). Este es un programa terciario de cuatro años de duración que tiene como requisito de ingreso un certificado de educación secundaria alta. Tras su exitosa conclusión, lo graduados reciben un grado en educación terciaria en el correspondiente campo de estudio. (CINE-P: 665; CINE-A: 660)

Países Bajos - Hoger beroepsonderwijs (HBO) (Programas profesionales de primer grado en educación terciaria). Los programas $\mathrm{HBO}$, que tienen una duración de cuatro años, ofrecen formación teórica y práctica para ocupaciones que requieren una certificación más avanzada. El tipo de enseñanza que imparten estos programas de nivel más avanzado es más práctica que la ofrecida en las universidades. Los campos de estudio más comunes son la agricultura, la pedagogía, el trabajo social y la educación comunitaria, el cuidado de la salud y las artes (CINE-P: 665; CINE-A: 660)

España - Diplomatura Universitaria, primer ciclo. Este es un primer programa de tres años de duración que otorga un título universitario, cuya conclusión conduce a las certificaciones Diplomado Universitario, Arquitecto Técnico o Ingeniero Técnico en un campo específico. Las personas poseedoras de estas certificaciones pueden ingresar directamente al mercado laboral, o avanzar a la educación universitaria de segundo ciclo. (CINE-P: 665; CINE-A: 660) 
Suiza - Fachhochschule, haute école spécialisée (Grado en educación terciaria). Estos programas de tres a cuatro años de duración requieren como requisito de ingreso la conclusión de la "Berufsmaturität/maturité professionnelle" (educación vocacional de nivel CINE 3 con una duración de tres a cuatro años y un componente de educación general sustancialmente ampliado). Preparan a los estudiantes para profesiones de alta exigencia en campos de estudio como la arquitectura, ingeniería, administración de empresas, diseño, salud, trabajo social, arte y educación. (CINE-P: 645; CINE-A: 640)

Tailandia - Vocational Education and Training programmes at Bachelor's level (continuing education). Estos programas de dos años de duración se ofrecen en el contexto de la educación permanente. La admisión a estos programas está predicada en la conclusión de un diploma profesional de dos años de duración clasificado como educación terciaria de ciclo corto (nivel CINE 5). Por lo tanto, el programa representa una duración acumulada total de cuatro años de estudio en el nivel terciario. Tras su conclusión exitosa, los graduados reciben un grado en educación terciaria o equivalente. (CINE-P: 665; CINE-A: 660)

Túnez - (Licenciatura aplicada). Este primer programa universitario de tres años de duración requiere la conclusión de educación secundaria alta con acceso a la educación terciaria como requisito mínimo de admisión. Tras su conclusión, los graduados reciben la licenciatura aplicada (Licence appliquée) en un campo específico de la educación, que conduce al mercado laboral o a un nivel más avanzado de educación. (CINE-P: 665; CINE-A: 660)

Reino Unido - Honours degree - Bachelor's degree programme. Este es un primer grado en educación terciaria otorgado habitualmente después de tres años de estudio. En general, los estudiantes deben someterse a una serie de exámenes anuales o a un sistema de evaluaciones permanentes y aprobar un examen de grado al finalizar el programa. La licenciatura superior normalmente considera solamente el estudio de una asignatura principal y una asignatura subsidiaria. (CINE-P: 665; CINE-A: 660)

Estados Unidos - Bachelor's degree programme. Este es el típico programa de cuatro años de duración impartido en institutos de educación superior o universidades. Normalmente, los programas de pre-grado tienen como requisito de ingreso un diploma de educación secundaria o equivalente. Los poseedores de un grado en educación terciaria pueden incorporarse a la fuerza laboral o continuar su educación participando en programas a nivel de maestría, doctorado o de primer título profesional (derecho, medicina, odontología). (CINE-P: 665; CINE-A: 660)

\section{Ejemplos nacionales - Grupo 2: \\ Programas largos de primer título del grado en educación terciaria o nivel equivalente (más de 4 años) [CINE-P: 646, 656 o 666; CINE-A: 640, 650 o 660]}

Argelia - (Ingeniero del estado). Este programa terciario de cinco años de duración se ofrece a los graduados de educación secundaria alta. Tras su conclusión, los graduados reciben el título de ingeniero del estado (Ingénieur d'état) en diversos campos de estudio. (CINE-P: 666; CINE-A: 660)

Colombia - Título Universitario. Estos son programas universitarios largos de primer título del grado (con una duración mínima de cuatro, más frecuentemente, cinco años), que otorgan al estudiante un título profesional o un título en un campo específico. Los requisitos de admisión son la conclusión de la educación secundaria alta (nivel CINE 3) y la aprobación del examen estatal que permite ingresar a la educación terciaria. (CINE-P: 666, CINE-A: 660)

Dinamarca -Mellemlange videregående uddannelser - professionsbachelor (Educación terciaria, ciclo intermedio, grado profesional en educación terciaria). Estos programas de cinco años de duración, que tienen como requisito de ingreso la conclusión exitosa de la educación secundaria alta (nivel CINE 3), preparan a los estudiantes para desempeñar cargos profesionales en campos como la ingeniería. El grado obtenido se considera similar en nivel al de otros programas del grado en educación terciaria que, sin embargo, tienen una duración inferior ( 3 o 4 años). Tras su conclusión, los estudiantes quedan libres de practicar la profesión seleccionada u optar por continuar su educación a nivel de maestría. (CINE-P: 666, CINE-A: 660)

México - Licenciatura universitaria (5 años de duración). El requisito de ingreso a estos programas universitarios es el Bachillerato (certificado de secundaria alta). Pese a que la duración de otros programas nacionales de Licenciatura es un año más corta, los grados obtenidos después de cinco años de estudio se consideran similares, y todo ellos se clasifican en el nivel CINE 6. Tras la conclusión de estos programas, los estudiantes pueden postular a una maestría (nivel CINE 7). (CINE-P: 666, CINE-A: 660) 
República Árabe Siria - (Programas de ingeniería técnica). Estos programas de educación terciaria en el campo de la ingeniería tienen una duración de cinco años y, como requisito mínimo de ingreso, la conclusión de la educación secundaria alta. Tras su conclusión exitosa, los graduados reciben un grado en educación terciaria en ingeniería. (CINE-P: 666, CINE-A: 660)

\section{Ejemplos nacionales - Grupo 3:}

Segundo o siguiente título (tras la conclusión exitosa de un grado en educación terciaria o nivel equivalente [CINE-P: 647, 657 o 667; CINE-A: 640, 650 o 660]

Côte d'Ivoire - Enseignement universitaire général : $2^{e}$ cycle (Maîtrise) (Educación universitaria general, $2^{\text {do }}$ ciclo, que conduce a una Maîtrise). Este es un programa de segundo título que requiere la conclusión exitosa de un programa License equivalente a un grado en educación terciaria. Este programa, de solo un año de duración, no incluye un componente significativo de investigación. (CINE-P: 667, CINE-A: 660)

India - Bachelor of Education (B.Ed). Este es un programa terciario de pedagogía de un año de duración ofrecido a personas que ya han obtenido un grado en educación terciaria en distintas disciplinas y están interesadas en seguir una carrera pedagógica. Al finalizar el programa se otorga un título de grado en educación terciaria. (CINE-P: 667, CINE-A: 660)

Irlanda - Higher Diploma. Normalmente, este diploma se otorga tras la conclusión de un programa de un año de duración impartido en una institución reconocida de educación superior. El requisito de entrada para un programa Higher Diploma es típicamente un título de Honours Bachelor's aunque un título Ordinary Bachelor's también da acceso. Las personas que finalizan con éxito el Higher Diploma pueden postular al diploma de postgraduado, maestría o, en algunos casos, a programas que conducen al nivel de doctorado. (CINE-P: 667, CINE-A: 660)

Marruecos - (Programa de formación de profesores de educación primaria). Este es un programa de un año de duración que requiere la conclusión de un programa equivalente al grado en educación terciaria (Diplôme de Licence d'études fondamentales (LEF)) como requisito de ingreso. Tras la conclusión del programa de formación de profesores, los estudiantes reciben el Certificat d'études normales d'instituteurs (CENI), que les permite desempeñarse como profesores de educación primaria calificados. CINE-P: 667, CINE-A: 660)

Noruega - Videreutdanning (Cursos de especialización). Estos programas incluyen diversas especializaciones profesionales particularmente para docentes y profesionales paramédicos, siendo la más prolongada la especialidad de obstetricia (dos años a partir de la certificación de enfermera). Refuerzan el grado en educación terciaria pero no conducen a una maestría. (CINE-P: 647, CINE-A: 640)

Arabia Saudita - (Programas de diplomas más avanzados). Estos son programas terciarios de uno a dos años de duración que tienen como requisito mínimo la conclusión de un grado en educación terciaria. Estos programas, que se ofrecen principalmente en el campo de la educación, conducen a un diploma más avanzado que, sin embargo, es considerado inferior al nivel de maestría a nivel nacional. (CINE-P: 667, CINE-A: 660)

Suiza - Fachhochschule Nachdiplom, haute école spécialisée diplôme postgrade. (Maestría en estudios avanzados). Después de la obtención del primer título, las universidades ofrecen programas de maestría o especialización que no conducen a un título de investigación (Maestría en estudios avanzados). Su duración típica es de un año o 60 créditos del sistema europeo de transferencia (ECTS). Algunos ejemplos son la administración de empresas para ingenieros o la especialización en aspectos ambientales para ingenieros químicos. La duración acumulada en el nivel CINE 6 fluctúa entre cuatro y seis años y medio, dependiendo de las características de cada programa. La certificación a que da lugar se considera de un nivel similar al primer grado en educación terciaria. (CINE-P: 647, CINE-A: 640)

Ejemplos nacionales - Grupo 4:

Programas de nivel CINE 6 considerados insuficientes para conclusión del nivel que en consecuencia conducen a un logro educativo de nivel CINE 5 [CINE-P: 641, 651 o 661; CINE-A: 540, 550 o 560]

Burkina Faso - Diplôme universitaire d'études générales (DEUG) (Diploma universitario en estudios generales). Este es un programa terciario de dos años de duración que requiere la conclusión de educación secundaria alta (nivel CINE 3). Tras la conclusión del DEUG, los estudiantes pueden participar en programas License (grado en educación terciaria) de un año de duración, u optar por el diploma de ingeniería de tres años de duración. (CINE-P: 661, CINE-A: 540) 
Burundi - 1er cycle de l'enseignement supérieur (Primer ciclo de educación terciaria). Este es un programa de dos años de duración que forma parte del primer ciclo del programa de grado en educación terciaria (o Licence). El segundo ciclo puede tener una duración de dos o tres años según el campo de estudio. Tras la conclusión exitosa del primer ciclo, que requiere como condición de ingreso la conclusión de educación secundaria alta con acceso a terciaria, los estudiantes pueden avanzar al segundo ciclo. (CINE-P: 661, CINE-A: 540)

Canadá - University Transfer Programmes. Estos programas de uno o dos años de duración son ofrecidos por institutos no universitarios a través de acuerdos especiales con universidades en virtud de los cuales el instituto ofrece el primer año (o los primeros años) de un programa universitario. Los estudiantes que finalizan estos programas en los institutos pueden transferir sus créditos a los programas de grado en educación terciaria impartidos por la universidad. Si bien la matrícula en estos programas se clasifica como nivel CINE 6, los estudiantes que finalizan estos programas no se reportan como graduados de este nivel. En términos de logro educativo, se reportan en el nivel CINE 5. (CINE-P: 641, CINE-A: 540)

Noruega - Høgskolekandidat (Título otorgado por university colleges). El título otorgado por un university college representa un programa terciario de dos años de duración. Los estudiantes deben haber completado la educación secundaria alta (nivel CINE 3) como requisito de ingreso. Con frecuencia, al momento de la graduación, este título se convierte en parte integral del programa de grado en educación terciaria. (CINE-P: 641, CINE-A: 540)

\section{Notas}

1. Los números de los párrafos refieren al documento de clasificación CINE 2011. Para mayores detalles, sírvase consultar la Guía del Lector.

2. Pese a no contar con definiciones internacionalmente consensuadas sobre orientaciones académicas y profesionales, algunos países han aplicado sus definiciones nacionales y utilizado estos códigos en sus mapas CINE. 


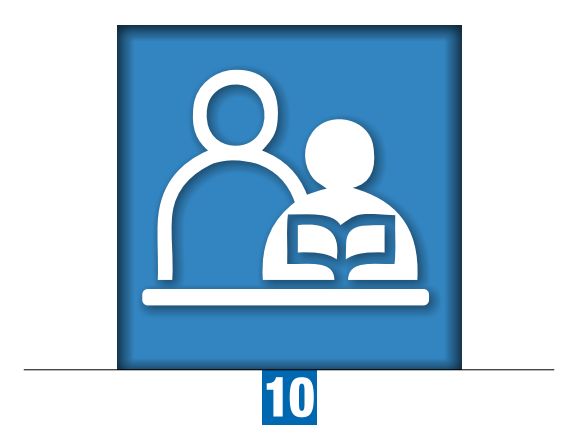

Capítulo 10

\section{Nivel 7 - Cine 2011:}

\section{Nivel de maestría, especialización o equivalente}

Los programas de nivel CINE 7, o nivel de maestría, especialización o equivalente, tienen un contenido significativamente más complejo que los programas de nivel CINE 6 y suelen ser más especializados. El contenido de los programas de nivel CINE 7 tiene por objetivo impartir al participante competencias académicas y/o profesionales avanzadas que conduzcan a un segundo título o a una certificación equivalente. Los programas de este nivel pueden incluir un importante componente de investigación, aunque no otorgan las certificaciones relacionadas al nivel de doctorado. La duración acumulada de estudios de nivel terciario puede prolongarse entre cinco y ocho años, e incluso más.

Los programas clasificados en el nivel CINE 7 pueden recibir distintas denominaciones, por ejemplo: maestrías, o magister. Para propósitos de comparación a nivel internacional, se usa el término "nivel de maestría, especialización o equivalente" para denominar al nivel CINE 7. 


\section{DESCRIPCIÓN}

\section{Definición}

$(\S 241)^{1}$ Los programas de nivel CINE 7, o nivel de maestría, especialización o equivalente, suelen tener como principal objetivo impartir al participante competencias académicas y/o profesionales avanzadas que conduzcan a un segundo título o a una certificación equivalente. Los programas de este nivel pueden incluir un importante componente de investigación, aunque no otorgan las certificaciones relacionadas al nivel de doctorado. Se caracterizan por ser esencialmente teóricos - si bien pueden incluir un componente práctico - y por estar basados en investigaciones que reflejan los últimos avances del campo o en las mejores prácticas profesionales.

(§243) El contenido de los programas de nivel CINE 7 es significativamente más complejo que el contenido de los programas de nivel CINE 6 y suele ser más especializado. Una vez concluidos estos programas, la persona puede continuar sus estudios en el nivel CINE 8 (nivel de doctorado). Sin embargo, no todos los programas de nivel CINE 7 dan acceso directo al nivel CINE 8.

\section{Criterios de clasificación (\$228)}

\section{Criterios principales}

a) Contenido esencialmente teórico y/o profesional

(§241) Los programas de este nivel se caracterizan por ser esencialmente teóricos - si bien pueden incluir un componente práctico - y por estar basados en investigaciones que reflejan los últimos avances del campo o en las mejores prácticas profesionales.

b) Posición en la estructura nacional de títulos y certificaciones

(§246) Habitualmente, los programas de este nivel preparan para un segundo o siguiente título luego de haber obtenido un primer título de nivel CINE 6 o 7.

(§247) Los programas con una duración mínima de cinco años destinados a preparar al estudiante para un primer título se incluirán en este nivel si en términos de complejidad del contenido son equivalentes a una maestría/especialización. También se incluyen en este nivel estudios profesionales altamente especializados de una duración acumulada similar o superior a los anteriormente mencionados (por ejemplo, medicina, odontología, ciencias veterinarias y, en algunos casos, derecho o ingeniería) que cubren, tanto en amplitud como profundidad, una cantidad equivalente de contenido.

a) Requisitos de ingreso

(§243) Habitualmente, el ingreso a programas de nivel CINE 7 que preparan para un segundo o siguiente título requiere la conclusión de un programa de nivel CINE 6 o 7. En el caso de programas largos que preparan para un primer título equivalente a un nivel de maestría/especialización, se exige como requisito de ingreso la conclusión exitosa de un programa de nivel CINE 3 o 4 que de acceso a la educación terciaria.

\section{Criterios subsidiarios}

b) Duración acumulada mínima de programas largos de primer título

(§247) Se incluyen en este nivel los programas con una duración mínima de cinco años destinados a preparar al estudiante para un primer título.

c) Acceso directo a programas de nivel CINE 8

(§249) Frecuentemente, los programas de educación terciaria que dan acceso directo al nivel CINE 8 se clasifican en el nivel CINE 7. Sin embargo, no todos los programas de nivel CINE 7 cumplen esta condición. 


\section{Dimensiones complementarias}

(§251) Dos dimensiones permiten diferenciar los programas educativos de nivel CINE 7.

(§252) Orientación del programa:

- Académica; y

- Profesional ${ }^{2}$.

(§253) Posición en la estructura nacional de títulos y certificaciones.

- Etapa (o programa) dentro del primer título de nivel maestría, especialización o equivalente con una duración teórica acumulada (en el nivel terciario) inferior a cinco años que, por lo tanto, no se considera suficiente para la conclusión del nivel CINE 7;

- Programa largo de primer título de nivel maestría, especialización o equivalente con una duración teórica acumulada (en el nivel terciario) de al menos cinco años (que no requiere estudios previos de educación terciaria);

- Programa de segundo o siguiente título de nivel maestría, especialización o equivalente (tras la conclusión exitosa de un programa del grado en educación terciaria o equivalente); y Programa de segundo o siguiente título de nivel maestría, especialización o equivalente (tras la conclusión exitosa de otro programa de maestría, especialización o equivalente).

\section{CORRESPONDENCIA ENTRE LOS NIVELES CINE 2011 Y CINE 1997}

Consulte esta sección en el capítulo de educación terciaria.

\section{DIRECTRICES PARA CLASIFICAR PROGRAMAS DE NIVEL CINE 7 Y CERTIFICACIONES RECONOCIDAS RELACIONADAS}

Los programas de nivel CINE 7 se caracterizan por tener un contenido significativamente más complejo que los programas de nivel CINE 6 y suelen ser más especializados (\$243). El contenido de los programas de nivel CINE 7 tiene por objetivo impartir al participante competencias académicas y/o profesionales avanzadas que conduzcan a un segundo título o a una certificación equivalente. Los programas de este nivel pueden incluir un importante componente de investigación, aunque no otorgan las certificaciones relacionadas al nivel de doctorado (§241).

Tradicionalmente, los programas de este nivel son ofrecidos por universidades y otras instituciones de educación superior (§224). Los programas con nombres similares a "maestría" deben ser incluidos en el nivel CINE 7 solo si son equivalentes en términos de complejidad del contenido a los programas ya clasificados en este nivel y cumplen los demás criterios principales (§244).

El ingreso a programas de nivel CINE 7 que preparan para un segundo o siguiente título requiere la conclusión de un programa de nivel CINE 6 o 7 . En el caso de programas largos que preparan para un primer título equivalente a un nivel de maestría/especialización, se exige como requisito de ingreso la conclusión exitosa de un programa de nivel CINE 3 o 4 que de acceso a la educación terciaria. El ingreso a programas impartidos en estos niveles puede depender de la selección de materias de estudio y/o las calificaciones obtenidas en los niveles CINE 3 y/o 4. Adicionalmente, podría ser necesario aprobar un examen de admisión (\$243).

Habitualmente, los programas de este nivel preparan para un segundo o siguiente título (Ejemplos nacionales Grupo 1) tras haber obtenido un primer título de nivel CINE $6 \circ$ 7. Las certificaciones equivalentes, por ejemplo, certificaciones profesionales de post-grado (Ejemplos nacionales - Grupo 1), también se clasifican en el nivel CINE 7 , salvo si ya han sido clasificadas en el nivel CINE 6 (\$246). Ambos tipos de programas suelen tener una duración que puede variar entre uno a cuatro años de estudio a tiempo completo. En los sistemas educativos que otorgan títulos en base a la acumulación de créditos, se requerirá un período comparable de tiempo y similar grado de intensidad. Por consiguiente, la duración acumulada de estudios de nivel terciario suele prolongarse entre cinco y ocho años, e incluso más (§248). 
Los programas con una duración mínima de cinco años destinados a preparar al estudiante para un primer título largo se incluirán en este nivel si en términos de complejidad del contenido son equivalentes a una maestría/especialización. Estos programas normalmente requieren la preparación de una tesis o disertación (§247). (Ejemplos nacionales Grupo 2).

También se incluyen en este nivel estudios profesionales altamente especializados de una duración acumulada similar o superior a los anteriormente mencionados (por ejemplo, medicina, odontología, ciencias veterinarias y, en algunos casos, derecho o ingeniería) que cubren, tanto en amplitud como profundidad, una cantidad equivalente de contenido (§247). (Ejemplos nacionales - Grupo 3).

Una vez concluidos estos programas, la persona puede continuar sus estudios en el nivel CINE 8 (nivel de doctorado). Sin embargo, no todos los programas de nivel CINE 7 dan acceso directo al nivel CINE 8 (§243).

\section{LOGRO EDUCATIVO EN EL NIVEL CINE 7}

El logro educativo en el nivel CINE 7 tiene como requisito la conclusión exitosa de un programa que conduzca a una certificación reconocida de una duración mínima de 5 años en el nivel terciario. En los países integrantes del Espacio Europeo de Educación Superior, esto sería equivalente a un mínimo de 300 créditos del Sistema Europeo de Transferencia y Acumulación de Créditos.

(§256) En términos de logro educativo, las certificaciones intermedias otorgadas tras la conclusión de etapas (o programas) de un primer título del nivel de maestría, especialización o equivalente consideradas insuficientes para concluir el nivel CINE 7 se clasifican en el nivel CINE 6.

La conclusión exitosa de un programa que represente menos de 5 años de estudio en el nivel terciario, generalmente da origen a un logro educativo de nivel CINE 6. (Ejemplos nacionales - Grupo 4).

(§257) Asimismo, las certificaciones intermedias otorgadas tras la conclusión exitosa de etapas (o programas) de nivel de doctorado o equivalente consideradas insuficientes para la conclusión del nivel CINE 8 se clasifican en el nivel CINE 7 para los efectos de logro educativo.

Los doctorados honoris causa otorgados por universidades aunque no necesariamente por motivos relacionados con la investigación, no son reconocidos para propósitos de logro educativo.

\section{EJEMPLOS DE PROGRAMAS Y CERTIFICACIONES CLASIFICADAS EN EL NIVEL CINE 7}

(§244) Los programas clasificados en el nivel CINE 7 pueden recibir distintas denominaciones, por ejemplo: maestrías, o magister. Cabe señalar, no obstante, que los programas con nombres similares a "maestría" deben ser incluidos en el nivel CINE 7 solo si cumplen los criterios descritos en la clasificación CINE 2011 (párrafo 245). Para propósitos de comparación a nivel internacional, se usa el término "nivel de maestría, especialización o equivalente" para denominar a nivel CINE 7.

\section{Ejemplos nacionales - Grupo 1: \\ Programa de segundo o siguiente título a nivel de maestría, especialización o equivalente (tras la exitosa conclusión de un grado en educación terciaria o programa equivalente) [CINE-P: 747, 757 o 767; CINE-A: 740, 750 o 760]}

Australia - Master's degree. Este título de nivel más avanzado se obtiene típicamente tras un período de estudio de dos años a partir de la conclusión del grado en educación terciaria. El ingreso al nivel de maestría requiere completar un curso habilitante de un año de duración. El título de maestría se puede obtener a través de iniciativas de investigación (generalmente iniciadas después de un período de empleo) que culmina con la presentación de una tesis, o a través de un trabajo teórico generalmente realizado paralelamente al desempeño de un cargo profesional. (CINE-P: 767; CINE-A: 760) 
Colombia - Maestría. Este programa conduce al título de Magister (maestría) y tiene como requisito de ingreso la posesión de un título profesional o universitario en el campo de la tecnología, la ciencia, las humanidades, las artes o la filosofía. La duración del programa suele ser de dos años. (CINE-P: 767, CINE-A: 760)

Japón - Daigakuin Shushi katei. (Programa post-grado que conduce a la shushi (maestría)). La obtención del título de shushi requiere dos años de estudio a tiempo completo a partir de la conclusión del gakushi (grado en educación terciaria), 30 créditos y una cantidad significativa de investigación que culmina en una tesis. (CINE-P: 767, CINE-A: 760)

México - Maestría. Este programa incluye investigación avanzada y amplios conocimientos sobre asignaturas y campos de estudio específicos. La duración del programa suele ser de dos años. El requisito de ingreso es la conclusión de un programa de Licenciatura de de cuatro o cinco años de duración. (CINE-P: 767, CINE-A: 760)

Santo Tomás y Príncipe - Mestrado (Maestría). Este es un clásico programa de post-grado de dos años de duración que conduce a un segundo título tras la conclusión exitosa de un programa equivalente al grado en educación terciaria (License). La conclusión de este programa, el más avanzado en el sistema nacional de educación, conduce a la maestría (Mestrado). (CINE-P: 767, CINE-A: 760)

Eslovenia - Magistrsko izobraževanje (2. bolonjska stopnja) (Maestría). La duración de estos estudios es de uno o dos años, tras la conclusión exitosa del nivel CINE 6 (Primer ciclo de Boloña). Los graduados obtienen el diploma de maestría (con el título profesional) que les da acceso a estudios de nivel de doctorado. (CINE-P: 767, CINE-A: 760)

Estados Unidos - First-professional degree programmes. La conclusión de estos programas significa tanto el cumplimiento de los requisitos académicos necesarios para iniciar el ejercicio de una profesión como haber adquirido un nivel de competencias profesionales que superan el normalmente requerido para el grado en educación terciaria. Típicamente, estos programas tienen una duración de tres años y requieren al menos dos años de estudio en el nivel CINE 6 previo a ingresar (si bien la mayoría requiere la obtención de un grado en educación terciaria de cuatro años de duración). Estos primeros títulos profesionales representan la ruta que generalmente toman los estudiantes para habilitarse como profesionales en los campos de odontología, medicina, optometría, farmacia, medicina veterinaria, derecho y profesiones teológicas. (CINE-P: 757, CINE-A: 750)

\section{Ejemplos nacionales - Grupo 2: \\ Primer título largo a nivel de maestría, especialización o equivalente (cinco años como mínimo) [CINE-P: 746, 756 o 667; CINE-A: 740, 750 o 760]}

Gambia - Medical degree. Este es un programa de siete años de duración a partir de la conclusión de la educación secundaria alta. Al finalizar el programa, los estudiantes reciben una maestría en medicina. (CINE-P: 766, CINE-A: 750)

Alemania - Universitäten - Diplom, Magister. (Universidad - Maestría). Estos ex programas universitarios no han sido adaptados a la estructura de Boloña. Al cabo de ocho a diez semestres de estudio conducían a un primer título equivalente a una maestría (CINE-P: 746; CINE-A: 740). Estos programas requerían la preparación de una tesis o disertación además del trabajo de curso realizado durante los semestres iniciales del programa. Los graduados de este programa tenían acceso a programas de doctorado. (CINE-P: 746; CINE-A: 740).

Alemania - Universitäten - Staatsexamen (Programas universitarios en los campos de formación docente, odontología, medicina, medicina veterinaria, farmacia, derecho y profesiones teológicas). Después de ocho a diez semestres de estudios universitarios, estos programas conducen a un examen administrado por el estado equivalente a la maestría (nivel CINE 7). (CINE-P: 746; CINE-A: 740).

Japón - Daigaku Yakugaku Ishigaku Juigaku (Programa universitario de pre-grado). El gakushi es la primera certificación otorgada después de seis años de estudio de farmacología (solo el curso práctico), medicina, odontología y veterinaria. Además de estudiar uno de estos campos especializados los participantes también tienen la obligación de estudiar educación general (que incluye humanidades y ciencias sociales y naturales). (CINE-P: 766; CINE-A: 760).

Kirguistán - Высшее профессиональное образование, ведущее к поступлению в программы продвинутых научных исследований и получению диплома специалиста (Programa de primer título terciario largo, que conduce a un diploma de especialista). El primer título universitario tiene una duración de cinco años. El requisito mínimo de ingreso es el certificado de educación secundaria alta. El programa incluye cursos con un contenido significativamente más complejo 
que otros programas de nivel CINE 6. Al finalizar el programa, los graduados reciben un diploma de especialista. (CINE-P: 766; CINE-A: 760).

República Popular Democrática de Lao - Licence de médecine (Grado en educación terciaria en medicina). Este es un programa terciario largo de primer título (seis años de duración) que requiere como requisito de entrada la conclusión de educación secundaria alta con acceso a educación terciaria (Certificat de Baccalauréat). Se caracteriza por su larga duración y alta especialización. Pese a que el título recibido es "grado en educación terciaria en medicina" el programa incluye estudios significativamente más complejos que los que habitualmente se encuentran en este nivel por lo cual se considera más avanzado (maestría). (CINE-P: 766; CINE-A: 760).

Mozambique - Mestrado Integrado (Maestría integrada). Este programa de primer título de cinco años de duración tiene como requisito mínimo de ingreso la conclusión de educación secundaria alta. Al finalizar el programa, los graduados reciben una maestría. (CINE-P: 766; CINE-A: 760).

Portugal - Ensino Superior - Licenciatura (Educación terciaria - primer título largo, cuatro a seis años). Estos son programas anteriores a Boloña. El ingreso a estos programas de cuatro a seis años de duración, normalmente ofrecidos por universidades, requiere la conclusión exitosa de educación secundaria alta. En la mayoría de los campos de estudio, los programas solían tener una duración de cuatro a cinco años, si bien también existían programas de seis años. Los estudiantes que obtenían una calificación de 16 o más en su examen de graduación podían acceder directamente al nivel de doctorado. Las certificaciones finales otorgadas por estos programas anteriores a Boloña son reconocidas a nivel nacional como equivalentes al nivel CINE 7 en la CINE 2011. (CINE-P: 766; CINE-A: 760).

\section{Ejemplos nacionales - Grupo 3: \\ Segundo o siguiente título a nivel de maestría o equivalente (tras la conclusión exitosa de un programa nivel de maestría, especialización o equivalente) [CINE-P: 748, 758 o 667; CINE-A: 740, 750 o 760]}

Australia - Doctor of Philosophy by coursework. Estos programas de tres años de duración requieren como condición de acceso la conclusión exitosa de una primera maestría y se caracterizan por ofrecer una mayor especialización en campos profesionales y académicos de estudio. El programa está basado en cursos y no conduce a una tesis a nivel de doctorado que sea el producto de una investigación original y represente una contribución significativa al conocimiento en el campo de estudio respectivo. Por consiguiente, el título obtenido se considera similar a uno de nivel de maestría (nivel CINE 7). (CINE-P: 748; CINE-A: 740).

Canadá - Graduate qualifying programme (third cycle). El requisito de ingreso a estos programas de uno a dos años de duración es la conclusión de un primer título de maestría. Estos programas preparan a los estudiantes para realizar estudios a nivel de doctorado en el caso que su formación previa no cumpliera los requisitos necesarios (por ejemplo, estudiantes que iniciaron sus estudios en un campo y desean continuar sus estudios a nivel de doctorado en una área diferente o de mayor complejidad, o que han obtenido una maestría más profesional que académica). La certificación obtenida corresponde al nivel de maestría (nivel CINE 7). Tras su conclusión, los estudiantes pueden postular a programas de doctorado. (CINE-P: 768; CINE-A: 760).

Alemania - Universitäten - zweiter Master (Estudios universitarios - segunda maestría). El requisito de ingreso a estos programas de uno a dos años de duración es la conclusión de un primer título de maestría. Los programas se caracterizan por ofrecer más especialización en campos profesionales y académicos de estudio. El título obtenido se considera similar a uno de nivel de maestría (nivel CINE 7). Tras su conclusión, los estudiantes pueden postular a programas de doctorado (Promotionsstudium). (CINE-P: 748; CINE-A: 740).

Italia - Master di $2^{\circ}$ livello (Maestría de segundo nivel). Estos programas de un año de duración requieren como condición de acceso la conclusión exitosa de un Master di $1^{\circ}$ livello (primer nivel de maestría de un año de duración) y ofrecen más especialización en un área determinada de estudio. El título obtenido se considera similar a uno de nivel de maestría (nivel CINE 7). Tras su conclusión, los estudiantes pueden postular al Dottorato di ricerca (Doctorado en investigación). (CINE-P: 768; CINE-A: 760).

Kazajstán - Резидентура, послевузовское углублённое медицинское образование (Residencia médica, formación médica de post-grado). La duración de estos programas de post-grado puede fluctuar entre dos y cuatro años según la especialidad médica. El acceso a estos programas requiere la conclusión exitosa de un primer título de maestría (una combinación de un título de medicina general y trabajo de internado). Los programas, que incluyen componentes de 
investigación y trabajo en el aula además de un período como residente en un hospital, conducen a un certificado de conclusión de la educación médica. (Свидетельство об окончании резидентуры). (CINE-P: 768; CINE-A: 760).

Mauritania - Formation des enseignants au secondaire (Formación de profesores de educación secundaria). Este programa de un año de duración requiere como requisito mínimo de ingreso haber obtenido un título de maestría. Al finalizar el programa, los graduados reciben el Certificat d'aptitude au professorat de l'enseignement secondaire (CAPES), que les permite desempeñarse como profesores de educación secundaria calificados. (CINE-P: 768; CINE-A: 760).

Nepal - Master of Philosophy (MPhil). Este programa de dos años de duración requiere como requisito de ingreso haber finalizado un título de maestría. Al finalizar el programa, los graduados reciben el título Master's of Philosophy (MPhil). (CINE-P: 768; CINE-A: 760)

España - Especialidades Sanitarias. Estos programas requieren como requisito de ingreso haber finalizado un primer título de maestría y ofrecen especialización en aéreas relacionadas con la salud. Los programas tienen una duración de dos a cinco años según la especialización. El Título de Especialista Sanitario se clasifica al nivel de maestría (nivel CINE 7). Generalmente, estos programas dan acceso a programas de doctorado. CINE-P: 758; CINE-A: 750)

Túnez - (Diploma Nacional de Auditoría). Este programa de un año de duración, es posterior al programa de segundo título a nivel de maestría en auditoría de dos años de duración (Révision comptable). Al finalizar el programa los participantes reciben el Diploma Nacional de Auditoría (Diplôme national de la révision comptable). (CINE-P: 768; CINE-A: 760)

\section{Ejemplos nacionales - Grupo 4:}

Etapa (o programa) dentro de un primer título de maestría o nivel equivalente insuficiente para conclusión del nivel CINE 7 (duración acumulada teórica a nivel terciario inferior a 5 años) que por consiguiente conduce a un logro educativo de nivel CINE 5 o 6 [CINE-P: 741, 751 o 761; CINE-A: 540, 550, 640, 650 o 660]

Túnez - (Ciclo preparatorio). Este programa es considerado la primera etapa del programa nacional de ingeniería clasificado como primer título largo del nivel de maestría. Solo graduados de secundaria alta de elite pueden tener acceso a este programa de dos años de duración, en teoría, a partir de los 19 años. Al finalizar el programa los participantes reciben el diploma nacional del ciclo preparatorio que solo es válido para cursar el programa nacional de ingeniería. (CINE-P: 761; CINE-A: 544)

\section{Notas}

1. Los números de los párrafos refieren al documento de clasificación CINE 2011. Para mayores detalles, sírvase consultar la Guía del Lector.

2. Pese a que aún no se cuenta con definiciones internacionalmente consensuadas sobre orientaciones académicas y profesionales, algunos países han optado por aplicar sus propias definiciones y utilizar estos códigos en sus mapas CINE. 



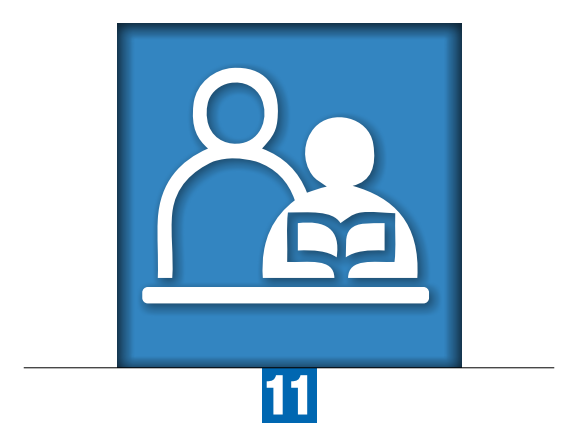

\section{Capítulo 11}

\section{Nivel 8 - CINE 2011:}

\section{Nivel de doctorado o equivalente}

Los programas de nivel CINE 8, o nivel de doctorado o equivalente, suelen tener como principal objetivo conducir a un título de investigación avanzada. Los programas de este nivel están dedicados a estudios avanzados e investigaciones originales, en tanto que suelen ser ofrecidos exclusivamente por instituciones de educación superior (universidades) dedicadas a la investigación. Se imparten programas de doctorado tanto en el campo académico como en el profesional.

En la mayoría de los países la duración teórica de estos programas es de 3 años a tiempo completo si bien el tiempo efectivo que le podría tomar a un estudiante completar el programa suele ser mayor.

Los programas clasificados en el nivel CINE 8 pueden recibir distintas denominaciones, por ejemplo: PhD, DPhil, D.Lit, D.SC, LL.D, Doctorado y otros términos similares. Para propósitos de comparación a nivel internacional, se usa el término "nivel de doctorado o equivalente" para denominar al nivel CINE 8. 


\section{DESCRIPCIÓN}

\section{Definición}

$(\S 259)^{1}$ Los programas de nivel CINE 8, o nivel de doctorado o equivalente, suelen tener como principal objetivo conducir a un título de investigación avanzada. Los programas de este nivel están dedicados a estudios avanzados e investigaciones originales, en tanto que suelen ser ofrecidos exclusivamente por instituciones de educación superior (universidades) dedicadas a la investigación. Se imparten programas de doctorado tanto en el campo académico como en el profesional.

(§261) Normalmente, el ingreso a programas de nivel CINE 8 o al cargo de investigador junior requiere la conclusión exitosa de un programa de nivel CINE 7. El nivel CINE 8 requiere como mínimo el equivalente a tres años de estudio a tiempo completo, lo que representa una duración acumulada total de por lo menos siete años de estudio a tiempo completo en el nivel terciario.

(§260) Por lo general, el nivel CINE 8 concluye con la presentación y defensa de una tesis o disertación (o trabajo escrito equivalente en importancia y con calidad de publicación) que representa una contribución significativa al conocimiento en los respectivos campos de estudio. En consecuencia, estos programas se caracterizan por estar basados en investigación y no únicamente en cursos.

\section{Criterios de clasificación}

\section{Criterios principales}

a) Requisitos de trabajo escrito

(§260) Los programas de nivel CINE 8 requieren la presentación y defensa de una tesis o disertación (o trabajo escrito equivalente en importancia y con calidad de publicación) que representa una contribución significativa al conocimiento en los respectivos campos de estudio.

b) Requisitos de ingreso

(§261) El ingreso a programas de nivel CINE 8 o al cargo de investigador junior requiere la conclusión exitosa de un programa de nivel CINE 7.

c) Duración mínima del nivel

(§265) El nivel CINE 8 requiere como mínimo el equivalente a tres años de estudio a tiempo completo.

\section{Criterios subsidiarios}

a) Título de doctor requerido para ocupaciones específicas

(§266) A menudo, la obtención de una certificación de nivel CINE 8 representa un requisito para desempeñar cargos en las facultades de las instituciones educativas que ofrecen programas de niveles CINE 6, 7 y 8 o para asumir funciones de investigación en la administración pública y la industria.

\section{Dimensiones complementarias}

(§268) Una dimensión podría ser usada para diferenciar los programas educativos de nivel CINE 8:

(§269) Orientación del programa

- Académica; y

- Profesional2. 
CORRESPONDENCIA ENTRE LOS NIVELES CINE 2011 Y CINE 1997

Véase esta sección en el capítulo de educación terciaria.

\section{DIRECTRICES PARA CLASIFICAR PROGRAMAS DE NIVEL 8 Y CERTIFICACIONES RECONOCIDAS RELACIONADAS}

Este nivel está reservado para programas de educación terciaria que conducen a un título de investigación avanzada. En la mayoría de los países la duración teórica de estos programas es de tres años de estudio a tiempo completo (esto representa una duración acumulada total de por lo menos siete años de estudio a tiempo completo en el nivel terciario), si bien el tiempo efectivo que los estudiantes requieren para finalizarlos suele ser mayor. Los programas de este nivel están dedicados a estudios avanzados e investigaciones originales. Los que otorgan un título similar al de "doctor" deben ser incluidos en el nivel CINE 8 solo si su contenido es equivalente en complejidad a programas ya clasificados en este nivel y cumplen los demás criterios principales (\$262).

Estos programas se caracterizan por estar basados en investigación y no únicamente en cursos. En algunos sistemas educativos, los programas de nivel CINE 8 ofrecen muy pocos cursos, o ninguno, y las personas que aspiran a un doctorado acostumbran a realizar trabajos de investigación en forma independiente o como parte de grupos reducidos con distintos grados de supervisión. En otros, la investigación doctoral es responsabilidad de personas contratadas por la universidad como investigadores junior o asistentes de investigación al mismo tiempo de estar matriculadas en cursos doctorales (\$260).

En tanto que la mayoría de los países ofrecen solo una "primera" certificación avanzada de investigación (Ejemplos nacionales - Grupo 1), algunos otorgan una certificación avanzada de investigación de carácter "intermedio" previo al título de doctorado (Ejemplos nacionales - Grupo 2). Asimismo, un número reducido de países otorgan una "segunda" certificación avanzada de investigación (Ejemplos nacionales - Grupo 3). Dar cuenta de estos últimos reconocimientos académicos en el sistema de clasificación es importante al momento de definir la línea divisoria entre una primera certificación avanzada y las demás certificaciones de nivel CINE 8.

Los programas que exigen un nivel de maestría, especialización o equivalente como requisito de admisión y conducen a una certificación intermedia de investigación deben clasificarse como la primera etapa o componente de programas de nivel CINE 8 (es decir, la conclusión de este componente no equivale a la conclusión del nivel) o como programas de segundo o siguiente título de nivel CINE 7 que siguen a la obtención de un nivel de maestría, especialización o equivalente. La decisión de cómo asignar estos programas debe estar basada en el grado en que el programa fue diseñado para conducir directamente al otorgamiento de una certificación de investigación avanzada. También sería conveniente determinar si el estudiante puede transferir créditos otorgados por este programa a un programa de doctorado, o si la certificación intermedia constituye un requisito de admisión a un programa de nivel de doctorado. Los programas que están principalmente destinados a preparar estudiantes para ingresar directamente al mercado laboral impartiendo destrezas básicas o intermedias de investigación, deben clasificarse en el nivel CINE 7, incluso si estos programas permiten la continuación de estudios que conduzcan a un título de investigación avanzada.

\section{LOGRO EDUCATIVO EN EL NIVEL CINE 8}

(\$272) En términos de logro educativo, las certificaciones intermedias otorgadas por la conclusión de etapas (o programas) de un primer título del nivel de doctorado o equivalente consideradas insuficientes para concluir este nivel se clasifican en el nivel CINE 7.

Los doctorados honoris causa otorgados por universidades a personas eminentes no necesariamente por motivos relacionados con la investigación, no son reconocidos para propósitos de logro educativo. 


\section{EJEMPLOS DE PROGRAMAS Y CERTIFICACIONES CLASIFICADAS EN EL NIVEL CINE 8}

(§262) Los programas clasificados en el nivel CINE 8 pueden recibir distintas denominaciones, por ejemplo: $P h D$, DPhil, D.Lit, D.Sc, LL.D, Doctorado y otros términos similares. Sin embargo, cabe destacar que los programas que otorgan un título similar al de "doctor" deben ser incluidos en el nivel CINE 8 solo si cumplen los criterios establecidos en la clasificación CINE 2011 (párrafo 263). Para propósitos de comparación a nivel internacional, se usa el término "nivel de doctorado o equivalente" para denominar al nivel CINE 8.

\section{Ejemplos nacionales - Grupo 1: \\ Programas de nivel de doctorado o equivalente suficiente para conclusión del nivel CINE 8 [CINE-P: 844, 854 o 864; CINE-A: 840, 850 o 860]}

Australia - Doctor's degree or doctorate. Se tiene acceso a estos programas después de haber concluido un grado en educación terciaria (mención honrosa) o un título de maestría y generalmente implican tres años de estudio a tiempo completo dedicado a la preparación de una tesis basada en un proyecto original de investigación que representa una contribución significativa al conocimiento, comprensión y/o aplicación de conocimientos dentro de un campo de estudio. (CINE-P: 864; CINE-A: 860)

Bahrein - (Programas de doctorado). Estos programas tienen como requisito mínimo de ingreso la conclusión de un título de maestría. Habitualmente, la duración de estos programas fluctúa entre tres a cinco años. Al finalizar el programa, los graduados reciben el título de doctorado. (CINE-P: 864; CINE-A: 860)

Colombia - Doctorado. Normalmente, este programa de doctorado tiene una duración de cinco años. El requisito mínimo de ingreso puede que no requiera necesariamente un título de maestría, pero exige al menos un título profesional o universitario en el campo de la tecnología, la ciencia, las humanidades, el arte o la filosofía. (CINE-P: 864; CINE-A: 860)

Francia - Doctorat (Doctorado). El Doctorat es un programa de tres años de duración que sigue en la secuencia académica al título de maestría y representa un total acumulado de ocho años de educación terciaria en el campo de la ciencia, las humanidades, la economía y el derecho. El título se otorga tras la presentación de una tesis basada en una investigación original que debe ser aprobada por el responsable de l'école doctorale (Director de la escuela de medicina) o la Conseil Scientifique (Junta de asesoramiento científico) de la universidad (CINE-P: 864; CINE-A: 860)

Alemania - Promotionstudium. (Estudios doctorales). Estos programas tienen una duración de tres a cinco años. En la mayoría de los casos, los estudiantes deben haber concluido con éxito programas universitarios (es decir, en disciplinas académicas) de cinco a siete años de duración antes de ingresar a los programas Promotion. Los estudiantes exitosos reciben un título de doctorado sobre la base de una tesis y un examen oral. Un Promotionsstudium se puede realizar bajo la forma de un freie Promotion (doctorado individual supervisado) que es el modelo más utilizado en el país, de un strukturierte Promotion que requiere estudios en Graduiertenkollegs (universidades de postgrado) o Graduiertenschulen (escuelas de postgrado). (CINE-P: 844; CINE-A: 840)

Italia - Dottorati di ricerca. (Doctorado en investigación). Este diploma representa el título académico más avanzado otorgado en el país. Se confiere después de haber dedicado un mínimo de tres años a desarrollar un programa de investigación específica en un departamento de la universidad bajo la dirección de profesores del plantel. La admisión al Dottorati di ricerca es restringida y se dirime mediante exámenes competitivos entre estudiantes que han obtenido la Laurea magistrale (maestría). (CINE-P: 864; CINE-A: 860)

Japón - Daigakuin Hakushi Katei (Curso de doctorado). El hakushi (título de doctorado) representa el título más avanzado otorgado a estudiantes que han finalizado el curso de doctorado en una universidad de postgrado o que poseen certificaciones que han sido reconocidas como equivalentes. El curso de doctorado requiere para su conclusión más de cinco años de estudio en una escuela de postgrado (además de cuatro años de estudio de pre-grado), 30 o más créditos, la presentación de una disertación, y la aprobación de un examen final. Los estudiantes que han desarrollado trabajos de investigación altamente calificados pueden recibir el hakushi después de tres años de estudio en una escuela de postgrado. (CINE-P: 864; CINE-A: 860)

Estados Unidos - Doctor of Philosophy (PhD). El PhD representa el título académico más avanzado de la secuencia académica y requiere dominio de un campo del conocimiento y una habilidad demostrada para conducir investigaciones 
de alto nivel académico (generalmente, tres a cinco años de estudio tras la obtención del título de maestría, es decir, ocho a diez años de estudios terciarios acumulados). (CINE-P: 844 u 854; CINE-A: 840 u 850)

\section{Ejemplos nacionales - Grupo 2:}

Programas de nivel de doctorado o equivalente es insuficiente para conclusión del nivel CINE 8 por consiguiente conducen a logro educativo de nivel CINE 7 [CINE-P: 841, 851 o 861; CINE-A: 740, 750 o 760]

Portugal - Ensino Superior: Curso de Especialização - Curso de doutoramento (Educación terciaria: curso de especialización - curso de doctorado). El Curso de Especialização - Curso de doutoramento representa la primera parte del Doutoramento - $3 .{ }^{\circ} \mathrm{Ciclo}$ (tercer ciclo de educación terciaria), y comprende unidades curriculares de formación sobre métodos de investigación. El diploma otorgado (certificación Especialização) no confiere un título PhD. El programa tiene un nivel de doctorado pero aún no es suficiente para conducir al título de doctorado. (CINE-P: 861; CINE-A: 760)

\section{Ejemplos nacionales - Grupo 3: \\ Segunda certificación de investigación avanzada de nivel CINE 8 (tras la conclusión de un programa de doctorado) [CINE-P: 844, 854 o 864; CINE-A: 840, 850 o 860]}

Kirguistán - Послевузовское профессиональное образование, степень доктора наук (Educación de postgrado, programa Doktor nauk). Esta es la segunda certificación de investigación avanzada que sigue en la secuencia académica a la послевузовское профессиональное образование, степень кандидата наук (Educación de postgrado, programa kandidat nauk) que conduce al título kandidat nauk, que ya está clasificado en el nivel CINE 8. En general, el programa doktor nauk no incluye un componente de trabajo de curso ni requiere supervisión formal. Habitualmente, exige por lo menos dos años de investigación. Al finalizar el programa, los graduados reciben el título doctor nauk degree (диплом с присвоением ученой степени доктора наук). (CINE-P: 864; CINE-A: 860)

\section{Notas}

1. Los números de los párrafos refieren al documento de clasificación CINE 2011. Para mayores detalles, sívase consultar la Guía del Lector.

2. Pese a que aún no se cuenta con definiciones internacionalmente consensuadas sobre orientaciones académicas y profesionales, algunos países han optado por aplicar sus propias definiciones y utilizar estos códigos en sus mapas CINE. 



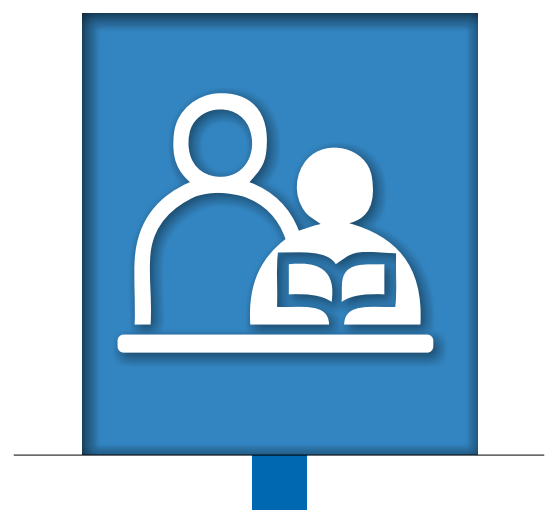

\section{Anexo A}

\section{Cuadro sinóptico de códigos y criterios CINE 2011}

Las unidades básicas de clasificación de la CINE son el programa educativo nacional y las certificaciones reconocidas relacionadas.

http://www.uis.unesco.org/Education/Pages/international-standardclassification-of-education.aspx

La clasificación CINE utiliza 3 dígitos: el primero es el nivel de educación, el segundo y tercero representan dimensiones complementarias.

El nivel CINE de un programa educativo refleja el grado de complejidad y especialización del contenido de un programa respecto de las gradaciones de las experiencias de aprendizaje y los conocimientos, destrezas y competencias que el programa tiene por objeto impartir. El logro educativo se mide con respecto al programa educativo más avanzado exitosamente concluido, que normalmente es avalado por una certificación reconocida. Si dicho programa no es concluido en forma exitosa, el nivel de logro de la persona es el mismo que exhibía antes de ingresar al programa. 


\section{NIVELES Y DIMENSIONES COMPLEMENTARIAS DE LA CLASIFICACIÓN INTERNACIONAL NORMALIZADA DE LA EDUCACIÓN (CINE) 2011}

\section{Codificación de programas de educación y logro educativo}

\begin{tabular}{|c|c|c|c|}
\hline \multirow{2}{*}{\multicolumn{2}{|c|}{$\begin{array}{l}\text { Nivel } \\
1^{\text {er }} \text { dígito }\end{array}$}} & \multicolumn{2}{|c|}{ Criterios para clasificar los programas nacionales por nivel } \\
\hline & & Criterios principales & Criterios subsidiarios \\
\hline \multicolumn{2}{|c|}{ Sin instrucción } & - & - \\
\hline \multirow{4}{*}{0} & \multirow{4}{*}{$\begin{array}{l}\text { Educación de la } \\
\text { primera infancia }\end{array}$} & $\begin{array}{l}\text { Aprendizaje estimulado por el entorno }(\S 105)^{\star} \\
\text { o por la interacción con educadores }(\$ 106) \text {. }\end{array}$ & $\begin{array}{l}\text { Certificaciones del personal docente: } \\
\text { certificaciones pedagógicas exigidas a los } \\
\text { profesores }(\$ 111) \text {. }\end{array}$ \\
\hline & & $\begin{array}{l}\text { Institucionalidad: escuelas o centros } \\
\text { comunitarios }(\S 107)\end{array}$ & Existencia de un marco regulatorio ( $\$ 112)$. \\
\hline & & $\begin{array}{l}\text { Ingreso/edad: los programas de educación } \\
\text { preprimaria se orientan a niños desde } \\
\text { los } 3 \text { años hasta el inicio de la educación } \\
\text { primaria (§102/108). }\end{array}$ & Típicamente no es obligatoria (§113). \\
\hline & & $\begin{array}{l}\text { Intensidad: } 2 \text { horas diarias de educación y } \\
100 \text { días al año (\$110). }\end{array}$ & \\
\hline \multirow{3}{*}{1} & \multirow{3}{*}{$\begin{array}{l}\text { Educación } \\
\text { primaria }\end{array}$} & $\begin{array}{l}\text { Instrucción en lectura, escritura y matemáticas } \\
\text { impartida en forma sistemática }(\$ 125) \text {. }\end{array}$ & $\begin{array}{l}\text { A menudo coincide con el inicio de la } \\
\text { educación obligatoria ( } \$ 127) \text {. }\end{array}$ \\
\hline & & $\begin{array}{l}\text { Ingreso/edad y duración: edad legal de } \\
\text { ingreso no inferior a los } 5 \text { años ni superior } \\
\text { a los } 7 \text { años; la duración típica es } 6 \text { años } \\
\text { (fluctúa entre } 4 \text { y } 7 \text { años) (\$122). }\end{array}$ & \\
\hline & & $\begin{array}{l}\text { Profesor: habitualmente, un profesor principal } \\
\text { es responsable de un grupo ( } \$ 126) \text {. }\end{array}$ & \\
\hline \multirow{3}{*}{2} & \multirow{3}{*}{$\begin{array}{l}\text { Educación } \\
\text { secundaria baja }\end{array}$} & $\begin{array}{l}\text { Punto de transición hacia la instrucción } \\
\text { orientada por asignaturas ( } \$ 144) \text {. }\end{array}$ & $\begin{array}{l}\text { Edad típica de ingreso varía entre los } 10 \text { y } \\
13 \text { años, siendo } 12 \text { años la edad más común } \\
(\$ 141) \text {. }\end{array}$ \\
\hline & & $\begin{array}{l}\text { Requisitos de ingreso: conclusión de la } \\
\text { educación primaria (o la habilidad de manejar } \\
\text { los contenidos del nivel CINE } 2)(\$ 145) \text {. }\end{array}$ & $\begin{array}{l}\text { Los profesores suelen estar certificados } \\
\text { en una o más asignaturas, así como en } \\
\text { pedagogía ( } \$ 147) \text {. }\end{array}$ \\
\hline & & $\begin{array}{l}\text { Duración acumulada: finaliza tras } 8 \text { a } 11 \text { años } \\
\text { de educación (generalmente } 9 \text { años) a partir } \\
\text { del inicio de la educación primaria ( } \$ 146) \text {. }\end{array}$ & $\begin{array}{l}\text { El fin del nivel coincide con el fin de la } \\
\text { educación obligatoria }(\$ 148) \text {. }\end{array}$ \\
\hline
\end{tabular}

\section{Notas}

* Los números de los párrafos refieren al documento de clasificación CINE 2011. Para mayores detalles, sívase consultar la Guía del Lector.

** Variable de la Encuesta de la Unión Europea sobre Fuerza de Trabajo HATLEVEL / HATVOC (Regulación 317/2013 de la Comisión Europea). 


\begin{tabular}{|c|c|c|c|c|c|c|}
\hline \multicolumn{4}{|c|}{ Dimensiones complementarias } & \multicolumn{3}{|l|}{ Codificación } \\
\hline \multicolumn{2}{|c|}{$2^{\text {do }}$ dígito } & \multicolumn{2}{|c|}{$3^{\text {er }}$ dígito } & $\begin{array}{l}\text { Programas } \\
\text { educativos } \\
\text { CINE-P } \\
\text { (Anexo II } \\
\text { de la CINE } \\
\text { 2011) }\end{array}$ & $\begin{array}{l}\text { Logro } \\
\text { educativo } \\
\text { CINE -A } \\
\text { (Anexo III } \\
\text { de la CINE } \\
2011 \text { ) }\end{array}$ & $\begin{array}{l}\text { Variable de } \\
\text { la Encuesta } \\
\text { de la Unión } \\
\text { Europea } \\
\text { sobre } \\
\text { Fuerza de } \\
\text { Trabajo } \\
\text { HATLEVEL / } \\
\text { HATVOC ** }\end{array}$ \\
\hline & - & & - & - & 010 & 000 \\
\hline \multicolumn{7}{|c|}{ Tipo de educación: } \\
\hline 1 & $\begin{array}{l}\text { Desarrollo } \\
\text { educacional de la } \\
\text { primera Infancia (de } \\
0 \text { a } 2 \text { años) }\end{array}$ & - & - & 010 & \multirow{2}{*}{020} & - \\
\hline 2 & $\begin{array}{l}\text { Educación } \\
\text { preprimaria (desde } \\
\text { los } 3 \text { años de edad } \\
\text { hasta el inicio de la } \\
\text { educación primaria) }\end{array}$ & - & - & 020 & & 000 \\
\hline- & - & - & - & 100 & 100 & 100 \\
\hline \multicolumn{2}{|c|}{$\begin{array}{l}\text { Orientación del } \\
\text { programa: }\end{array}$} & \multicolumn{2}{|c|}{$\begin{array}{l}\text { Conclusión del nivel y acceso aun nivel } \\
\text { CINE superior: }\end{array}$} & & & \\
\hline \multirow{2}{*}{4} & \multirow{2}{*}{ General } & 1 & $\begin{array}{l}\text { Insuficiente para la conclusión, o la } \\
\text { conclusión parcial, del nivel (duración } \\
<2 \text { o duración acumulada }<8 \text { años a } \\
\text { partir del Inicio del nivel CINE 1). }\end{array}$ & 241,251 & 100 & 100 \\
\hline & & 2 & $\begin{array}{l}\text { Conclusión parcial del nivel } \\
\text { (programas intermedios con una } \\
\text { duración } \geq 2 \text { años y duración } \\
\text { acumulada de } \geq 8 \text { años). }\end{array}$ & 242,252 & 242,252 & 200 \\
\hline \multirow{2}{*}{5} & \multirow{2}{*}{ Vocacional } & 3 & $\begin{array}{l}\text { Conclusión del nivel sin acceso directo } \\
\text { al nivel CINE } 3 \text { (duración } \geq 2 \text { años, } \\
\text { duración acumulada de } \geq 8 \text { años). }\end{array}$ & 243,253 & 243,253 & 200 \\
\hline & & 4 & $\begin{array}{l}\text { Conclusión del nivel con acceso directo } \\
\text { al nivel CINE } 3 \text { (duración } \geq 2 \text { años, } \\
\text { duración acumulada de } \geq 8 \text { años). }\end{array}$ & 244,254 & 244,254 & 200 \\
\hline
\end{tabular}

\section{Notas}

* Los números de los párrafos refieren al documento de clasificación CINE 2011. Para mayores detalles, sírvase consultar la Guía del Lector. ** Variable de la Encuesta de la Unión Europea sobre Fuerza de Trabajo HATLEVEL / HATVOC (Regulación 317/2013 de la Comisión Europea). 


\begin{tabular}{|c|c|c|c|}
\hline \multicolumn{2}{|c|}{ Nivel } & \multicolumn{2}{|c|}{ Criterios para clasificar los programas nacionales por nivel } \\
\hline \multicolumn{2}{|c|}{1 er dígito } & Criterios principales & Criterios subsidiarios \\
\hline \multirow{3}{*}{3} & \multirow{3}{*}{$\begin{array}{l}\text { Educación } \\
\text { secundaria alta }\end{array}$} & $\begin{array}{l}\text { Segunda etapa o etapa final de educación } \\
\text { secundaria, programas generales o } \\
\text { vocacionales (\$167). }\end{array}$ & $\begin{array}{l}\text { Programas caracterizados por un mayor } \\
\text { grado de diferenciación y un espectro más } \\
\text { amplio de opciones y ramificaciones }(\$ 169) \text {. }\end{array}$ \\
\hline & & $\begin{array}{l}\text { Requisitos de ingreso: conclusión de la } \\
\text { educación secundaria baja (o la habilidad de } \\
\text { manejar los contenidos del nivel CINE 3) ( } \$ 168) \text {. }\end{array}$ & \multirow[t]{2}{*}{$\begin{array}{l}\text { Docentes suelen ser más especializados } \\
\text { que los profesores de secundaria baja en las } \\
\text { materias que enseñan }(\S 170) \text {. }\end{array}$} \\
\hline & & $\begin{array}{l}\text { Duración acumulada: los programas suelen } \\
\text { tener una duración de } 12 \text { o } 13 \text { años a partir } \\
\text { del inicio del nivel CINE } 1(\$ 164) \text {. }\end{array}$ & \\
\hline \multirow{3}{*}{4} & \multirow{3}{*}{$\begin{array}{l}\text { Educación } \\
\text { postsecundaria } \\
\text { no terciaria }\end{array}$} & $\begin{array}{l}\text { Educación postsecundaria, programas } \\
\text { generalmente vocacionales y terminales que } \\
\text { preparan para el mercado laboral. A nivel } \\
\text { nacional no suelen considerarse programas } \\
\text { de educación terciaria }(\$ 190) \text {. }\end{array}$ & \\
\hline & & $\begin{array}{l}\text { Programas caracterizados por ampliar - en } \\
\text { lugar de profundizar - los conocimientos, } \\
\text { destrezas y competencias de participantes. } \\
\text { No suelen ser mucho más avanzados que los } \\
\text { programas de nivel CINE } 3 \text { (§191). }\end{array}$ & \\
\hline & & $\begin{array}{l}\text { Requisitos de ingreso: conclusión de } \\
\text { educación secundaria alta ( } \$ 186) \text {. }\end{array}$ & \\
\hline \multirow[t]{3}{*}{5} & \multirow{3}{*}{$\begin{array}{l}\text { Educación } \\
\text { terciaria } \\
\text { de ciclo corto }\end{array}$} & $\begin{array}{l}\text { Programas generalmente destinados a } \\
\text { impartir al participante conocimientos, } \\
\text { habilidades y competencias profesionales; } \\
\text { pueden facilitar el ingreso a programas } \\
\text { académicos }(\$ 207) \text {. Contenido más complejo } \\
\text { que el característico de los niveles } 3 \text { o } 4 \text {, pero } \\
\text { menos complejo que el del nivel } 6(\S 212) \text {. }\end{array}$ & \multirow[t]{2}{*}{$\begin{array}{l}\text { Punto de transición entre instituciones: con } \\
\text { frecuencia, los programas de este nivel se } \\
\text { imparten en instituciones educativas distintas } \\
\text { a las instituciones que ofrecen programas de } \\
\text { nivel CINE } 6,7 \text { y } 8 \text { (\$214). }\end{array}$} \\
\hline & & $\begin{array}{l}\text { Requisitos de ingreso: conclusión exitosa } \\
\text { de educación secundaria alta o educación } \\
\text { secundaria no terciaria que de acceso a los } \\
\text { niveles CINE } 5,6 \text { o } 7 \text { (\$208). }\end{array}$ & \\
\hline & & Duración mínima: 2 años (§213). & Duración típica: 2 a 3 años (§213). \\
\hline
\end{tabular}

\section{Notas}

* Los números de los párrafos refieren al documento de clasificación CINE 2011. Para mayores detalles, sívase consultar la Guía del Lector.

** Variable de la Encuesta de la Unión Europea sobre Fuerza de Trabajo HATLEVEL/ HATVOC (Regulación 317/2013 de la Comisión Europea). 


\begin{tabular}{|c|c|c|c|c|c|c|}
\hline \multicolumn{4}{|c|}{ Dimensiones complementarias } & \multicolumn{3}{|c|}{ Codificación } \\
\hline \multicolumn{2}{|c|}{$2^{\text {do }}$ dígito } & \multicolumn{2}{|c|}{$3^{\text {er }}$ dígito } & $\begin{array}{l}\text { Programas } \\
\text { educativos } \\
\text { CINE-P } \\
\text { (Anexo II } \\
\text { de la CINE } \\
\text { 2011) }\end{array}$ & $\begin{array}{l}\text { Logro } \\
\text { educativo } \\
\text { CINE -A } \\
\text { (Anexo III } \\
\text { de la CINE } \\
\text { 2011) }\end{array}$ & $\begin{array}{l}\text { Variable de } \\
\text { la Encuesta } \\
\text { de la Unión } \\
\text { Europea } \\
\text { sobre } \\
\text { Fuerza de } \\
\text { Trabajo } \\
\text { HATLEVEL / } \\
\text { HATVOC ** }\end{array}$ \\
\hline \multicolumn{2}{|c|}{$\begin{array}{l}\text { Orientación del } \\
\text { programa: }\end{array}$} & \multicolumn{2}{|c|}{$\begin{array}{l}\text { Conclusión del nivel y acceso a un nivel } \\
\text { CINE superior: }\end{array}$} & & & \\
\hline \multirow[t]{2}{*}{4} & \multirow[t]{2}{*}{ General } & 1 & $\begin{array}{l}\text { Insuficiente para la conclusión, o la } \\
\text { conclusión parcial, del nivel (duración } \\
<2 \text { años o duración acumulada } \\
<11 \text { años) a partir del inicio del nivel } \\
\text { CINE 1). }\end{array}$ & 341,351 & 244,254 & 200 \\
\hline & & 2 & $\begin{array}{l}\text { Conclusión parcial del nivel (programas } \\
\text { intermedios de duración } \geq 2 \text { años y } \\
\text { duración acumulada de } \geq 11 \text { años). }\end{array}$ & 342,352 & 342,352 & $302 / 1,302 / 2$ \\
\hline \multirow[b]{2}{*}{5} & \multirow[b]{2}{*}{ Vocacional } & 3 & $\begin{array}{l}\text { Conclusión del nivel sin acceso } \\
\text { directo al nivel CINE } 3 \text { (duración } \geq 2 \text { y } \\
\text { duración acumulada } \geq 11 \text { años). }\end{array}$ & 343,353 & 343,353 & $303 / 1,303 / 2$ \\
\hline & & 4 & $\begin{array}{l}\text { Conclusión del nivel con acceso } \\
\text { directo a programas de nivel CINE } 5 \text {, } \\
6 \text { o } 7 \text { (duración } \geq 2 \text { y duración } \\
\text { acumulada } \geq 11 \text { años). }\end{array}$ & 344,354 & 344,354 & $304 / 1,304 / 2$ \\
\hline \multicolumn{2}{|c|}{$\begin{array}{l}\text { Orientación del } \\
\text { programa: }\end{array}$} & \multicolumn{2}{|c|}{$\begin{array}{l}\text { Conclusión del nivel y acceso a un nivel } \\
\text { CINE superior: }\end{array}$} & & & \\
\hline 4 & General & 1 & $\begin{array}{l}\text { Insuficiente para la conclusión del } \\
\text { nivel (duración }<6 \text { meses) }\end{array}$ & 441,451 & 344354 & $300 / 1,300 / 2$ \\
\hline \multirow{2}{*}{5} & \multirow{2}{*}{ Vocacional } & 3 & $\begin{array}{l}\text { Conclusión del nivel sin acceso directo } \\
\text { a programas de nivel CINE 5, } 6 \text { o } 7\end{array}$ & 443,453 & 443,453 & $400 / 1,400 / 2$ \\
\hline & & 4 & $\begin{array}{l}\text { Conclusión del nivel con acceso directo } \\
\text { a programas de nivel CINE } 5,6 \text { o } 7\end{array}$ & 444,454 & 444,454 & \\
\hline \multicolumn{2}{|c|}{$\begin{array}{l}\text { Orientación del } \\
\text { programa: }\end{array}$} & \multicolumn{2}{|c|}{$\begin{array}{l}\text { Conclusión del nivel y acceso a un nivel } \\
\text { CINE superior: }\end{array}$} & & & \\
\hline 4 & $\begin{array}{l}\text { General } \\
\text { (o académica) }\end{array}$ & 1 & $\begin{array}{l}\text { Insuficiente para la conclusión del } \\
\text { nivel (duración }<2 \text { años) }\end{array}$ & 541,551 & 444,454 & 400 \\
\hline 5 & $\begin{array}{l}\text { Vocacional } \\
\text { (o profesional) }\end{array}$ & 4 & Conclusión del nivel & 544,554 & 540,550 & 500 \\
\hline
\end{tabular}

\section{Notas}

* Los números de los párrafos refieren al documento de clasificación CINE 2011. Para mayores detalles, sírvase consultar la Guía del Lector. ** Variable de la Encuesta de la Unión Europea sobre Fuerza de Trabajo HATLEVEL / HATVOC (Regulación 317/2013 de la Comisión Europea). 


\begin{tabular}{|c|c|c|c|}
\hline \multirow{2}{*}{\multicolumn{2}{|c|}{$\begin{array}{l}\text { Nivel } \\
\text { er dígito }\end{array}$}} & \multicolumn{2}{|c|}{ Criterios para clasificar los programas nacionales por nivel } \\
\hline & & Criterios principales & Criterios subsidiarios \\
\hline \multirow{4}{*}{6} & \multirow{4}{*}{$\begin{array}{l}\text { Grado en } \\
\text { educación } \\
\text { terciaria o nivel } \\
\text { equivalente }\end{array}$} & $\begin{array}{l}\text { Programas frecuentemente destinados a impartir } \\
\text { conocimientos, destrezas y competencias } \\
\text { académicas o profesionales intermedias que } \\
\text { conducen a un primer título o a una certificación } \\
\text { equivalente (\$224). }\end{array}$ & $\begin{array}{l}\text { El requisito que parte del personal docente } \\
\text { haya obtenido certificaciones de nivel de } \\
\text { doctorado (CINE 8) permite establecer una } \\
\text { distinción entre los programas de nivel } \\
\text { CINE } 5 \text { y } 6 \text { (§231). }\end{array}$ \\
\hline & & $\begin{array}{l}\text { Requisitos de ingreso: conclusión exitosa } \\
\text { de un programa de educación secundaria } \\
\text { alta o educación postsecundaria no terciaria } \\
\text { que otorgue acceso a los niveles } 5,6 \text { o } 7 \text {; } \\
\text { podría ser necesario aprobar un examen de } \\
\text { admisión (\$226). }\end{array}$ & \multirow[t]{3}{*}{$\begin{array}{l}\text { Estudios más avanzados: normalmente, no } \\
\text { dan acceso a programas de doctorado (nivel } \\
\text { CINE 8) (§226). }\end{array}$} \\
\hline & & $\begin{array}{l}\text { Duración acumulada mínima de los } \\
\text { programas de primer título: } 3 \text { a } 4 \text { años de } \\
\text { estudio a tiempo completo (\$229). }\end{array}$ & \\
\hline & & $\begin{array}{l}\text { Posición en la estructura nacional de títulos y } \\
\text { certificaciones: típicamente, un primer título de } \\
\text { educación terciaria; a veces, un segundo título } \\
\text { de una duración de } 1 \text { a } 2 \text { años (\$230). }\end{array}$ & \\
\hline \multirow{3}{*}{7} & \multirow{3}{*}{$\begin{array}{l}\text { Nivel de maestría, } \\
\text { especialización o } \\
\text { equivalente }\end{array}$} & $\begin{array}{l}\text { Programas generalmente orientados a impartir } \\
\text { al participante competencias académicas y/o } \\
\text { profesionales avanzadas que conduzcan a un } \\
\text { segundo título, por ejemplo una maestría, o a } \\
\text { una certificación equivalente ( } \$ 241) \text {. }\end{array}$ & $\begin{array}{l}\text { Duración mínima de un primer título, cinco } \\
\text { años: nivel de complejidad del contenido es } \\
\text { comparable al de una maestría/especialización } \\
\text { (§247). }\end{array}$ \\
\hline & & $\begin{array}{l}\text { Posición en la estructura nacional de títulos } \\
\text { y certificaciones: típicamente, un segundo o } \\
\text { siguiente título de educación terciaria tras la } \\
\text { obtención un primer título de nivel CINE } 6 \text { o } 7 \\
\text { (§246) o un primer título con una duración mínima } \\
\text { de cinco años si en términos de complejidad } \\
\text { del contenido es equivalente a una maestría/ } \\
\text { especialización por ej., medicina) (\$247). }\end{array}$ & $\begin{array}{l}\text { Estudios más avanzados: normalmente, dan } \\
\text { acceso directo a programas de doctorado (nivel } \\
\text { CINE 8) (\$249). }\end{array}$ \\
\hline & & $\begin{array}{l}\text { Requisitos de ingreso: en el caso de un } 2^{\text {do }} \\
\text { o siguiente título, se requiere la conclusión } \\
\text { exitosa de un programa que prepara para un } \\
\text { título en educación terciaria o nivel equivalente } \\
\text { (nivel CINE 6) o un programa de nivel de } \\
\text { maestría, especialización o equivalente (nivel } \\
\text { CINE 7). En el caso de un 1er título, se requiere } \\
\text { la conclusión exitosa de educación secundaria } \\
\text { alta o del nivel CINE } 4 \text { que da acceso a la } \\
\text { educación terciaria. En algún momento, } \\
\text { también podría requerirse aprobar un examen } \\
\text { de admisión (§243). }\end{array}$ & \\
\hline \multirow{3}{*}{8} & \multirow{3}{*}{$\begin{array}{l}\text { Doctorado } \\
\text { o equivalente }\end{array}$} & $\begin{array}{l}\text { Su conclusión exitosa requiere la presentación } \\
\text { de una tesis, o un trabajo escrito equivalente } \\
\text { con calidad de publicación que sea el producto } \\
\text { de una investigación original y que represente } \\
\text { una contribución significativa al conocimiento } \\
\text { en campo de estudio respectivo (\$264). }\end{array}$ & \multirow[t]{2}{*}{$\begin{array}{l}\text { El título permite postular a cargos en las } \\
\text { facultades de instituciones educativas o } \\
\text { asumir funciones de investigación ( } \$ 266) \text {. }\end{array}$} \\
\hline & & $\begin{array}{l}\text { Requisitos de ingreso: conclusión exitosa de } \\
\text { un programa de nivel CINE } 7 \text { ( } \$ 261) \text {. }\end{array}$ & \\
\hline & & $\begin{array}{l}\text { Duración mínima: se requiere como mínimo el } \\
\text { equivalente a tres años de estudio a tiempo } \\
\text { completo y una duración acumulada total de por } \\
\text { lo menos } 7 \text { años en educación terciaria ( } \$ 265) \text {. }\end{array}$ & \\
\hline
\end{tabular}




\begin{tabular}{|c|c|c|c|c|c|c|}
\hline \multicolumn{4}{|c|}{ Dimensiones complementarias } & \multicolumn{3}{|l|}{ Codificación } \\
\hline \multicolumn{2}{|c|}{$2^{\text {do }}$ dígito } & \multicolumn{2}{|c|}{$3^{\text {er dígito }}$} & $\begin{array}{l}\text { Programas } \\
\text { educativos } \\
\text { CINE-P } \\
\text { (Anexo II } \\
\text { de la CINE } \\
\text { 2011) }\end{array}$ & $\begin{array}{l}\text { Logro } \\
\text { educativo } \\
\text { CINE -A } \\
\text { (Anexo III } \\
\text { de la CINE } \\
\text { 2011) }\end{array}$ & $\begin{array}{l}\text { Variable de } \\
\text { la Encuesta } \\
\text { de la Unión } \\
\text { Europea } \\
\text { sobre } \\
\text { Fuerza de } \\
\text { Trabajo } \\
\text { HATLEVEL / } \\
\text { HATVOC ** }\end{array}$ \\
\hline \multicolumn{2}{|c|}{$\begin{array}{l}\text { Orientación } \\
\text { del programa }\end{array}$} & \multicolumn{2}{|c|}{$\begin{array}{l}\text { Posición en la estructura nacional de títulos y } \\
\text { certificados }\end{array}$} & & & \\
\hline 4 & Académica & 1 & $\begin{array}{l}\text { Insuficientes para la conclusión del nivel } \\
\text { (duración del primer título }<3 \text { años) }\end{array}$ & $\begin{array}{l}641,651 \\
\quad 661\end{array}$ & 540,550 & 500 \\
\hline 5 & Profesional & 5 & $\begin{array}{l}\text { Primer título (grado en educación terciaria) } \\
\text { (duración de 3-4 años) }\end{array}$ & $\begin{array}{l}645,655 \\
\quad 665\end{array}$ & \multirow{3}{*}{$\begin{array}{l}640,650 \\
\quad 660\end{array}$} & \multirow{3}{*}{600} \\
\hline \multirow{2}{*}{6} & & 6 & $\begin{array}{l}\text { Programas largos de primer título (grado } \\
\text { en educación terciaria) (duración }>4 \text { años) }\end{array}$ & $\begin{array}{l}646,656 \\
\quad 666\end{array}$ & & \\
\hline & no especificada & 7 & $\begin{array}{l}\text { Segundo o siguiente título (tras cursar } \\
\text { un programa del grado en educación } \\
\text { terciaria) }\end{array}$ & $\begin{array}{l}647,657 \\
\quad 667\end{array}$ & & \\
\hline \multicolumn{2}{|c|}{$\begin{array}{l}\text { Orientación } \\
\text { del programa }\end{array}$} & \multicolumn{2}{|c|}{$\begin{array}{l}\text { Posición en la estructura nacional de títulos y } \\
\text { certificados }\end{array}$} & & & \\
\hline 4 & Académica & 1 & $\begin{array}{l}\text { Insuficientes para la conclusión del nivel } \\
\text { (duración del primer título }<5 \text { años) }\end{array}$ & $\begin{array}{l}741,751 \\
\quad 761\end{array}$ & $\begin{array}{l}640,650 \\
660\end{array}$ & 600 \\
\hline 5 & Profesional & 6 & $\begin{array}{l}\text { Programas largos de primer título (nivel de } \\
\text { maestría) (duración } \geq 5 \text { años) }\end{array}$ & $\begin{array}{l}746,756 \\
766\end{array}$ & \multirow{3}{*}{$\begin{array}{l}740,750 \\
760\end{array}$} & \multirow{3}{*}{700} \\
\hline \multirow{2}{*}{6} & \multirow{2}{*}{$\begin{array}{l}\text { Orientación } \\
\text { no especificada }\end{array}$} & 7 & $\begin{array}{l}\text { Segundo o siguiente título (tras cursar } \\
\text { un programa del grado en educación } \\
\text { terciaria) }\end{array}$ & $\begin{array}{l}747,757 \\
767\end{array}$ & & \\
\hline & & 8 & $\begin{array}{l}\text { Segundo o siguiente título (tras cursar un } \\
\text { programa de nivel de maestría) }\end{array}$ & $\begin{array}{l}748,758 \\
768\end{array}$ & & \\
\hline \multicolumn{2}{|c|}{$\begin{array}{l}\text { Orientación } \\
\text { del programa }\end{array}$} & \multicolumn{2}{|c|}{$\begin{array}{l}\text { Posición en la estructura nacional de títulos y } \\
\text { certificados }\end{array}$} & & & \\
\hline 4 & Académica & 1 & $\begin{array}{l}\text { Insuficientes para la conclusión del nivel } \\
\text { (duración del primer título }<3 \text { años) }\end{array}$ & $\begin{array}{l}841,851 \\
861\end{array}$ & $\begin{array}{l}740,750 \\
760\end{array}$ & 700 \\
\hline 5 & Profesional & \multirow[b]{2}{*}{4} & \multirow[t]{2}{*}{ Conclusión del nivel } & \multirow{2}{*}{$\begin{array}{l}844,854 \\
864\end{array}$} & \multirow[b]{2}{*}{$\begin{array}{l}840,850 \\
860\end{array}$} & \multirow[b]{2}{*}{800} \\
\hline 6 & $\begin{array}{l}\text { Orientación } \\
\text { no especificada }\end{array}$ & & & & & \\
\hline
\end{tabular}





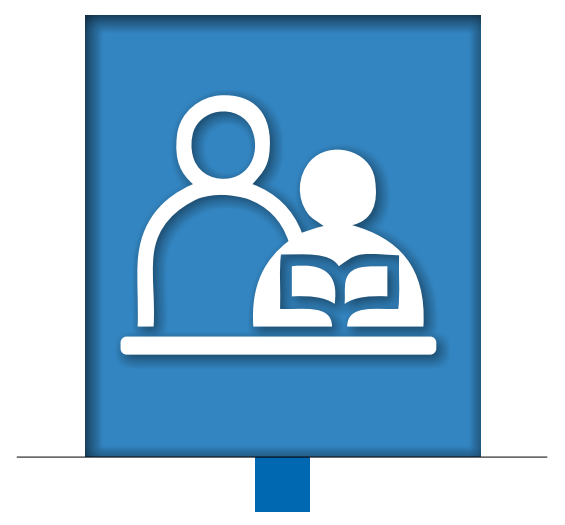

Anexo B

\section{Trayectorias educativas potenciales en la CINE 2011}


TRAYECTORIAS POTENCIALES EN LA CINE 2011 ELABORADAS CON TODOS LOS CÓDIGOS CINE-P

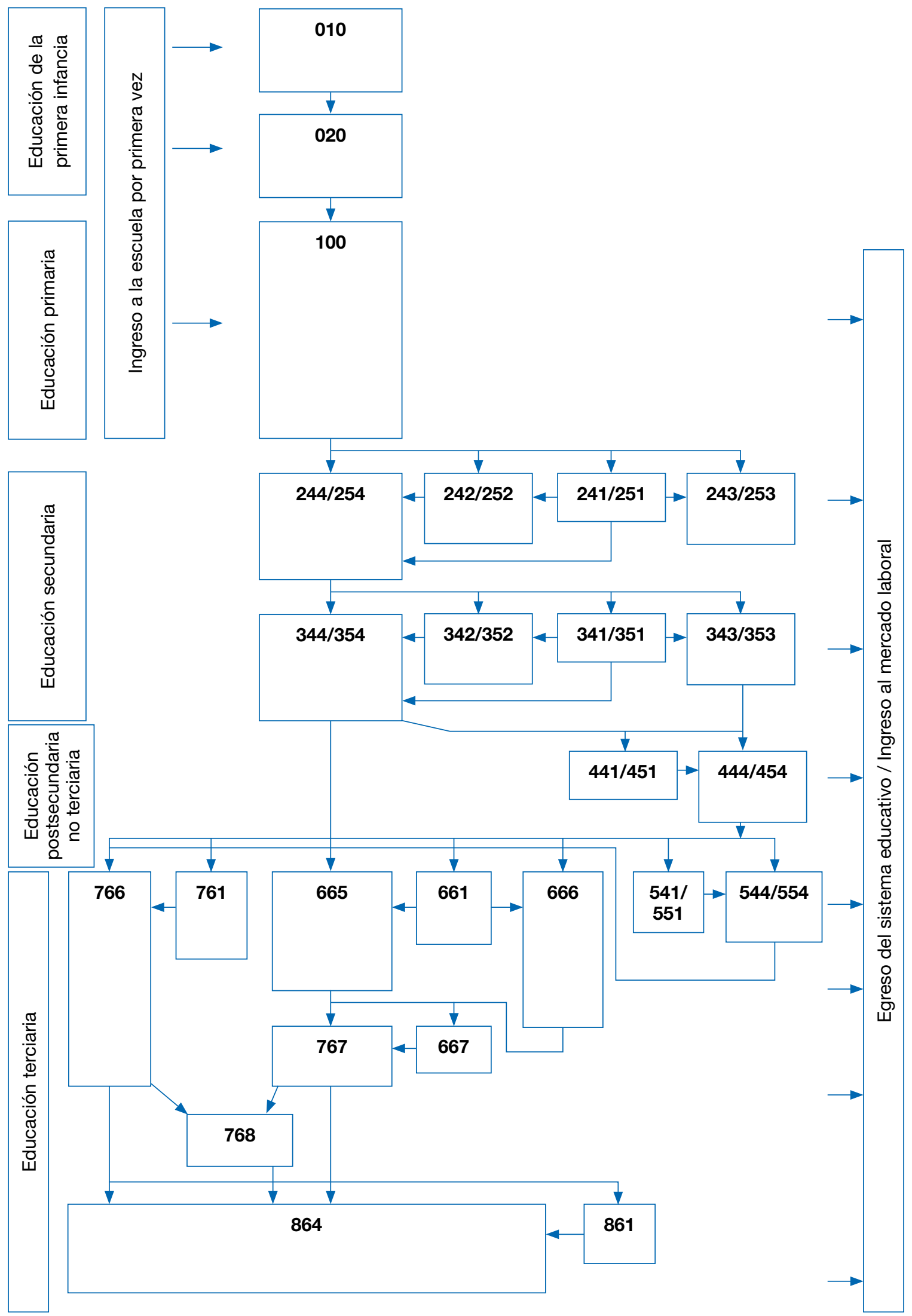




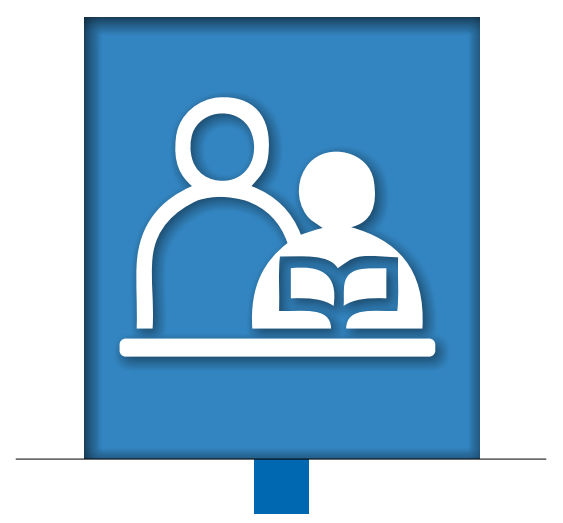

Anexo C

\section{Cuadro de referencia rápida de códigos CINE-P y CINE-A en la CINE 2011}




\begin{tabular}{|c|c|c|c|}
\hline \multirow{2}{*}{$\begin{array}{l}\text { CINE-P } \\
\text { (no se aplica) }\end{array}$} & \multicolumn{2}{|l|}{ Notas sobre codificación } & \multirow{2}{*}{ CINE-A } \\
\hline & (no se aplica) & Never attended an education programme & \\
\hline 010 & Desarrollo educacional de la primera infancia & Some early childhood education & 020 \\
\hline \multirow[t]{2}{*}{020} & Educación preprimaria & Some early childhood education & 020 \\
\hline & & $\begin{array}{l}\text { Some primary education (without level } \\
\text { completion) }\end{array}$ & 030 \\
\hline 100 & \multicolumn{2}{|l|}{ Educación primaria } & 100 \\
\hline $241 / 251$ & \multicolumn{2}{|c|}{$\begin{array}{l}\text { Educación secundaria baja, insuficiente para la conclusión, o conclusión parcial del nivel, } \\
\text { sin acceso directo a la educación secundaria alta }\end{array}$} & 100 \\
\hline $242 / 252$ & \multicolumn{2}{|c|}{$\begin{array}{l}\text { Educación secundaria baja, conclusión parcial del nivel sin acceso directo a la educación } \\
\text { secundaria alta }\end{array}$} & $242 / 252$ \\
\hline $243 / 253$ & \multicolumn{2}{|c|}{$\begin{array}{l}\text { Educación secundaria baja, conclusión del nivel, sin acceso directo a la educación } \\
\text { secundaria alta }\end{array}$} & $243 / 253$ \\
\hline $244 / 254$ & \multicolumn{2}{|c|}{$\begin{array}{l}\text { Educación secundaria baja, conclusión del nivel, con acceso directo a la educación } \\
\text { secundaria alta }\end{array}$} & $244 / 254$ \\
\hline $341 / 351$ & \multicolumn{2}{|c|}{$\begin{array}{l}\text { Educación secundaria alta, insuficiente para la conclusión, o la conclusión parcial del nivel, } \\
\text { sin acceso directo a la educación terciaria }\end{array}$} & $244 / 254$ \\
\hline $342 / 352$ & \multicolumn{2}{|c|}{$\begin{array}{l}\text { Educación secundaria alta, conclusión parcial del nivel sin acceso directo a la educación } \\
\text { terciaria }\end{array}$} & $342 / 352$ \\
\hline $343 / 353$ & \multicolumn{2}{|c|}{ Educación secundaria alta, conclusión del nivel, sin acceso directo a la educación terciaria } & $343 / 353^{*}$ \\
\hline $344 / 354$ & \multicolumn{2}{|c|}{ Educación secundaria alta, conclusión del nivel, con acceso directo a la educación terciaria } & $344 / 354$ \\
\hline $441 / 451$ & \multicolumn{2}{|c|}{$\begin{array}{l}\text { Educación postsecundaria no terciaria, insuficiente para la conclusión del nivel, sin acceso } \\
\text { directo a la educación terciaria }\end{array}$} & $344 / 354$ \\
\hline $443 / 453$ & \multicolumn{2}{|c|}{$\begin{array}{l}\text { Educación postsecundaria no terciaria, conclusión del nivel, sin acceso directo a la } \\
\text { educación terciaria }\end{array}$} & $443 / 453^{*}$ \\
\hline $444 / 454$ & \multicolumn{2}{|c|}{$\begin{array}{l}\text { Educación postsecundaria no terciaria, conclusión del nivel, con acceso directo a la } \\
\text { educación terciaria }\end{array}$} & $444 / 454$ \\
\hline $541 / 551$ & \multicolumn{2}{|c|}{ Educación terciaria de ciclo corto insuficiente para la conclusión del nivel } & $444 / 454$ \\
\hline $544 / 554$ & \multicolumn{2}{|c|}{ Educación terciaria de ciclo corto, conclusión del nivel } & $540 / 550$ \\
\hline $641 / 651 / 661$ & \multicolumn{2}{|c|}{ Grado en educación terciaria o nivel equivalente, insuficiente para la conclusión del nivel } & $540 / 550 / 560$ \\
\hline $645 / 655 / 665$ & \multicolumn{2}{|c|}{ Grado en educación terciaria o nivel equivalente, primer título (3 a 4 años) } & $640 / 650 / 660$ \\
\hline $646 / 656 / 666$ & \multicolumn{2}{|c|}{$\begin{array}{l}\text { Grado en educación terciaria o nivel equivalente, programa largo de primer título (más de } 4 \\
\text { años de duración) }\end{array}$} & $640 / 650 / 660$ \\
\hline $647 / 657 / 667$ & \multicolumn{2}{|c|}{$\begin{array}{l}\text { Grado en educación terciaria o nivel equivalente, segundo o siguiente título (tras cursar un } \\
\text { programa del grado en educación terciaria o equivalente) }\end{array}$} & $640 / 650 / 660$ \\
\hline $741 / 751 / 761$ & \multicolumn{2}{|c|}{ Nivel de maestría, especialización o equivalente, insuficiente para la conclusión del nivel } & $640 / 650 / 660$ \\
\hline $746 / 756 / 766$ & \multicolumn{2}{|c|}{$\begin{array}{l}\text { Nivel de maestría, especialización o equivalente, programa largo de primer título (duración } \\
\text { mínima de } 5 \text { años) }\end{array}$} & $740 / 750 / 760$ \\
\hline $747 / 757 / 767$ & \multicolumn{2}{|c|}{$\begin{array}{l}\text { Nivel de maestría, especialización o equivalente, segundo o siguiente título (tras cursar un } \\
\text { programa del grado en educación terciaria o equivalente) }\end{array}$} & $740 / 750 / 760$ \\
\hline $748 / 758 / 768$ & \multicolumn{2}{|c|}{$\begin{array}{l}\text { Nivel de maestría, especialización o equivalente, segundo o siguiente título (tras cursar un } \\
\text { programa de nivel de maestría, especialización o equivalente) }\end{array}$} & $740 / 750 / 760$ \\
\hline $841 / 851 / 861$ & \multicolumn{2}{|c|}{ Nivel de doctorado o equivalente, insuficiente para la conclusión del nivel } & $740 / 750 / 760$ \\
\hline $844 / 854 / 864$ & \multicolumn{2}{|c|}{ Nivel de doctorado o equivalente, conclusión del nivel } & $840 / 850 / 860$ \\
\hline
\end{tabular}

\section{Note}

* Los códigos CINE-A correspondientes a los programas CINE-P 343/353 y 443/453 también podrían ser 344/354 y 444/454, respectivamente, si los requisitos mínimos de ingreso al programa ya consideraran el acceso a la educación terciaria (pese a que el programa está destinado a conducir al mercado laboral, no a la educación terciaria). 


\section{UNESCO}

La Constitución de la Organización de las Naciones Unidas para la Educación, la Ciencia y la Cultura (UNESCO) fue aprobada por 20 países en la Conferencia de Londres, en noviembre de 1945, y entró en vigor el 4 de noviembre de 1946. La Organización cuenta actualmente con 195 Estados Miembros y 9 Miembros Asociados.

El principal objetivo de la UNESCO es contribuir a la paz y la seguridad en el mundo promoviendo, mediante la educación, la ciencia, la cultura y la comunicación, la colaboración entre las naciones, a fin de asegurar el respeto universal de la justicia, el estado de derecho, los derechos humanos y las libertades fundamentales que la Carta de las Naciones Unidas reconoce a todos los pueblos del mundo sin distinción de raza, sexo, idioma o religión.

Para cumplir este mandato, la UNESCO desempeña cinco funciones principales: 1) estudios prospectivos sobre la educación, la ciencia, la cultura y la comunicación para el mundo del mañana; 2) el fomento, la transferencia y el intercambio del conocimiento mediante actividades de investigación, formación y educativas; 3) acciones normativas, para la preparación y aprobación de instrumentos internos y recomendaciones estatutarias; 4) conocimientos especializados transmitidos a los Estados Miembros mediante iniciativas de cooperación técnica con el propósito de facilitar la elaboración de políticas y proyectos de desarrollo; y 5) el intercambio de información especializada.

La Sede de la UNESCO se encuentra en París, Francia

\section{INSTITUTO DE LA ESTADÍSTICA DE LA UNESCO}

El Instituto de Estadística de la UNESCO (UIS) es la oficina de estadística de la UNESCO y es el depositario de la ONU en materia de estadísticas mundiales en los campos de la educación, la ciencia y la tecnología la cultura y la comunicación.

EI UIS fue fundado en 1999. Se creó con el fin de mejorar el programa de estadística de la UNESCO, así como para desarrollar y suministrar estadísticas exactas, oportunas y políticamente relevantes, requeridas en un contexto actual cada vez más complejo y rápidamente cambiante.

La Sede del UIS se encuentra en Montreal, Canadá.

\section{ORGANIZACIÓN PARA LA COOPERACIÓN Y EL DESARROLLO ECONÓMICOS}

La OCDE es un foro único en su género que permite a los gobiernos trabajar conjuntamente para abordar los desafíos económicos, sociales y ambientales planteados por la globalización. Asimismo, la OCDE está a la vanguardia de los esfuerzos orientados a entender y ayudar a los gobiernos a responder a nuevos fenómenos e inquietudes tales como, los gobiernos corporativos, la economía de la información y el envejecimiento de la población. La Organización proporciona el entorno que promueve la comparación de políticas entre los gobiernos, busca respuesta a problemas comunes, identifica las buenas prácticas y coordina las políticas nacionales e internacionales.

Los Países Miembros de la OCDE son: Alemania, Australia, Austria, Bélgica, Canadá, Chile, Corea, Dinamarca, Eslovenia, España, Estados Unidos, Estonia, Finlandia, Francia, Grecia, Hungría, Irlanda, Islandia, Israel, Italia, Japón, Luxemburgo, México, Nueva Zelanda, Noruega, Países Bajos, Polonia, Portugal, la República Checa, la República Eslovaca, Suiza, Suecia, Turquía y el Reino Unido. La Unión Europea participa en el trabajo de la OCDE.

"OECD Publishing" difunde los resultados de la Organización en iniciativas de recolección de estadísticas e investigaciones sobre problemas económicos, sociales y ambientales, y proporciona información acerca de las convenciones, directrices y estándares acordados por sus integrantes.

\section{EUROSTAT}

El Eurostat es la oficina estadística de la Unión Europea (UE). Es la fuente reconocida de estadísticas europeas oficiales y promueve comparaciones entre los 28 Estados Miembros, los países integrantes de la Asociación Europea de Libre Comercio (EFTA), los países candidatos a la UE y otros países vecinos de la UE, y entre las regiones de estos países. El Eurostat coopera estrechamente con las autoridades nacionales de estadística en los países integrantes de la UE y de la EFTA a través del Sistema Estadístico Europeo (ESS). El ESS, se desarrollado gradualmente con el objetivo de proporcionar estadísticas comparables a nivel de la UE, opera como una red donde la función del Eurostat es promover la armonización de los métodos estadísticos. Trabaja en coordinación con los países candidatos a la UE, las agencias del Banco Central Europeo (ECB), y con organizaciones internacionales como la OCDE, la ONU, el Fondo Monetario Internacional y el Banco Mundial. Los datos y las publicaciones están a disposición del público general en: http://ec.europa.eu/eurostat. 




\section{Manual Operativo CINE 2011: \\ DIRECTRICES PARA CLASIFICAR PROGRAMAS NACIONALES DE EDUCACIÓN Y CERTIFICACIONES RELACIONADAS}

La estructura de los sistemas educativos varía marcadamente entre los países. Por consiguiente, la elaboración de indicadores y estadísticas de educación internacionalmente comparables hace necesario disponer de un marco que permita acopiar y reportar datos sobre programas educativos con niveles similares de contenido educacional. La Clasificación Internacional Normalizada de la Educación (CINE) de la UNESCO, es la clasificación de referencia utilizada para categorizar los programas educativos y sus respectivas certificaciones por niveles y campos de estudio. Las definiciones y los conceptos básicos utilizados en la CINE se han propuesto como internacionalmente válidos e integrales y cubren todo el espectro de los sistemas educativos.

La clasificación CINE 2011 representa la segunda importante revisión de esta clasificación (inicialmente elaborada en la década de los 70 y objeto de una primera revisión en 1997). Fue aprobada por la Conferencia General de la UNESCO en noviembre de 2011. Este manual operativo, resultado de la colaboración del Instituto de Estadística de la UNESCO, OCDE y Eurostat, proporciona directrices y notas explicativas para cada nivel de educación que facilitan la interpretación de la clasificación actualizada. Adicionalmente se incluyen ejemplos nacionales de programas y certificaciones que han sido clasificadas en la CINE 2011.

El presente manual será de gran utilidad tanto para estadísticos nacionales abocados a acopiar y reportar datos sobre educación a las organizaciones internacionales como para elaboradores de políticas e investigadores interesados en lograr una mejor comprensión de estas estadísticas.

\section{Contenidos}

Capítulo 1. Aspectos generales de la CINE 2011

Capítulo 2. Nivel 0 - CINE 2011: Educación de la primera infancia

Capítulo 3. Nivel 1 - CINE 2011: Educación primaria

Capítulo 4. Nivel 2 - CINE 2011: Educación secundaria baja

Capítulo 5. Nivel 3 - CINE 2011: Educación secundaria alta

Capítulo 6. Nivel 4 - CINE 2011: Educación postsecundaria no terciaria

Capítulo 7. Aspectos generales de los niveles CINE 2011 de educación terciaria

Capítulo 8. Nivel 5 - CINE 2011: Educación terciaria de ciclo corto

Capítulo 9. Nivel 6 - CINE 2011: Grado en educación terciaria 0 equivalente

Capítulo 10. Nivel 7 - CINE 2011: Nivel de maestría, especialización o equivalente

Capítulo 11. Nivel 8 - CINE 2011: Nivel de doctorado o equivalente

Consulte esta publicación en línea visitando: $\boldsymbol{h t t p : / / d x . d o i . o r g / 1 0 . 1 5 2 2 0 / 9 7 8 - 9 2 - 9 1 8 9 - 1 8 1 - 8 - s p a ~}$ 